\title{
O uso de MPEG-7 na personalização da TV interativa
}

\author{
Gustavo Blengini Faria
}

Orientador:

Prof. Dr. Edson dos Santos Moreira

Dissertação apresentada ao Institulo de Ciências Matemáticas e de Computação ICMC-USP, como parte dos requisitos para obtenção do titulo de Mestre em Ciências de Computação e Matemática Computacional.

\section{USP - São Carlos \\ Novembro/2001}

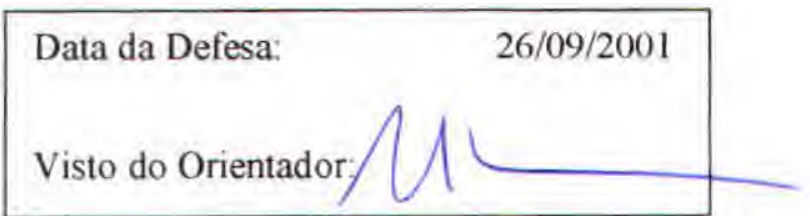


Ao meu pai, Carlos Augusto 


\section{Agradecimentos}

À minha mãe Rosina pelo apoio que recebi em todas as etapas da minha vida. Ao meu irmão, Henrique, pela sua presença, sempre ao meu lado, como meu melhor amigo e conselheiro. À Tatiana, por sua paciência e compreensão.

Ao meu orientador e grande mestre, prof. Dr. Edson dos Santos Moreira, pelo direcionamento nos momentos mais importantes e pela confiança em mim e no meu trabalho.

Aos meus dois companheiros, colaboradores e amigos João Benedito dos Santos Junior e Rudinei Goularte, pela fundamental ajuda, pelas idéias, pelas discussões sempre bastante proveitosas e pelas revisões e colaborações tanto nos artigos quanto neste texto.

Ao meu amigo Taboca pelo companheirismo, pelos ensinamentos e pelo apoio. Ao Roger e ao Fabrício, pela oportunidade proporcionada.

ÀAna Vitória pelas conversas sempre produtivas sobre este projeto.

Ao pessoal da "velha guarda" do Intermídia, Pissioli, Elder, Manzato, Chaves e também aos da "nova guarda" Dalton, Dani, Fúlvio, Leonardo, Luciano, Milagres, Renato, Stênio, Tom e a todos os outros que por lá passaram, pelo companheirismo e ajuda quando precisei.

Ao casal Humberto e Elaine pela revisão do trabalho.

A todos os professores, que ao me transmitirem seus conhecimentos me auxiliaram na conclusão deste trabalho. 


\section{Sumário}

1.

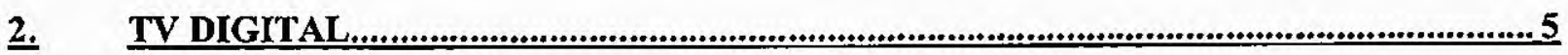

2.1. ATSC

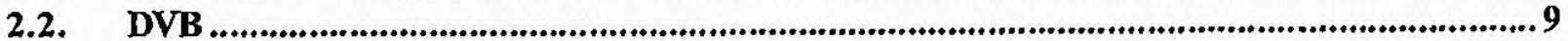

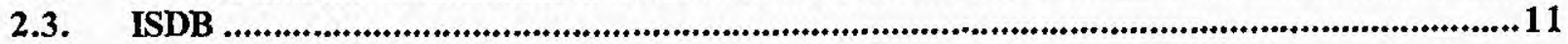

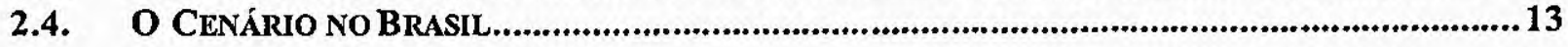

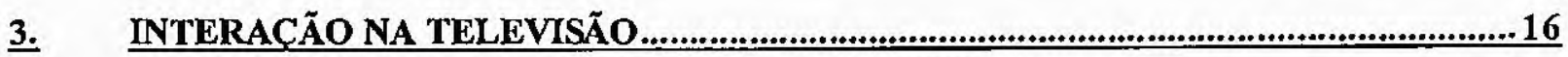

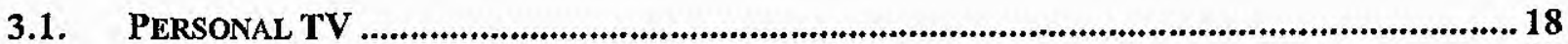

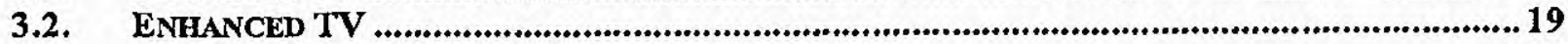

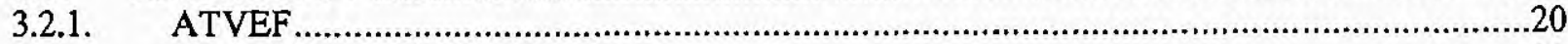

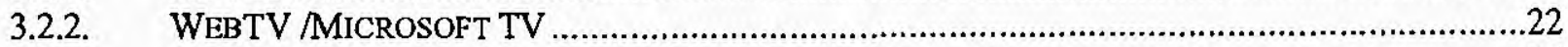

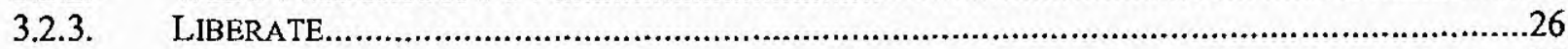

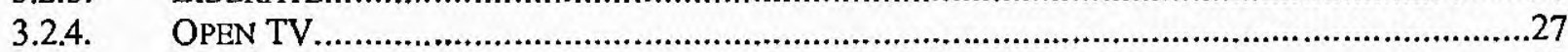

3.2.5. MYTV

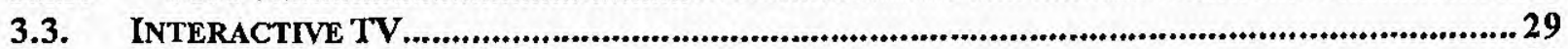

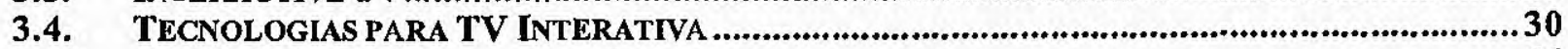

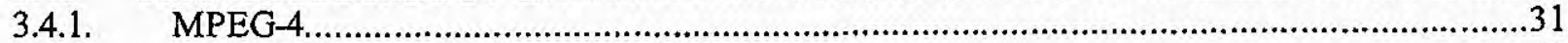

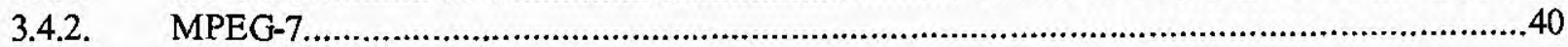

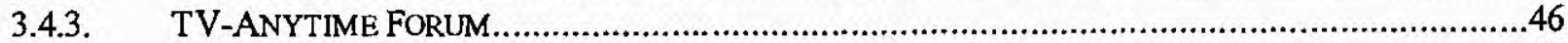

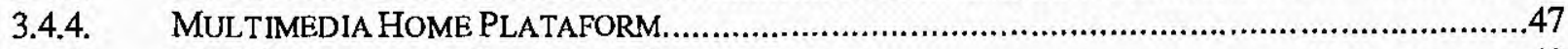

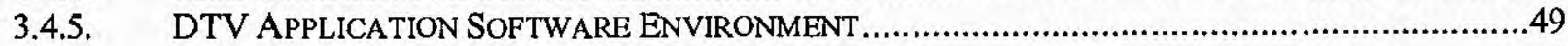

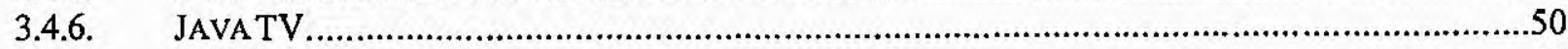

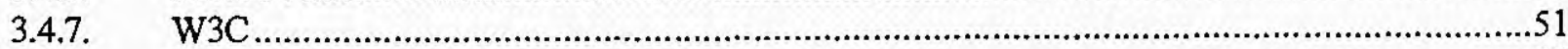

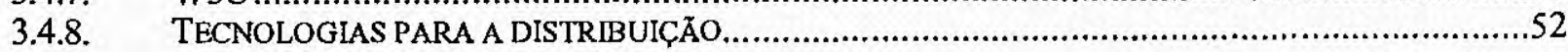

4. IMPLEMENTACÃO DE UM PROGRAMA DE TV INTERATIVA...........................56

4.1. ASPECTOS DE CONSCIÊNCIA DE CONTEXTO APLICADOS Ȧ TV INTERATIVA ........................56

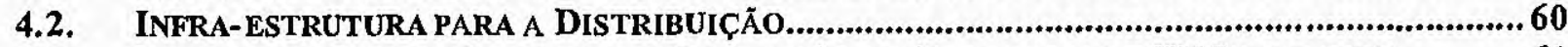

4.3. Requisitos Necess Ários Para a ProduçÃo do Programa de TV INTERATIVA ........... 61

4.4. MODELAGEM DA APLICAÇĀO DE TV INTERATIVA........................................................62

4.5. ESTRUTURA E IMPLEMENTAÇĀO DE UM PROGRAMA DE TV INTERATIVA ...........................6 64

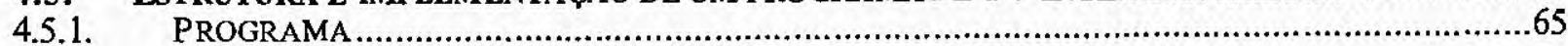

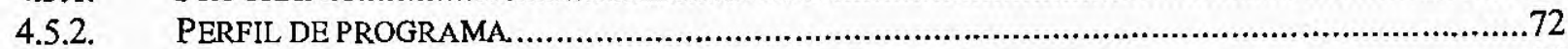

4.5.3. UTILIZAÇÃO DOS PERFIS EM UM PROGRAMA DE TV INTERATIVA

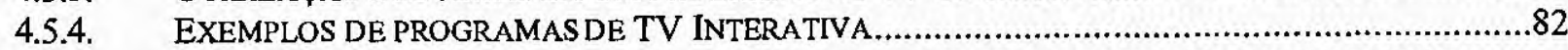

4.5.5. APLICAÇÃO DOS CONCEITOS DE PROGRAMA E DE PERFIL A UM PROGRAMA DE EVENTO

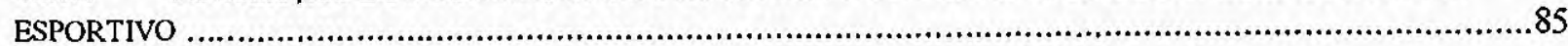

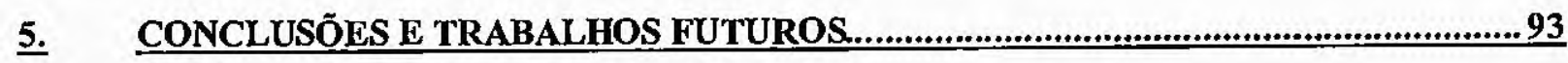

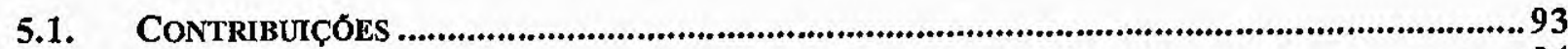

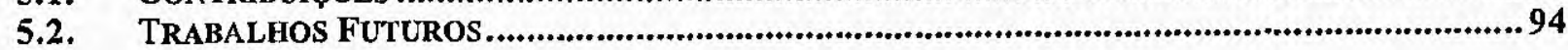




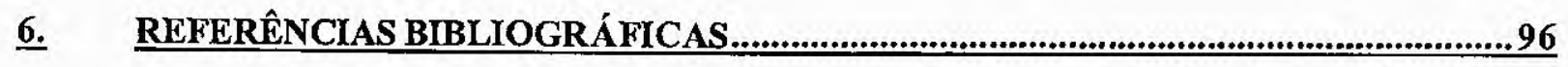

APÊNDICE A

APÊNDICE B

GLOSSÁRIO 


\section{Lista de Figuras}

FIGURA 1 - MODELO DE CAMADAS APUCADO ÀS TELECOMUNICAÇŌES ........................................ 2

FIGURA 2 - MODELO DE REFERENCIA ITU PARA A TELEVISÃo DIGITAL ..................................... 6

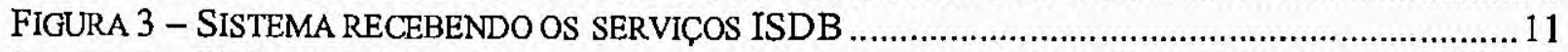

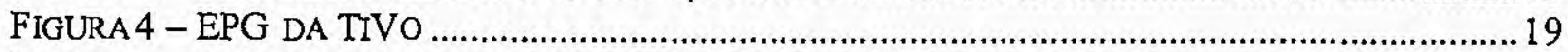

FIGURA 5 - TRANSMISSÃO DE PROGRAMA QUE PERMTE INTERATIVIDADE …................................22

FIGURA 6 - INFORMAÇÕES ADICIONAIS DO PROGRAMA ….................................................... 22

FIGURA 7 - PLATAFORMA DE TV INTERATIVA DA MICROSOFT TV E SUA DISTRIBUIÇÃO. EXTRAIDA

DO SITE DA MICROSOFT TV.

FIGURA 8 - ESTRUTURA DO MICROSOFT TV SERVER. EXTRAIDA DO SITE DA MICROSOFT TV .....25

FIGURA 9 - INFRA-ESTRUTURA DA DISTRIBUIÇÃO DO TV ACCESS CHANNEL SERVER. EXTRAÍDA

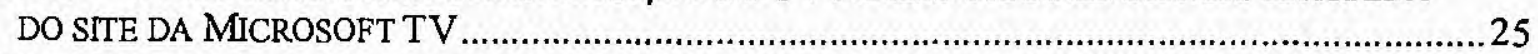

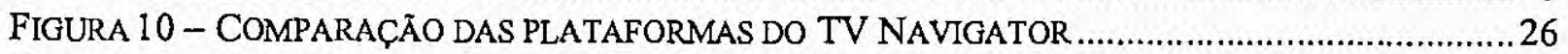

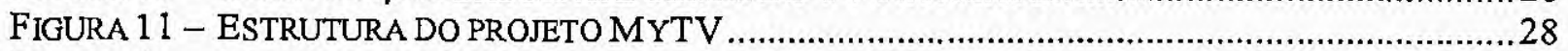

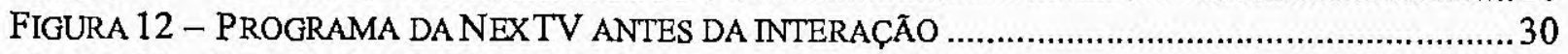

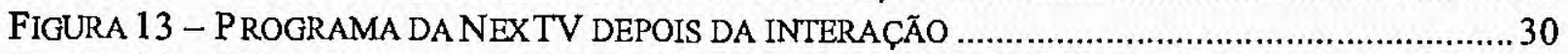

FIGURA 14 - EXEMPLO DA ESTRUTURA DE UM BITSTREAM MPEG-4. EXTRAIDA DE [EBR1999] ....37

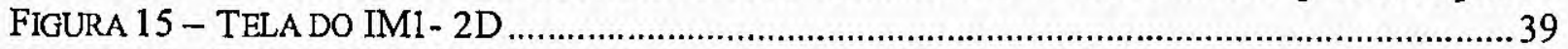

FIGURA 16 - TELA DO IST MPEG-4 VIDEO COMPLIANT FRAMEWORK ......................................40

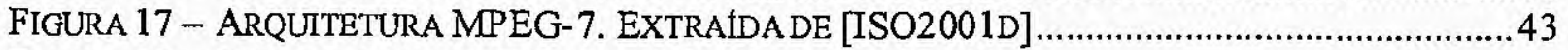

FIGURA 18 - ESTRUTURA DOMDS. EXTRAIDA DE [ISO2001G] ….........................................45

FIGURA 19 - EXEMPLO DE UMA DESCRIÇÃO DE UM VÍDEO EM MPEG-7 ....................................46

FIGURA 20 - PERFIS DE INTERATIVIDADE DEFINIDOS NO MHP ................................................48

FIGURA 21 - EXEMPLO DE APLICAÇÃO SINCRONZZADA COM O CONTEÚDO. APRESENTADA NO

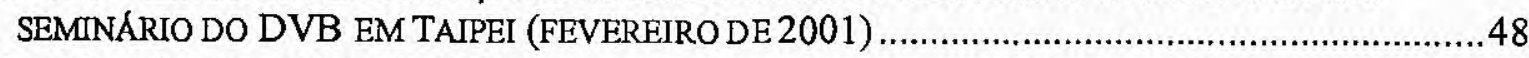

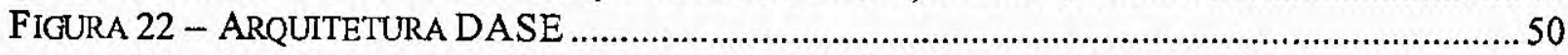

FIGURA 23 - PILHA DE SOFTWARE EM UMSTB. EXTRAfDA DO SITE JAVATV ...............................5 51

FIGURA 24 - MAPEAMENTO DE ENTIDADES DE CONSCIENCIA DE CONTEXTO EM ELEMENTOS DE

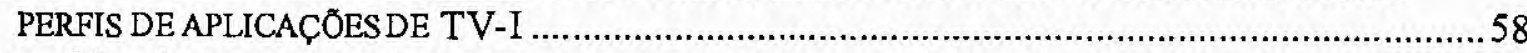

FIGURA 25 - AMBIENTE CONSCIENTE DE CONTEXTO PARA A TV INTERATIVA ............................61

FIGURA 26 - DIAGRAMA DE ClASSES DE UMA APLICAÇÃO DE TV INTERATIVA. EXTRAídA DE

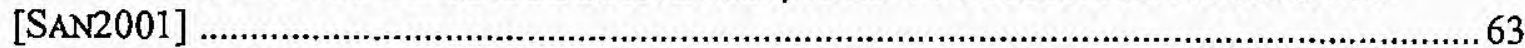

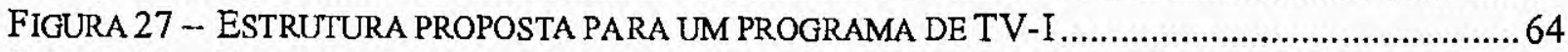

FIGURA 28 - ENTIDADES QUE COMPÕEM UM PROGRAMA EM UMA APLICACุÃO DE TV-I ................65

FIGURA 29 - EXEMPLO DE SCHEMA PARA O ELEMENTO PROGRAM ...........................................6 66

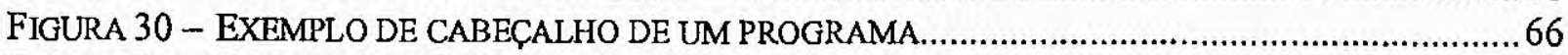

FIGURA 31 - EXEMPLO DO SCHEMA PARA DESCREVER A CENA …............................................67

FIGURA 32 - EXEMPLO DO SCHEMA PARA A DESCRIÇÃO DAS MIDIAS .........................................70

FIGURA 33 - EXEMPLO DO SCHEMA PARA OS ELEMENTOS DA LINHA DO TEMPO …...........................71

FIGURA 34 - ENTIDADES QUE COMPÕEM UM PROFLE EM UMA APLICACุĀO DE TV-I ..................... 72

FIGURA 35 - EXEMPLO DO SCHEMA PARA O ELEMENTO PROFILE........................................... 73

FIGURA 36 - EXEMPLO DO CABEÇALHO DE UM PERFIL DE PROGRAMA …....................................73

FIGURA 37 - EXEMPLO DO SCHEMA PARA O ELEMENTO LAYOUT.............................................75

FIGURA 38 - EXEMPLO DE SCHEMA PARA O ELEMENTO COMMUNICATION...................................76

FIGURA 39 - EXEMPLO DE SCHEMA PARA OS ELEMENTOS DE CONSCIENCIA DE CONTEXTO ............77

FIGURA 40 - EXEMPLO DO USO DOS ELEMENTOS DE CONSCIENCIA DE CONTEXTO .........................78 
FIGURA 41 - EXEMPLO DO SCHEMA PARA OS ELEMENTOS DE INTERAÇÃO ....................................79

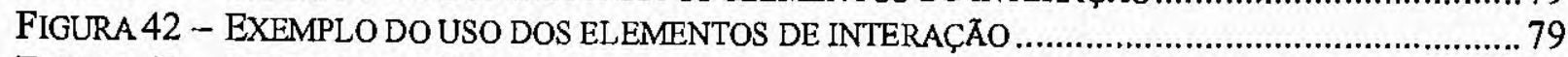

FIGURA 43 - EXEMPLO DE SCHEMA PARA OS ELEMENTOS DE PREFERENCIAS DO USUÁRIO ................80

FIGURA 44 - EXEMPLO DO USO DOS ELEMENTOS DE PREFERENCIAS DO USUÁRIO ............................80

FIGURA 45 - DIAGRAMA DE SEQÜENCIA UML PARA AS ENTIDADES DEUM PROGRAMA DE TV-I... 81

FIGURA 46 - DIAGRAMA DE SEQUENCIA UML PARA UMA APLICAÇÃO DE TV-I CONSCIENTE DE

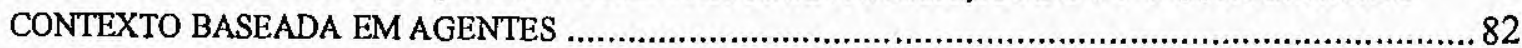

FIGURA 47 - EXEMPLO DA DESCRIÇÃO DE UM PROGRAMA DE EVENTO ESPORTIVO ….....................88

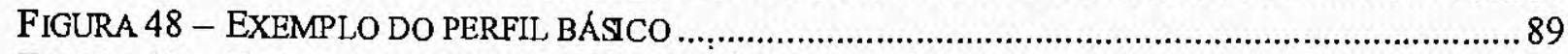

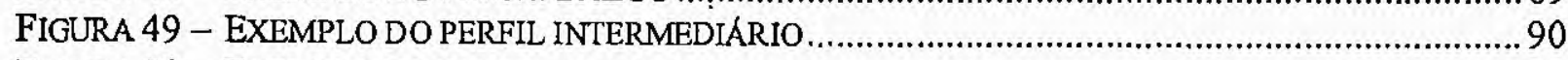

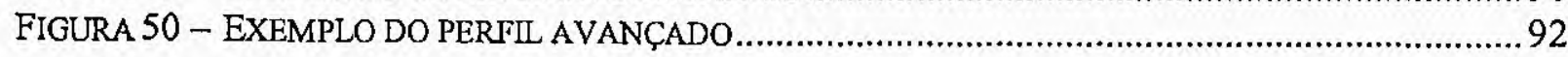




\section{Lista de Tabelas}

TABELA 1 - PRINCIPAIS FORMATOS DE TELEVISÃo DIGITAL. EXTRAIDA DE [ANA2001 B] ............. 7

TABELA 2 - RESOLUÇÕES DEFINIDAS PELO ATSC. EXTRAIDA DE [ATS2001] …...........................

TABELA 3 - RESOLUÇÕES DEFINIDAS PELO DVB. EXTRAIDA DE [ANA2001] ............................... 10

TABELA 4 - RESOLUÇÕES DEFINIDAS PELO ISDB. EXTRAIDA DE [DIG2001] ............................... 13

TABELA 5 - COMPARAÇĀO ENTRE OS TRES SISTEMAS DE TV DIGITAL ….................................... 14

TABELA 6 - DIMENSÃO DOS MER CADOSJÁ DEFINIDOS. EXTRAIDA DE [ANA2001] ...........................15

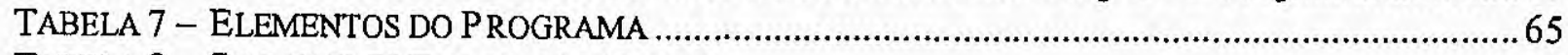

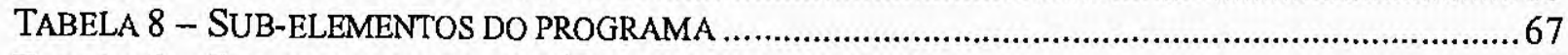

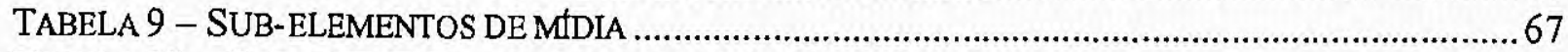

TABELA 10 - SUB-ELEMENTOS DE LINHA DO TEMPO ............................................................ 71

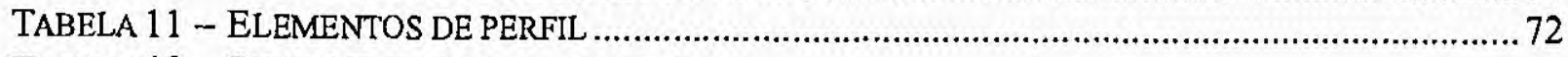

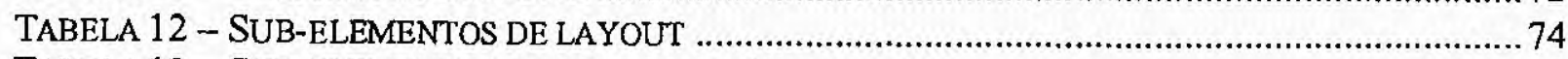

TABELA 13 - SUB-ELEMENTOS DE COMUNICAÇĀO ................................................................ 75

TABELA 14 - SUB-ELEMENTOS DE CONSCIÊNCIA DE CONTEXTO …............................................ 76

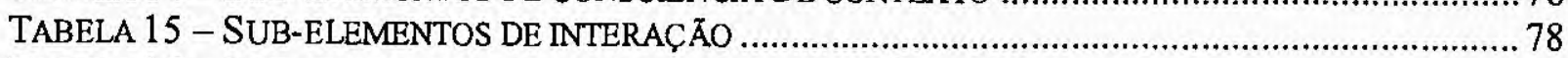

TABELA 16 - ELEMENTOS DE PERSONALUZAÇĀO DO USUÁRIO …..................................................... 79

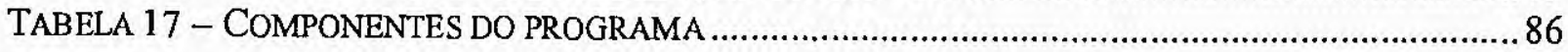




\section{Lista de Abreviaturas}

ABERT

ADSL

ANATEL

API

ARIB

ATM

ATSC

ATVEF

BIFS

$\mathrm{BiM}$

BML

BST-OFDM

$\mathrm{CD}$

CDMA

CSELT

CSS

COFDM

DASE

DAVIC

DCT

DDL

DMIF

DSL

DTV
Associação Brasileira de Emissoras de Rádio e Televisão

Asymmetric Digital Subscriber Line

Agência Nacional de Telecomunicaçōes

Application Programming Interface

Association of Radio Industries and Businesses

Asynchronous Transfer Mode

Advanced Television Systems Committee

Advanced Television Enhancement Forum

BInary Format for Scenes

Binary Format for MPEG-7

Broadcast Markup Language

Band Segmented Transmission - Orthogonal Frequency

Division Multiplexing

Compact Disk

Code Division Multiple Access

Centro Studi E Laboratori Telecomunicazioni

Cascading Style Sheets

Coded Orthogonal Frequency Division Multiplexing

DTV Application Software Environment

Digital Audio-Video Council

Discrete Cosine Transform

Definition Description Language

Delivery Multimedia Integration Framework

Digital Subscriber Line

Digital Television 
DVB

DVD

DVR

EDTV

EPG

GPS

GSM

HAVi

HDTV

HTML

HTTP

ICMC

IETF

ISDB

ITU

LDTV

MHP

MP3

MPEG

MPEG-2 AAC

MUSE

NTSC

NVoD

PAL

PDA

PDR

PVR
Digital Video Broadcast

Digital Versatile Disk

Digital Video Recorder

Enhanced Definition Television

Electronic Program Guide

Global Positioning System

Global System for Mobile Communications

Home Audio and Video Interoperability

High Definition Digital Television

Hypertext Markup Language

Hypertext Transfer Protocol

Instituto de Ciências Matemáticas e de Computação

Internet Engineering Task Force

Integrated Service Digital Broadcast

International Telecommunication Union

Low Definition Television

Multimedia Home Plataform

MPEG-1 Audio Layer 3

Motion Pictures Experts Group

MPEG-2 Advanced Audio Coding

Multiple Sub-Nyquist Sampling Encoding

National Television Systems Committee

Near Video on Demand

Phase Alternate Line

Personal Digital Assistant

Personal Digital Recorder

Personal Video Recorder 


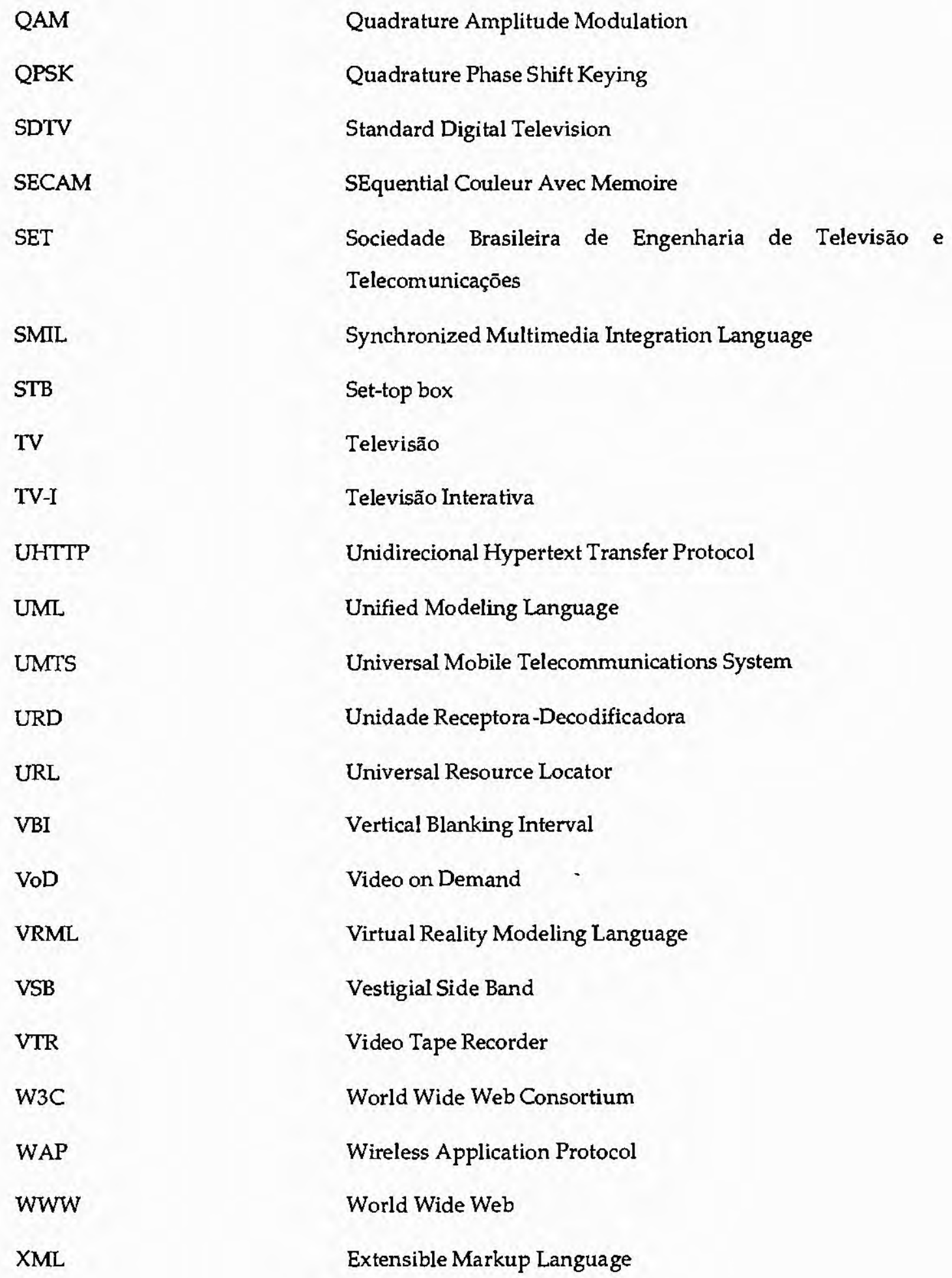




\section{Resumo}

A televisão é um meio de comunicação extremamente popular e que possui linguagem e funcionalidades próprias. A televisão está passando por um período de revolução; a primeira grande mudança está sendo a digitalização do sinal e a segunda é a possibilidade de interação. Essas duas mudanças terão um grande impacto no modo como as pessoas assistem a um programa de TV. A TV Interativa é uma aplicação multimídia que insere novas funcionalidades em um ambiente anteriormente não interativo. Um grande número de tecnologias pode ser usado em sua implementação e, devido ao crescente interesse da indústria na área, diversos esforços têm sido feitos para sua padronização. Este trabalho apresenta um novo conceito para criar e distribuir programas interativos que provê um avanço na adaptação dos programas às necessidades ou expectativas dos usuários. Este trabalho utiliza os padrões para a TV Interativa e estende-os para o uso em ambientes conscientes de contexto. 


\section{Abstract}

The TV is a communication medium very popular with its own language and functionalities. The television is passing through a revolution; the first big change is the digitalization of the signal and the second is the possibility of interaction. These two big changes will have a great impact on the way people watch a TV show. The Interactive TV is a multimedia application that provides new functionalities in an environment where interaction was not previously possible. A number of technologies can be used on its implementation, and as this is an area of great interest to the industry there are some efforts to build standards. This work presents a new concept to create and distribute interactive programs that provides a better adaptation of the programs to the viewers. This work also uses Interactive TV standards and extending them to the use on context aware environments. 


\section{Introdução}

A "Era da Informação" já é uma realidade e é possível observar diversos exemplos de como a vida mudou nessa nova era. $O$ acesso à informação tem se tornado mais fácil; pessoas trabalham cooperativamente em localidades extremamente distantes e a um custo baixo; a comunicação sem fio revolucionou a vida de muitas pessoas e o trabalho de outras e, com a miniaturização dos componentes eletrônicos, muitos equipamentos eletrônicos acompanham as pessoas no cotidiano.

Neste momento, observa-se o início da segunda fase dessa era: a fase da convergência. É provável que essa nova fase, assim como a anterior, também transforme paradigmas e tenha uma influência bastante grande na vida cotidiana das pessoas.

A primeira fase foi caracterizada pela "explosão" de dispositivos que ajudavam (mas às vezes só complicavam ainda mais) as pessoas em suas atividades de trabalho e lazer. $\mathrm{E}$ comum um executivo carregar em sua pasta um notebook, um PDA (Personal Digital Assistant), um telefone celular e, em alguns casos, um aparelho de CD ou MP3.

A segunda fase deverá ser marcada pela presença de dispositivos "multitarefa" que englobam várias funções, tais como um PDA com acesso à telefonia celular e que também é um receptor de televisão digital, ou então um televisor que acessa a Internet e ao mesmo tempo grava seus programas prediletos. Nessa nova fase, esses aparelhos eletrônicos devem ser categorizados de acordo com novos parâmetros: a) se são móveis ou fixos; b) por seu tamanho e suas funcionalidades; c) se permitem acesso à Internet; d) se têm acesso à telefonia celular; e) se recebem sinais da TV Digital. Pode-se dizer que esse tipo de aparelho será o veículo para se obter a informação ou para transportar a informação.

Essa mudança de conceitos também se aplica às telecomunicaçōes. Anteriormente, telefonia fixa, transmissão de TV e transmissão de dados eram tópicos bastante 
distintos. Hoje, observa-se a telefonia fixa através de serviços como as DSLs (Digital Subscriber Line) e as operadoras de TV a Cabo oferecendo acesso à Internet. Por outro lado, é possível assistir programas de TV de outro país via Internet, ou então fazer ligações telefônicas através de redes de computadores (via Voice-IP). Num futuro próximo, poder-se-á ter acesso à Internet e, possivelmente, à rede telefônica, via TV Digital.

Pode-se aplicar um modelo de camadas de modo a representar como serviços, plataformas e aplicações podem ser divididos. A independência dessas camadas permite que diversas categorias de informações possam ser transmitidas por diferentes plataformas. A Figura 1 apresenta esse modelo de camadas e mostra alguns exemplos para cada camada. Evidentemente, plataformas para a transmissão de TV Digital são especializadas no transporte de vídeo digital, assim como redes de telefonia são especializadas na transmissão de sons (e, atualmente, dados); porém, com a digitalização de seus sinais, ambas permitem outros usos para sua infra-estrutura.

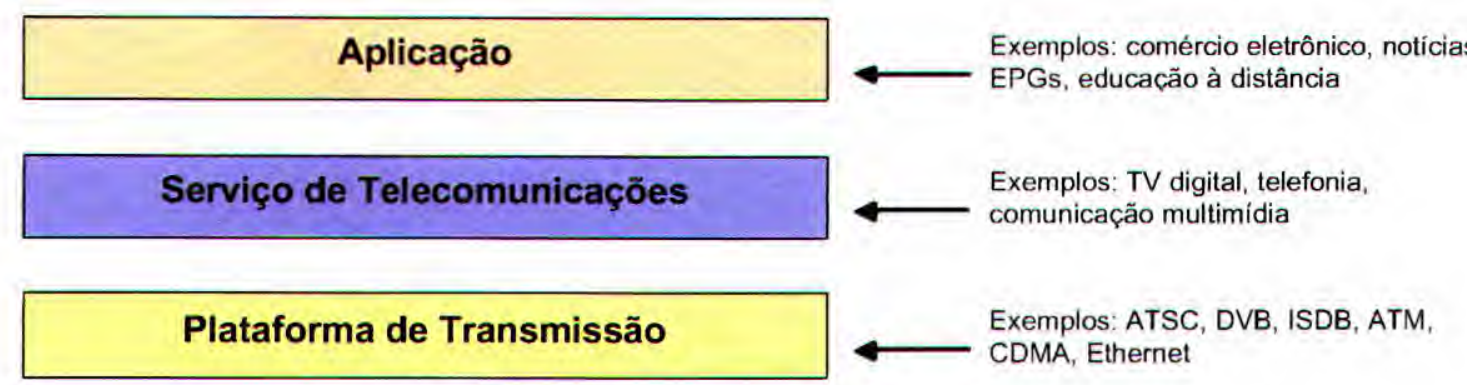

Figura 1 - Modelo de camadas aplicado às telecomunicações

Existem tecnologias desenvolvidas para que a comunicação entre os diferentes dispositivos que fazem e farão parte da vida cotidiana seja facilitada, como HAVi (Home Audio and Video Interoperability $)^{1}$ e Jini ${ }^{2}$, visto que num futuro não muito distante será possivel a construção de casas "inteligentes", totalmente integradas com seus aparelhos eletrônicos e conscientes do contexto.

\footnotetext{
1 http://www.havi.org/

2 http://www.sun.com/jini/
} 
Segundo Dey [Dey2000]: "Um sistema é consciente de contexto se ele usa o contexto para prover informações e/ou serviços relevantes ao usuário, onde a relevância depende da tarefa do usuário".

Uma aplicação que tem sido motivo de muitas pesquisas é a televisão com a qual o usuário pode interagir, a chamada "televisão interativa". Quando se pensa na televisão interativa inserida em um ambiente consciente de contexto, vislumbra-se inúmeras novas aplicações. É possível pensar que as redes de televisão conseguirão fazer uma transmissão diferenciada para diferentes contextos; os anunciantes poderão transmitir suas propagandas somente para seu público-alvo; certas cenas poderão ser excluídas em determinadas situações (a presença de uma criança, por exemplo). No entanto, deve-se observar que não só a transmissão mudará: a a presentação também passará por sensíveis mudanças. Como exemplo, pode-se citar que a televisão poderá ser capaz de detectar o nível de iluminação (as luzes estão apagadas e as cortinas fechadas, por exemplo) e fazer os ajustes de brilho e contraste necessários, ou, então, através da informação do número de pessoas na sala e suas posições, poderá alterar o volume ou re-distribuir o som no ambiente.

A TV Interativa (TV-I) tem como um de seus objetivos a disponibilização da informação sobre os programas ao usuário. Um modo para se descrever um programa de TV é utilizar o padrão MPEG-7 [ISO2001c], que especifica esquemas de descrição para cenas audiovisuais. Existem esforços para descrever um programa de TV Interativa, sendo um dos mais importantes o realizado pelo TV-Anytime Forum ${ }^{3}$.

O TV-Anytime Forum descreve programas da TV Interativa em MPEG-7, no entanto, ele somente descreve as mídias, deixando a cena para ser feita por outras tecnologias como - MPEG-4 [ISO2001a] ou MHP (Multimedia Home Plataform) [DVB2000], por exemplo. Como escopo da pesquisa na qual este projeto está inserido, é proposta a descrição do programa e a definição dos aspectos para a apresentação do mesmo em MPEG-7,

${ }^{3}$ http://www.tv-anytime.org/ 
conceito denominado perfil, para o qual ainda não se encontram referências na literatura. Deste modo, a emissora do programa poderá consultar o usuário antes de apresentar a ele qualquer tipo de programa. Essa também é uma forma eficiente para a apresentação, uma vez que exibirá o programa do modo que o usuário prefere e, muitas vezes, com economia de banda passante (uma vez que mídias podem ser descartadas pelo usuário). Adicionalmente, tem sido realizado todo um trabalho de investigação para composição da infra-estrutura de comunicação e de componentes de hardware e software, necessária ao escopo deste projeto.

Este trabalho está estruturado em 5 capítulos. No Capítulo 2, será apresentada uma introdução à TV Digital, em termos da base para a TV Interativa e seus padrões. No Capítulo 3, a Enhanced TV e a TV Interativa serão apresentadas, bem como seus padrões e tecnologias para implementação. O Capítulo 4 apresenta o contexto no qual este trabalho se insere, apresentando a infra-estrutura necessária e definindo os conceitos de programa e perfis e, em seguida, mostrando como aplicar esses conceitos em um programa de TV-I. O Capítulo 5 apresenta as conclusões e os trabalhos futuros. 


\section{TV Digital}

Desde a popularização dos computadores pessoais, na década de 80 , a mudança da televisão analógica para a digital é discutida. Isso conduz a uma questão: por que a televisão não é digital, já que as tecnologias necessárias existem há muito tempo? A resposta para essa pergunta é relativamente simples: os custos e os investimentos.

Pode-se dividir um sistema completo de televisão em três partes. A primeira é a produção dos programas e seu armazenamento; a segunda é a transmissão do sinal digital até o usuário final (broadcast); e a terceira é a recepção do sinal digital pelo usuário. $\mathrm{Na}$ parte da produção, a digitalização já é bastante utilizada; muitos estúdios utilizam equipamentos de filmagem digitais com os padrões Betacam, D1 e D2, por exemplo, além de illhas de edição não-linear.

Do lado do usuário também é cada vez maior a presença da digitalização, seja por meio de Unidades Receptora-Decodificadoras (URDs) da TV por assinatura, por aparelhos de TV com filtros e entradas digitais ou por meio dos Personal Digital Recorders (PDRs). No entanto, com a TV Digital que se espera para o futuro, o telespectador precisará desembolsar uma quantia considerável de capital de modo a adaptar seus sistemas à nova TV.

O que está se discutindo atualmente é a segunda parte: a transmissão, que é feita de modo analógico. A transmissão terá impacto tanto na parte das produtoras, que terão que adaptar seus equipamentos, quanto do lado dos usuários, que comprarão equipamentos para aquele tipo de transmissão. Do mesmo modo que ocorreu uma disputa entre os padrões para a transmissão de cores no sinal analógico (NTSC, PAL e SECAM), existe uma disputa entre padrões da TV Digital. A União Internacional de Telecomunicações (ITU) criou um modelo de referência para a televisão digital que é utilizado pelos três padrões públicos existentes: o ATSC (americano), o DVB (europeu) e o ISDB (japonês). 
A Figura 2 apresenta o modelo de referência da ITU para a televisão digital, e divide a transmissão em três blocos principais:

- Codificação do sinal: responsável pela codificação e compressão dos sinais de áudio e vídeo analógicos em um formato digital, chamado de fluxo elementar;

- Multiplexação dos sinais: responsável pela multiplexação dos fluxos elementares (de vídeo, áudio ou dados), de modo a formar somente um stream de dados;

- Codificação do canal e modulação: responsável por converter o stream de dados em um meio de transmissão por um meio físico, como ar ou cabos de cobre.

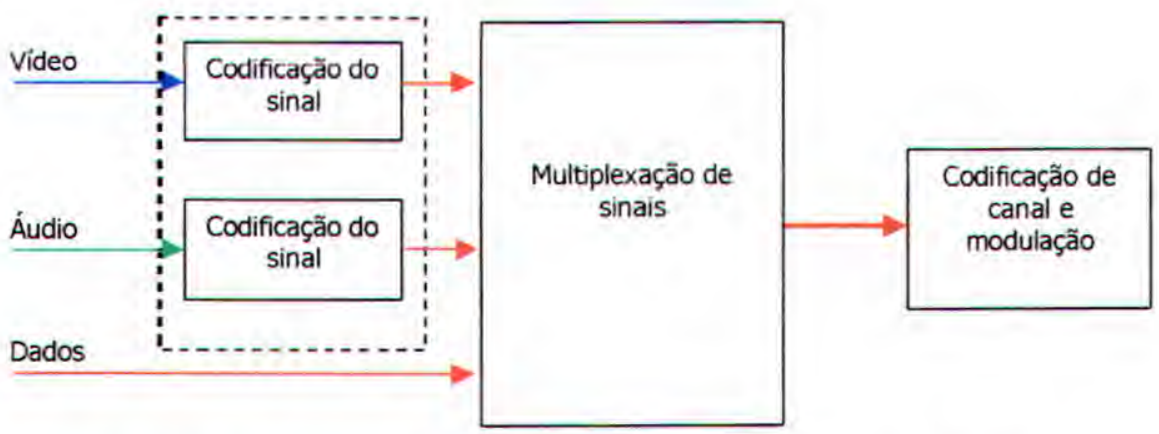

Figura 2 - Modelo de referência ITU para a Televisão Digital

Os padrões de resolução de imagem para TV Digital são divididos segundo a Tabela 1. O formato LDTV (Low Definition Television) é o mais indicado para aplicações móveis e portáteis; já o SDTV (Standard Definition Television) é o substituto digital para a Televisão atual, apresentando a vantagem de mostrar imagens mais nítidas e o formato de tela 16:9. O EDTV Enhanced Definition Television) conta com 480 linhas de resolução visual em detrimento das 336 do SDTV, como se pode observar na Tabela 1. Os dois padrões a seguir são os padrões de HDTV (High Definition Television), possuindo 720 linhas progressivas ou 1080 entrelaçadas. A resolução de $1080 \times 1920$ com 60 quadros por segundo está em testes, porém, não é implementada por nenhum dos padrões de TV Digital. 
Tabela 1 - Principais formatos de Televisão Digital. Extraída de [ANA2001b]

\begin{tabular}{|c|c|c|c|c|}
\hline Formato & Padrão de & Resolução & $\begin{array}{c}\text { Resolução visual (fator } \\
\text { vertical-temporal para } \\
\text { sinais entrelaçados }=0.7)\end{array}$ & $\begin{array}{c}\text { Taxa média de bits } \\
\text { (estimativa) (Mbits/s) }\end{array}$ \\
\hline $1080 p$ & HDTV & $\begin{array}{c}1080 \times 1920 \\
60 \mathrm{i}\end{array}$ & $\begin{array}{c}756 \times 1920 \\
60 \text { campos / seg }\end{array}$ & $19(12-32)$ \\
\hline $720 \mathrm{i}$ & HDTV & $\begin{array}{c}720 \times 1280 \\
60 \mathrm{p}\end{array}$ & $\begin{array}{c}720 \times 1280 \\
30 \text { quadros / seg }\end{array}$ & $14(8-20)$ \\
\hline $480 \mathrm{p}$ & EDTV & $\begin{array}{c}480 \times 720 \\
60 \mathrm{p}\end{array}$ & $\begin{array}{c}480 \times 720 \\
30 \text { quadros / seg }\end{array}$ & $6(4-8)$ \\
\hline $480 \mathrm{i}$ & SDTV & $\begin{array}{c}480 \times 720 \\
60 \mathrm{i}\end{array}$ & $\begin{array}{c}336 \times 720 \\
60 \text { campos / seg }\end{array}$ & $4,8(3-8)$ \\
\hline $240 \mathrm{p}$ & LDTV & $\begin{array}{c}240 \times 320 \\
30 \mathrm{p}\end{array}$ & $\begin{array}{c}240 \times 320 \\
30 \text { quadros / seg }\end{array}$ & $1,1(0,5-1,2)$ \\
\hline
\end{tabular}

Há consenso entre os três padrões de TV Digital para a codificação do sinal de vídeo, em que se utiliza o MPEG-2 [ISO1997a], e para a multiplexação dos sinais, para a qual também é utilizado o padrão MPEG-2 Systems [ISO1997a]. Nas outras etapas (de codificação de canal e modulação), cada padrão adota uma solução diferente, que serão mostradas a seguir.

\subsection{ATSC}

O padrão do ATSC ${ }^{4}$ (Advanced Television Systems Committee) [ATS2001], desenvolvido nos EUA, teve início em 1993, começou a operar em 1999 e hoje possui cerca de um milhão de usuários. O ATSC teve como principal objetivo a HDTV (High Definition Television), embora ele também suporte a SDTV (Standard Definition Television). A Tabela 2 apresenta as resoluções definidas pelo ATSC.

O padrão americano de televisão digital utiliza a compressão MPEG-2 e a compressão de áudio no padrão Dolby Digital (AC-3) [ATS1995]. Atualmente, as quatro grandes redes de televisão americanas ( $\mathrm{ABC}, \mathrm{NBC}, \mathrm{CBS}$ e $\mathrm{FOX}$ ) transmitem pelo menos uma parte de sua programação em HDTV (cerca de 2 horas por dia, por emissora).

4 http://www.atsc.org/ 
Tabela 2 - Resoluções definidas pelo ATSC. Extraida de [ATS2001]

\begin{tabular}{|c|c|c|c|}
\hline $\begin{array}{c}\text { Pixels } \\
\text { verticais }\end{array}$ & $\begin{array}{c}\text { Pixels } \\
\text { horizontais }\end{array}$ & $\begin{array}{c}\text { Relação de } \\
\text { aspecto }\end{array}$ & $\begin{array}{c}\text { Freqüência de } \\
\text { varredura }\end{array}$ \\
\hline 1080 & 1920 & $1: 1$ e $16: 9$ & $\begin{array}{c}23.97 p, 24 p, 29.97 p \\
30 p, 29.97 i, 30 i\end{array}$ \\
\hline 720 & 1280 & $1: 1$ e $16: 9$ & $\begin{array}{c}23.97 p, 24 p, 29.97 p, \\
30 p, 59.94 p, 60 p\end{array}$ \\
\hline 480 & 704 & $4: 3$ e 16:9 & $\begin{array}{c}23.97 p, 24 p, 29.97 p \\
30 p, 59.94 p, 60 p, \\
29.97 i, 30 i\end{array}$ \\
\hline 480 & 640 & $1: 1$ e 4:3 & $\begin{array}{c}23.97 p, 24 p, 29.97 p \\
30 p, 59.94 p, 60 p, \\
29.97 i, 30 i\end{array}$ \\
\hline
\end{tabular}

O padrão do ATSC prevê uma arquitetura para a implementação da TV Interativa definida pelo DAVIC 5 (Digital Audio-Video Council), na qual se especifica como deve ser feita a requisição de informação extra, como diferentes áudios ou dados complementares. Esse padrão chama-se DTV Application Software Environment (DASE) e será apresentado na seção 3.4.5.

A área que recebe mais críticas na especificação do ATSC é a parte de transmissão. Inicialmente, o ATSC havia escolhido o COFDM (Coded Orthogonal Frequency Division Multiplexing) como modulação e, depois, mudou para o 8VSB (Vestigial Side Band com oito níveis discretos de amplitude). Os maiores problemas do 8-VSB são o ruído e o mau desempenho na computação móvel [ABE2001]. Seus defensores argumentam que o 8-VSM freqüentemente atinge seu pico de transmissão, ao contrário do COFDM.

A TV Digital americana conquistou um mercado muito aquém do previsto, apesar dos esforços por parte da indústria de entretenimento e dos equipamentos eletrônicos. Um dos grandes motivos é o custo dos televisores de alta definição (cerca de U\$3000) e das URDs para HDTV (cerca de U\$500). Outro motivo importante é a pouca quantidade de programas em HDTV transmitidos (apesar das emissoras transmitirem em HDTV, muitas de suas retransmissoras ainda não atualizaram seus equipamentos, continuando a transmitir analogicamente).

\footnotetext{
${ }^{5}$ http://www.davic.org/
} 


\section{2. $D V B$}

O DVB (Digital Video Broadcast) 6 é um consórcio que desenvolveu uma família de padrões para a transmissão de TV Digital: a) via satélite (DVB-S); b) cabo (DVB-C); c) terrestre (DVB-T); d) microondas (DVB-MC e DVB-MS). O DVB-T [DVB1999] foi o desenvolvido para ser o padrão para a transmissão de TV Digital na Europa. O DVB está sendo utilizado na Inglaterra para a transmissão de SDTV desde novembro de 1998 e possui, atualmente, cerca de 1,4 milhão de usuários na transmissão terrestre, 1 milhão via cabo e 5 milhões via satélite [DVB2001]. É importante salientar que a introdução da TV Digital na Inglaterra foi subsidiada por uma operadora de TV por assinatura.

O DVB permite tanto o SDTV quanto o HDTV. Uma das principais características do DVB-T é o uso da modulação COFDM (Coded Orthogonal Frequency Division Multiplexing), que é menos suscetível a ruídos e permite a recepção móvel (nos testes da ABERT foi atingida a velocidade máxima de $60 \mathrm{Km} / \mathrm{h}$ para a recepção dos sinais de DVB-T com a taxa de transmissão de 19,76 Mbps [ABE2001]). O COFDM funciona de modo similar ao CDMA (Code Division Multiple Access) utilizado na telefonia celular.

Dois modos de operação são admitidos pelo DVB: o $2 \mathrm{k}$ (que utiliza 1705 portadoras) e o $8 \mathrm{k}$ (que utiliza 6817 portadoras), sendo que um maior número de portadoras significa uma maior imunidade a ruídos na transmissão. O DVB ainda apresenta a possibilidade de transmissão hierárquica, na qual parte do sinal pode ser transmitida com um grau de robustez maior do que a outra parte. Nesse ponto, o DVB permite dois graus de robustez, também chamados de camadas, e nessas camadas podem ser transportadas diferentes informaçōes sobre um mesmo programa, ou programas diferentes. Com isso, em um mesmo canal podem trafegar um programa em HDTV em uma camada e na camada mais robusta, sua versão em LDTV. A Tabela 3 apresenta as resoluções definidas pelo consórcio DVB.

${ }^{6}$ http://www.dvb.org/ 
Outra característica importante é o fato de que todos os padrões utilizados pelo DVB são compatíveis com a família de padrões MPEG. O MPEG-2 é o padrão de vídeo (incluindo o Main Profile at High Level, MP@HL) e o MPEG-2-Layer II audio [ISO1994], o padrão de áudio. Contudo, o DVB também suporta para o áudio o padrão AC-3 de 5.1 canais [ATS1995] (a Austrália adotou o DVB-T para a transmissão terrestre, porém, utiliza o AC-3 para a codificação de áudio), e existem pesquisas para o suporte do MPEG-2 Audio (AAC) [ISO1997b].

Tabela 3 - Resoluções definidas pelo DVB. Extraida de [ANA2001]

\begin{tabular}{|c|c|c|c|}
\hline Pixels verticais & $\begin{array}{c}\text { Pixels } \\
\text { horizontais }\end{array}$ & $\begin{array}{c}\text { Relação de } \\
\text { aspecto }\end{array}$ & $\begin{array}{c}\text { Freqüência de } \\
\text { varredura }\end{array}$ \\
\hline 1080 & 1920 & $16: 9$ & $25 / 30 i$ \\
\hline \multirow{5}{*}{576} & \multirow[t]{2}{*}{720} & $4: 3,16: 9$ & $50 p$ \\
\hline & & $4: 3,16: 9$ & $25 \mathrm{p}, \mathrm{i}$ \\
\hline & 544 & $4: 3,16: 9$ & $25 p_{1} i$ \\
\hline & 480 & $4: 3,16: 9$ & $25 \mathrm{p}, \mathrm{i}$ \\
\hline & 352 & $4: 3,16: 9$ & $25 \mathrm{p}, \mathrm{i}$ \\
\hline \multirow{7}{*}{480} & \multirow[t]{2}{*}{720} & $4: 3,16: 9$ & $60 p$ \\
\hline & & $4: 3,16: 9$ & $30 p, i$ \\
\hline & \multirow[t]{2}{*}{640} & \multirow[t]{2}{*}{$4: 3$} & $60 p$ \\
\hline & & & $30 \mathrm{p}, \mathrm{i}$ \\
\hline & 544 & $4: 3,16: 9$ & $30 \mathrm{p}, \mathrm{i}$ \\
\hline & 480 & $4: 3,16: 9$ & $30 \mathrm{p}, \mathrm{i}$ \\
\hline & 352 & $4: 3,16: 9$ & $30 \mathrm{p}, \mathrm{i}$ \\
\hline 288 & 352 & $4: 3,16: 9$ & $25 p$ \\
\hline 240 & 352 & $4: 3,16: 9$ & $30 p$ \\
\hline
\end{tabular}

Como última característica importante, a especificação do DVB-MHP (Multimedia Home Plataform) [DVB2000, Eva1999] consiste na definição de uma API (Application Programme Interface) para URDs para o desenvolvimento de EPGs (Electronic Program Guides), serviços de informação, game shows e outros tipos de programas interativos. O DVBMHP será apresentado na seção 3.4.4.

Para uma TV completamente interativa é necessário um canal de retorno, que está sendo especificado pelo consórcio, o DVB-RCT (canal de retorno terrestre). Além desse 
canal de retorno, existem pesquisas em desenvolvimento para a utilização do GSM (padrão adotado para a banda C de telefonia celular no Brasil), e sua atualização UMTS, como canais de retorno para o DVB-T.

\subsection{ISDB}

Apesar do Japão ter criado o primeiro sistema digital para a transmissão de HDTV via satélite (MUSE - Multiple Sub-Nyquist Sampling Encoding), o ISDB (Integrated Service Digital Broadcast) [ARI1998], desenvolvido no Japão pela ARIB $^{7}$ (Association of Radio Industries and Businesses), foi o último a ser especificado. É, entre os três padrões, o mais ambicioso, já que, ao contrário dos padrões americano e europeu, tem como objetivos a transmissão móvel e de informações multimídia, conforme ilustra a Figura 3.

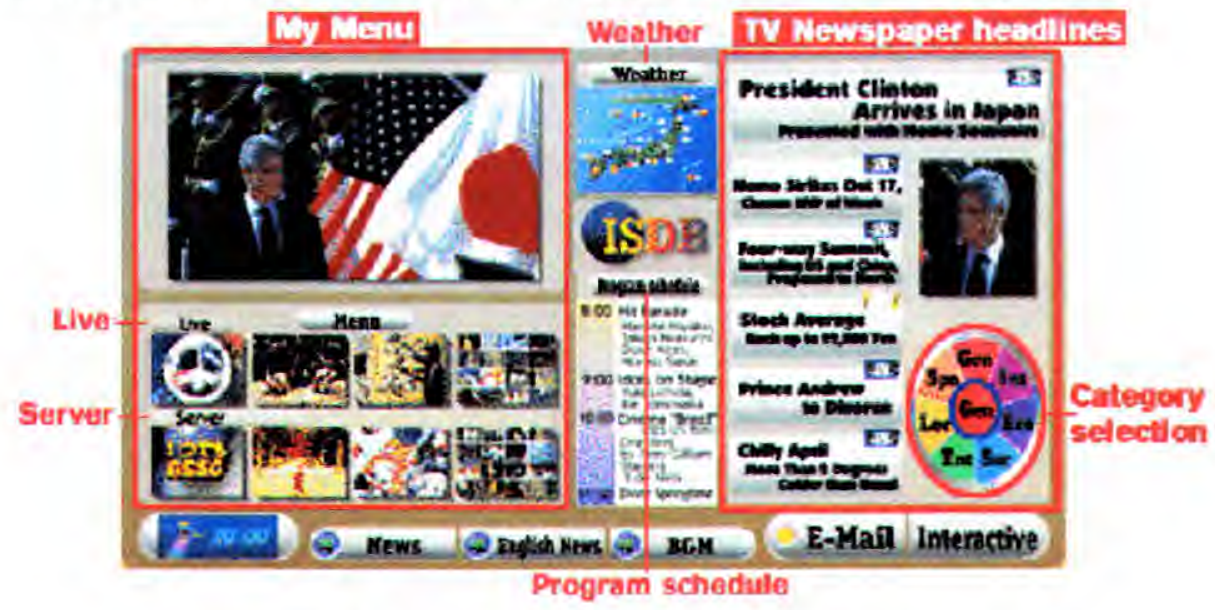

Figura 3-Sistema recebendo os serviços ISDB

O ISDB, assim como o DVB e o ATSC, é uma família de padrões, tendo diferentes especificações para a transmissão terrestre (ISDB-T), via cabo (ISDB-C) e satélite (ISDBS). É bastante similar ao DVB e já é utilizado na transmissão via satélite desde dezembro de 2000 (em lugar do MUSE), tendo sido vendidos cerca de 700 mil receptores. A transmissão terrestre é esperada para 2003, principalmente devido ao problema de alocação de espectro no Japão, sendo previsto o término da transmissão analógica em 2011.

\footnotetext{
${ }^{7}$ http://www.arib.or.jp/arib/english/index.html
} 
O ISDB possui como modulação o Band Segmented Transmission-OFDM (BST-OFDM), uma variação do COFDM utilizado no DVB-T. A vantagem que o ISDB possui é que enquanto no DVB um único embaralhamento (de frequêencias) é utilizado, no ISDB utiliza-se um segundo embaralhamento: o de transposição temporal (time interleaving), que também é utilizado no DAB (Digital Audio Broadcasting) permitindo, assim, uma transmissão menos sujeita a erros.

O ISDB possui três modos de operação: $2 \mathrm{k}$ (1405 portadoras), $4 \mathrm{k}$ (2809 portadoras) e $8 \mathrm{k}$ (5617 portadoras). O modo de $4 \mathrm{k}$ foi feito para ser um formato híbrido, para transmissões para SDTV e móvel simultâneas. A grande vantagem do ISDB em relação ao DVB está na transmissão móvel, pois, pelo fato do ISDB utilizar o segundo embaralhamento e ter um modo de operação híbrido (4k), a qualidade de sua transmissão móvel é bastante superior e mais flexível. Testes foram feitos para a transmissão de TV para um trem-bala com a velocidade de $270 \mathrm{Km} / \mathrm{h}$ [DIG2001] (A ABERT também testou a recepção móvel e conseguiu bons resultados a $215 \mathrm{Km} / \mathrm{h}$, transmitindo à taxa de $19,33 \mathrm{Mbps}$, e a $710 \mathrm{Km} / \mathrm{h}$, à taxa de $5,73 \mathrm{Mbps}$ [ABE2001]). $\mathrm{O}$ ISDB-T também possui a transmissão hierárquica, como o DVB-T, no entanto, nele são permitidas três camadas.

A codificação de vídeo no ISDB utiliza o padrão MPEG-2, e na Tabela 4 são apresentadas as resoluções por ele defini das. A codificação de áudio no padrão ISDB é feita através do MPEG-2 AAC [ISO1997b], que tem como destaque a capacidade de transmitir 48 canais de áudio simultâneos.

Como foi dito, além da transmissão móvel, o ISDB também tem como um objetivo a transmissão de informação multimídia. Para isso, o ISDB agrupa portadoras em treze segmentos, chamados de segmentos de dados. Por exemplo, podem ser utilizados doze para a transmissão de um programa de HDTV e um para a transmissão de dados. A estruturação de documentos multimídia em XML está especificada em [ARI1999, ARI2000], nos quais a ARIB propõe a linguagem BML (Broadcast Markup Language). A 
especificação para a apresentação (semelhante ao DVB-MHP) está sendo feita e sua conclusão é esperada para 2002.

Tabela 4 - Resoluções definidas pelo ISDB. Extraída de [DIG2001]

\begin{tabular}{|c|c|c|c|}
\hline $\begin{array}{c}\text { Pixels } \\
\text { verticais }\end{array}$ & $\begin{array}{c}\text { Pixels } \\
\text { horizontais }\end{array}$ & $\begin{array}{c}\text { Relação de } \\
\text { aspecto }\end{array}$ & $\begin{array}{c}\text { Freqüência de } \\
\text { varredura }\end{array}$ \\
\hline \multirow{2}{*}{1080} & 1920 & $16: 9$ & $30 \mathrm{i}$ \\
\cline { 2 - 4 } & 1440 & $16: 9$ & $30 \mathrm{i}$ \\
\hline \multirow{2}{*}{720} & 1280 & $16: 9$ & $30 \mathrm{p}$ \\
\hline \multirow{3}{*}{480} & 720 & $16: 9$ & $30 \mathrm{p}$ \\
\cline { 2 - 4 } & 720 & $16: 9$ & $30 \mathrm{i}$ \\
\cline { 2 - 4 } & 544 & $16: 9$ & $30 \mathrm{i}$ \\
\cline { 2 - 4 } & 480 & $4: 3$ & $30 \mathrm{i}$ \\
\hline
\end{tabular}

\subsection{O Cenário no Brasil}

O Brasil realizou testes comparativos entre os três padrões de DTV através da Sociedade Brasileira de Engenharia de TV ${ }^{8}$ (SET) e da Associação Brasileira de Emissoras de Rádio e Televisão9 (ABERT), e essas entidades entregaram um relatório em maio de 2000. A partir desse relatório, a Agência Nacional de Telecomunicações ${ }^{10}$ (ANATEL) escreveu um Relatório Integrador [ANA2001] que ficou disponível em abril de 2001 para consulta pública, e até o dia 23 de julho de 2001, para contribuições. No site da ANATEL, é possível o acesso tanto ao relatório da ANATEL quanto ঐs contribuições feitas.

O relatório SET/ABERT [ABE2000] considerou o padrão ISDB como o melhor, em termos técnicos, tendo como pontos fortes a recepção móvel ea flexibilidade para novos modelos de negócios. Ele tem como maiores desvantagens o fato de não estar disponível até 2002 e o fato de possuir o menor mercado, fazendo com que os produtos fiquem mais caros.

\footnotetext{
${ }^{8}$ http://www.set.com.br/

${ }^{9}$ http://www.abert.org.br/

${ }^{10}$ http://www.anatel.gov.br/
} 
O relatório da SET/ABERT não recomendou o padrão ATSC principalmente devido ao uso do 8-VSM, tendo sido considerado o padrão insatisfatório. Porém, existem várias empresas que o apoiam, uma vez o ATSC possui um vasto mercado (o que geraria uma economia de escala) e é o que está há mais tempo em testes. O relatório da SET/ABERT elogiou bastante o DVB-T, principalmente devido ao uso do COFDM, porém, evidencia que obteve melhores resultados, principalmente no que diz respeito à recepção móvel, utilizando o ISDB-T. A Tabela 5 apresenta uma comparação entre os sistemas analisados.

Tabela 5 - Comparação entre os três sistemas de TV Digital

\begin{tabular}{|c|c|c|c|c|}
\hline \multicolumn{2}{|c|}{} & ATSC & \multicolumn{3}{|c|}{ DVB } & ISDB \\
\hline \multirow{2}{*}{ Codificação } & video & \multicolumn{3}{|c|}{ MPEG - 2 Video } \\
\cline { 2 - 5 } & áudio & Dolby AC-3 & $\begin{array}{c}\text { MPEG - 2 Áudio } \\
\text { (Dolby AC-3 opcional) }\end{array}$ & MPEG-2 AAC \\
\hline \multicolumn{3}{|c|}{ Multiplexação de sinais } & \multicolumn{3}{|c|}{ MPEG } \\
\hline \multirow{3}{*}{ Transmissão } & terrestre & $8-V S B$ & COFDM & BST-OFDM \\
\cline { 2 - 5 } & cabo & 64 QAM & QAM (16,32,64,128 e 256) & 64 QAM \\
\cline { 2 - 5 } & satélite & QPSK & QPSK & 8-PSK \\
\hline
\end{tabular}

A ANATEL, além de se basear no relatório SET/ABERT para avaliar as questões técnicas relativas as tecnologias, realizou pesquisas sobre a expectativa dos usuários em relação à TV do futuro, avaliando a importância de itens como: ajuda para deficientes físicos, gravação de programas, imagem de alta definição, múltiplos programas, informativos, programas defasados $(\mathrm{NVoD})$, interatividade, vídeo adicional, áudio adicional, legenda adicional, hipermídia e áudio digital [ANA2001].

Como última variável importante na escolha de um padrão estão as questões políticas e econômicas. O Brasil está avaliando o tamanho do mercado mundial de cada um dos padrões (Tabela 6) e as vantagens políticas e econômicas que cada um deles dará em contrapartida à sua adoção, como a quantidade de tecnologia transferida, isenção de royalties e o impacto na indústria eletrônica brasileira. A ABERT estima que as emissoras gastarão cerca de U\$1,62 bilhão somente em equipamentos para a transmissão e recepção. 
Tabela 6 - Dimensão dos mercados já definidos. Extraida de [ANA2001]

\begin{tabular}{|l|l|c|c|}
\hline \multicolumn{1}{|c|}{ Padrão } & \multicolumn{1}{|c|}{ Países } & \multicolumn{1}{|c|}{$\begin{array}{c}\text { Lares com TV } \\
\text { (milhões) }\end{array}$} & $\begin{array}{c}\text { Número de TVs } \\
\text { (milhões) }\end{array}$ \\
\hline \multirow{2}{*}{ ATSC } & EUA, Canadá, Coréia do Sul & 125 & 267 \\
\cline { 2 - 4 } & Argentina *, Taiwan * Austrália, Nova & 15 & 18 \\
\hline \multirow{2}{*}{ DVB } & $\begin{array}{l}\text { União Européia, Audia } \\
\text { Zelândia, Sigapura, India }\end{array}$ & 205 & 270 \\
\hline ISDB & Japão & 45 & 100 \\
\hline & Brasil ** & 38 & 53 \\
\hline
\end{tabular}

* Possivel revisão do padrão

** Colocado somente para comparação

Até hoje, as escolhas dos padrões de TV Digital tiveram como principal aspecto a questão política. O Brasil foi o primeiro país a fazer um teste comparativo entre os três padrões (o DVB-T e o ATSC já haviam sido comparados, porém, com um detalhamento menor) e, por isso, os testes feitos no Brasil estão sendo acompanhados com muita atenção, tanto pelos três grupos responsáveis pelos padrões, quanto pelos países que ainda não decidiram o padrão a ser adotado. O Brasil está em uma posição privilegiada, uma vez que é o sétimo maior mercado de TV do mundo, tendo mais da metade dos televisores da América do Sul e o papel de líder do Mercosul (a Argentina provavelmente adotará o mesmo padrão que o Brasil decidir). Fica clara a importância do mercado brasileiro nas contribuições à consulta pública da ANATEL. 


\section{Interação na Televisão}

A possibilidade da interação com um programa de televisão é um desejo antigo. Diversos programas incentivam a interação dos espectadores, na maioria das vezes por telefone, e essa interação ocorre tanto em game shows, quanto para fazer pesquisa de opinião, como para escolher o final de um programa. O maior inconveniente é que essa interação é bastante limitada e a TV e o telefone são aparelhos que não se comunicam de forma integrada. Com a evolução da tecnologia e o aparecimento das URDs, a ligação do aparelho de TV com o telefone tornou-se possível, possibilitando o lançamento de diversos modelos e produtos de TV Interativa em todo o mundo.

A transmissão da TV Interativa pode ser feita de três modos: a) via broadcast, em que todos os usuários recebem toda a informação possível, porém, as URDs só apresentam o necessário; b) via unicast, que permite a entrega individual da informação para o usuário (tem a vantagem de que só a informação que interessa ao usuário é disponibilizada, porém, tem a desvantagem no caso da transmissão de vídeo de vários threads, necessitando muitos recursos computacionais dos servidores); c)via multicast, em que para a transmissão de cada objeto o servidor necessita de um thread, independente do número de receptores (nesse modo, cada receptor entra num grupo para receber o objeto). Em Martins [Mar2001] é mostrada uma comparação de desempenho entre um servidor de vídeo unicast e um multicast, na qual fica evidente a melhor utilização da banda e o menor processamento necessário no servidor multicast.

O canal de retorno é um outro fator que categoriza a TV Interativa em três grupos. O primeiro grupo é o que não possui canal de retorno, sendo que toda a informação com a qual o usuário pode interagir sempre é entregue ao usuário. Esse tipo de interação apresenta alto custo em termos de transmissão e apresenta limitaçōes para o usuário. $O$ segundo grupo possui canal de retorno não-dedicado, em que a linha telefônica é utilizada como o canal de retorno. A interação fica mais "rica" e menos limitada. A maioria dos modelos de Enhanced TV pode ser inserida nesse grupo. Como parte do 
último grupo estão as TVs Interativas com canal de retorno dedicado. Desse grupo fazem parte as TVs Interativas por Cabo ou que utilizam linhas DSL para o retorno. A existência de um canal dedicado permite uma interação completa, uma vez que a possibilidade de interação está sempre presente e o tempo de resposta, normalmente, é menor.

Atualmente, existem diversas soluções de TV Interativa no mundo. Essas soluções, apesar de permitirem alguma interação do usuário, são bastante limitadas em relação às expectativas dos usuários, acostumados à interação existente na WWW. Existem diversos nomes dados às diferentes implementações de TV Interativa em relação à sua funcionalidade. A seguir, algumas denominaçōes serão apresentadas:

- Enhanced TV - na Enhanced TV os programas podem possuir conteúdo relacionado que, normalmente, é acessado através de um clique em um ícone; a Enhanced TV será detalhada na seção 3.2;

- Individualized TV - nesse tipo de TV Interativa o usuário possui opções de câmera e áudio, semelhante às funcionalidades de um DVD;

- Internet TV - é a TV Interativa que permite o acesso à Internet via televisor, utilizando a linha telefônica para o acesso;

- On demand TV - é a TV que permite o Video on Demand (ou a sua variação Near Video on Demand);

- Personal TV - a Personal TV é o tipo de TV que permite ao usuário o controle do vídeo; ela é bastante conhecida e funciona a partir dos PDRs Personal Data Recorders); a Personal TV será detalhada na seção 3.1.

Uma das aplicações mais conhecidas e úteis da TV Interativa é o Guia Eletrônico de Programação (EPG). É uma aplicação presente tanto nos modelos de Enhanced TV quanto em Interactive TV. Tamanha importância deve-se ao fato de que o EPG é o programa centralizador de toda a informação sobre a programação dos canais de TV. Os EPGs são aplicações que diferenciam as funcionalidades entre modelos de TV 
Interativa, podendo ser simples indicadores da programação atual (como os utilizados nas TVs por satélite), como controladores da gravação de programas (como os usados nos PVRs), ou para fazer recomendações de programação [Bar2001; Kur2001].

A Personal TV e os PDRs serão apresentados na seção 3.1. Em seguida, a Enhanced TV será detalhada e algumas das soluções existentes apresentadas. $\mathrm{Na}$ seção 3.3 serão apresentados uma definição da TV Interativa do futuro e um trabalho acadêmico para a sua implementação. Finalmente, na seção 3.4, serão apresentadas as tecnologias que poderão tornar concreta a implementação desse tipo de TV.

\subsection{Personal TV}

O PDR pode ser considerado o sucessor do videocassete, uma vez que tem como principal funcionalidade a gravação de programas de televisão, porém possui diversas características que o tornam bastante atraente para o consumidor. O PDR é composto por uma placa de captura de vídeo, transformando um vídeo analógico em digital (MPEG-2), e por um disco rígido que pode variar de tamanho de acordo com o modelo. O PDR pode gravar com diversos níveis de compressão, permitindo gravar até 30 horas de programas na pior qualidade de imagem (qualidade semelhante a gravação na velocidade VHS EP/SLP). As informações da programação das redes de TV para o EPG são transmitidas através de uma ligação telefônica em um horário pré-programado pelo usuário. Diversas empresas investem na criação de PDR, dentre elas a TiVo ${ }^{11}$, a ReplayTV12, a Microsoft ${ }^{13}$ e a Philips [Bar2001].

Os custos e investimentos são as primeiras características importantes do PDR, iniciando em U\$300.00 para o STB (Set Top Box) e U\$9.99 pelo serviço mensal nos EUA. Outra característica interessante é o uso intensivo do EPG (Figura 4), fazendo com que a programação se torne bastante intuitiva, permitindo a gravação sem comerciais, a programação instantânea (gravação a partir de uma chamada comercial de um

\footnotetext{
11 http://www.tivo.com/

12 http://www.replaytv.com/

13 http://www.microsoft.com/
} 
programa) e, ainda, a criação de canais especiais, de modo que, por exemplo, um aficionado pelos filmes de Hitchcock possa criar o canal Hitchcock para armazenar toda a programação referente ao famoso diretor.

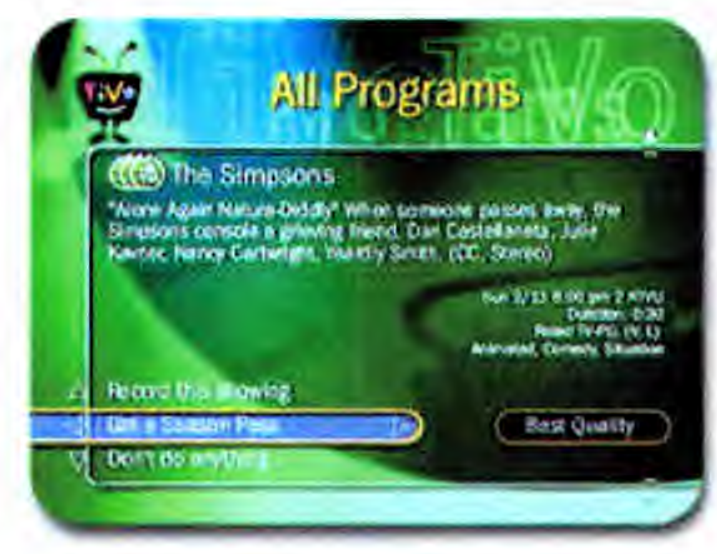

Figura 4 - EPG da TiVo

Pelo fato dos programas serem gravados em um disco rígido, é possível o acesso aleatório a qualquer ponto do programa. Outro "sonho" de muitos consumidores também tornou-se realidade com os PDRs: as funções de pause e rewind em eventos ao vivo.

A integração dos PDRs com o acesso à Internet, a TV Digital, os padrões MPEG-4 e MPEG-7 permitirá um novo universo de interações bastante significativo. É importante ressaltar que tanto o modelo da ATVEF quanto o modelo da TV-Anytime Forum utilizam os conceitos de EPG e PDR.

\subsection{Enhanced TV}

A Enhanced TV pode ser vista como a evolução da TV atual, sendo um dos tipos de TV Interativa com maior número de funcionalidades. A Enhanced TV possui implementações tanto para a TV analógica quanto para a TV Digital. A Enhanced TV, muitas vezes, engloba as funcionalidades da Internet TV e tenta integrar as informações da TV com informações de um site, sendo essa a sua característica mais marcante. Na Enhanced TV não é comum a possibilidade de mudança de câmeras ou idiomas (a não ser quando é utilizada a transmissão digital), e nem vídeo-sob-demanda (VoD). Já a 
integração com os PDRs é cada vez maior, existindo algumas soluções no mercado com essas funções. Devido à crescente quantidade de diferentes implementações, foi criado um padrão para a Enhanced TV. Esse padrão e alguns exemplos de soluções de TV Interativa existentes no mundo serão apresentados a seguir.

\subsubsection{ATVEF}

O ATVEF (Advanced Television Enhancement Forum) ${ }^{\mathbf{1 4}}$ é um grupo formado por empresas que atuam nos setores de programação de TV, transmissão de TV, eletrônicos e empresas de informática, tendo como objetivo criar uma televisão interativa independente de plataforma, utilizando, para isso, diversos padrões existentes e criando novos quando necessário.

Essa aliança já criou uma especificação para programas de TV Interativa, baseada em HTML, intitulada ATVEF Specification for Interactive Television 1.1 [ATV2000]. As principais características desse padrão são:

- Uso de HTML 4.0 [Rag1999];

- Cascading Style Sheets, Level1 (CSS1) - permitindo a aplicação de estilos a documentos HTML [Lie1999];

- ECMAScript - uma linguagem de programação do tipo script, independente de plataforma;

- Document Object Model (DOM 0) - uma plataforma que permite, a programas e scripts, o acesso dinâmico e a atualização de conteúdo, estrutura e estilo dos documentos [W3C2000a];

- O suporte ao Javascript 1.1 é equivalente ao uso do ECMAScript e do DOM 0.

A integração da TV com as páginas WWW é feita através das URIs "tv:" [Vic2000, Fin2000] e "lid:" [Bla2000]. A URI "tv:" tem como função inserir um conteúdo de televisão em uma página HTML, já a URI “lid:", local identifier, é um identificador local de um arquivo. O ATVEF especifica que as URDs devem possuir, no mínimo, $1 \mathrm{MB}$

14 http://www.atvef.org/ 
para cache simultâneo e é necessário especificar, antes da transmissão, a quantidade de memória cache para cada programa (essa quantidade será o pico e não o total).

O modelo do ATVEF é baseado no conceito de triggers (gatilho) [ATV2000], isto é, as páginas HTML da TV Interativa devem possuir um objeto receptor de triggers. Os triggers são eventos em tempo real, transmitidos para programas da TV Interativa. As implementaçōes dos receptores permitirão a criação de diferentes políticas para o recebimento dos triggers, como, por exemplo, o aviso de chegada de triggers para notificar os usuários da disponibilidade de conteúdo extra. Eles devem sempre possuir uma URL e podem possuir, opcionalmente, um nome, validade e um script.

O ATVEF definiu dois tipos de transportes: o do tipo A, que é o transporte dos triggers, e o transporte do tipo $B$, que se destina ao transporte de dados. O primeiro tipo deve ser implementado de acordo com cada padrão de televisão; o ATVEF tem documentos mostrando como deve ser implementado tanto para o NTSC quanto para o PAL, além de apresentar trabalhos no sentido de implementar para o DVB e o ATSC. O segundo, do tipo B, ao contrário do transporte A, faz com que a TV Digital seja independente de conexões Internet auxiliares (por exemplo, o telefone), uma vez que esse tipo de transporte já é feito para receber dados também. O ATVEF desenvolveu um protocolo especial para cuidar do broadcast, o Unidirecional Hypertext Transfer Protocol (UHTTP), que é uma versão simplificada do HTML, desenvolvida para ser eficiente na transmissão de dados broadcast.

O ATVEF tem cerca de 130 empresas afiliadas e muitos dos atuais projetos de TV Interativa estão sendo feitos de acordo com sua especificação. 


\subsubsection{WebTV/Microsoft TV}

A WebTV ${ }^{15}$ é uma empresa que surgiu em 1995 e tinha como grande novidade o acesso à Internet via TV. Sua solução era composta por uma URD com saídas para TV e entrada RJ-11 (telefone), e um teclado com joystick. Assim, tudo que a WebTV permitia era a navegação na WWW através de uma conexão ao provedor WebTV. O aparelho fez um grande sucesso, principalmente devido ao custo, menor que o de um computador, e à comodidade de navegar na WWW sentado no sofá.

A Microsoft comprou a WebTV em 1997 e iniciou a implementação de características de interatividade. Foram feitos acordos com grandes emissoras dos EUA. Atualmente, a WebTV já permite alguma interação com alguns programas de televisão, como o Jeopardy (um game show) e o NBC News (telejornal), entre outros.

A WebTV possui uma solução chamada de WebTV Plus Interactive, na qual a interação só está disponível em determinados momentos de determinados programas. $\mathrm{O}$ usuário fica sabendo da possibilidade de interação devido à presença de um ícone "i" na tela (Figura 5). Esse "i" possui um link para uma URL e a velocidade de transmissão é limitada a 60 caracteres por segundo ( 2 caracteres por frame e 30 frames por segundo).

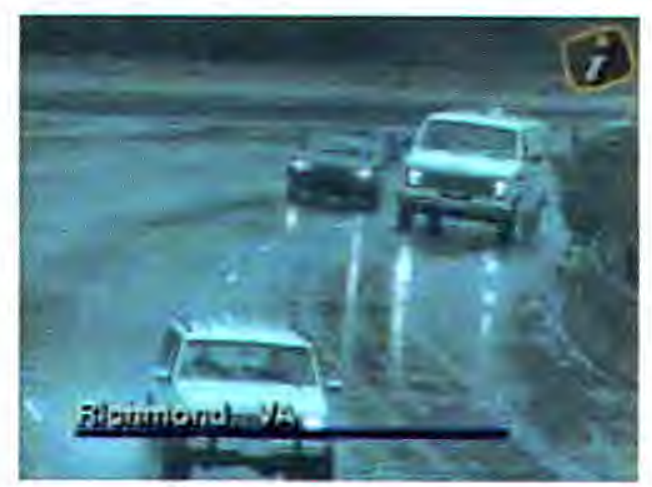

Figura 5 - Transmissão de programa que permite interatividade

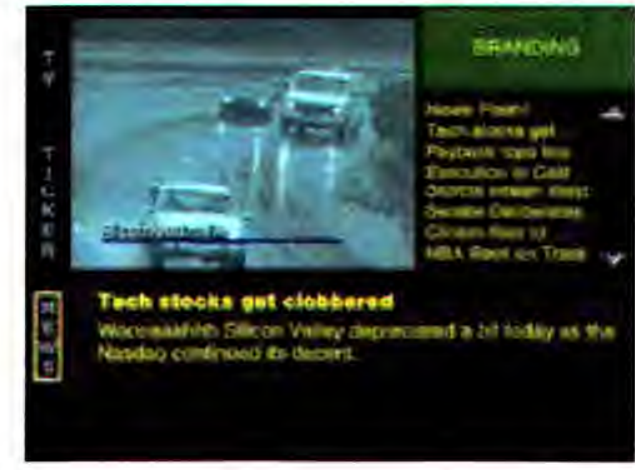

Figura 6 - Informações adicionais do programa

15 http://www.webtv.com/ 
Para acessar a informação extra disponível, o usuário "clica" no ícone e então pode obter mais informações (Figura 6). A partir disso, o usuário passa a utilizar a linha telefônica tanto para receber quanto para enviar os dados (com exceção do vídeo, que continua sendo analógico).

A solução WebTV é bastante semelhante à especificação 1.1 do ATVEF [ATV2000] (mesmo porque a Microsoft teve uma participação bastante ativa no ATVEF), utilizando o conceito de triggers, os links da TV. As informaçōes são transmitidas do mesmo modo que o closed caption (no caso do NTSC a linha 21 VBI).

Além do Plus Interactive, a WebTV possui um produto chamado Personal TV, criado em conjunto com a rede de TV por satélite Dish Networks, que associa o WebTV com um PDR (Personal Data Recorder) que, no entanto, não suporta o conteúdo interativo. Mais recentemente, a WebTV criou um produto chamado Ultimate TV ${ }^{16} \mathrm{em}$ conjunto com a TV por satélite Direct TV, que uniu a WebTV Plus Interactive e um PDR.

Desenvolver uma página para WebTV é bastante simples, uma vez que ela utiliza como linguagem o HTML com pequenas modificações [MIC2000]. A Microsoft anuncia que, em um futuro próximo, as URDs WebTV serão completamente compatíveis com a especificação do ATVEF.

Além da WebTV, a Microsoft está desenvolvendo um outro modelo de TV Interativa, chamado de Microsoft TV ${ }^{17}$. Os produtos Microsoft TV incluem os softwares Microsoft TV Basic Digital e o Microsoft TV Advanced, para decodificadores, e o Microsoft TV Server e o Microsoft TV Access Channel Server, para o fornecimento de novos serviços através da central da operadora. Como uma extensão da plataforma Microsoft TV, as tecnologias da empresa fornecerão serviços de transmissão e funções nas futuras gerações do sistema operacional Windows, criando a base para os serviços de TV Interativa em computadores pessoais e outros dispositivos para a computação. A Microsoft TV, criada

\footnotetext{
16 http://www.ultimatetv.com/

17 http://www.microsoft.com/tv
} 
segundo a especificação da ATVEF, é compatível com os padrões de transmissão de TV analógica e com os novos padrões de transmissão de TV Digital, além disso, suporta os padrões da Internet como HTML, Javascript e Dynamic HTML.

A Figura 7 mostra como funciona a plataforma Microsoft TV e seu processo de distribuição. Conteúdo e serviços (Content $\mathcal{E}$ Services) podem ser feitos por qualquer um e é possível a utilização de serviços como a MSN (Microsoft Network). Esse conteúdo é transmitido para um servidor, que pode ser ou o Microsoft TV Server, ou o Microsoft TV Access Channel Server, e que transmite a informação via um meio de transporte, que pode ser TV a Cabo, Satélite ou Difusão (tanto analógica quanto digital). O Microsoft TV Access Channel Server transmitirá informações para o Microsoft TV Basic Digital STB (porém, o Advanced também pode receber essa informação), e o Microsoft TV Server transmitirá informação para o Microsoft TV Advanced STB. Computadores pessoais também podem receber o conteúdo Microsoft TV. A Figura 8 mostra o funcionamento do Microsoft TV Server e a Figura 9 apresenta o funcionamento do Microsoft TV Access Channel Server. Pode-se perceber que o Microsoft TV Server possui mais funcionalidades.

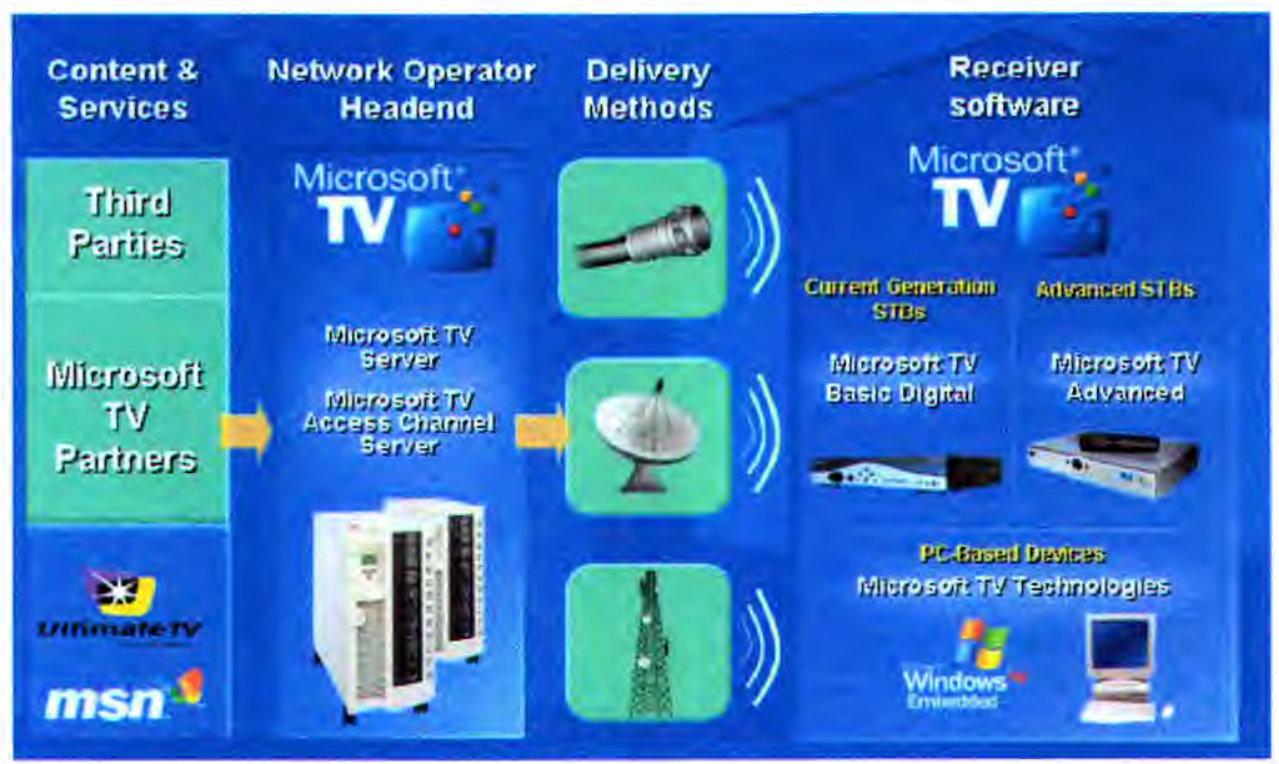

Figura 7 - Plataforma de TV Interativa da Microsoft TV e sua distribuição. Extraída do site da Microsoft TV 


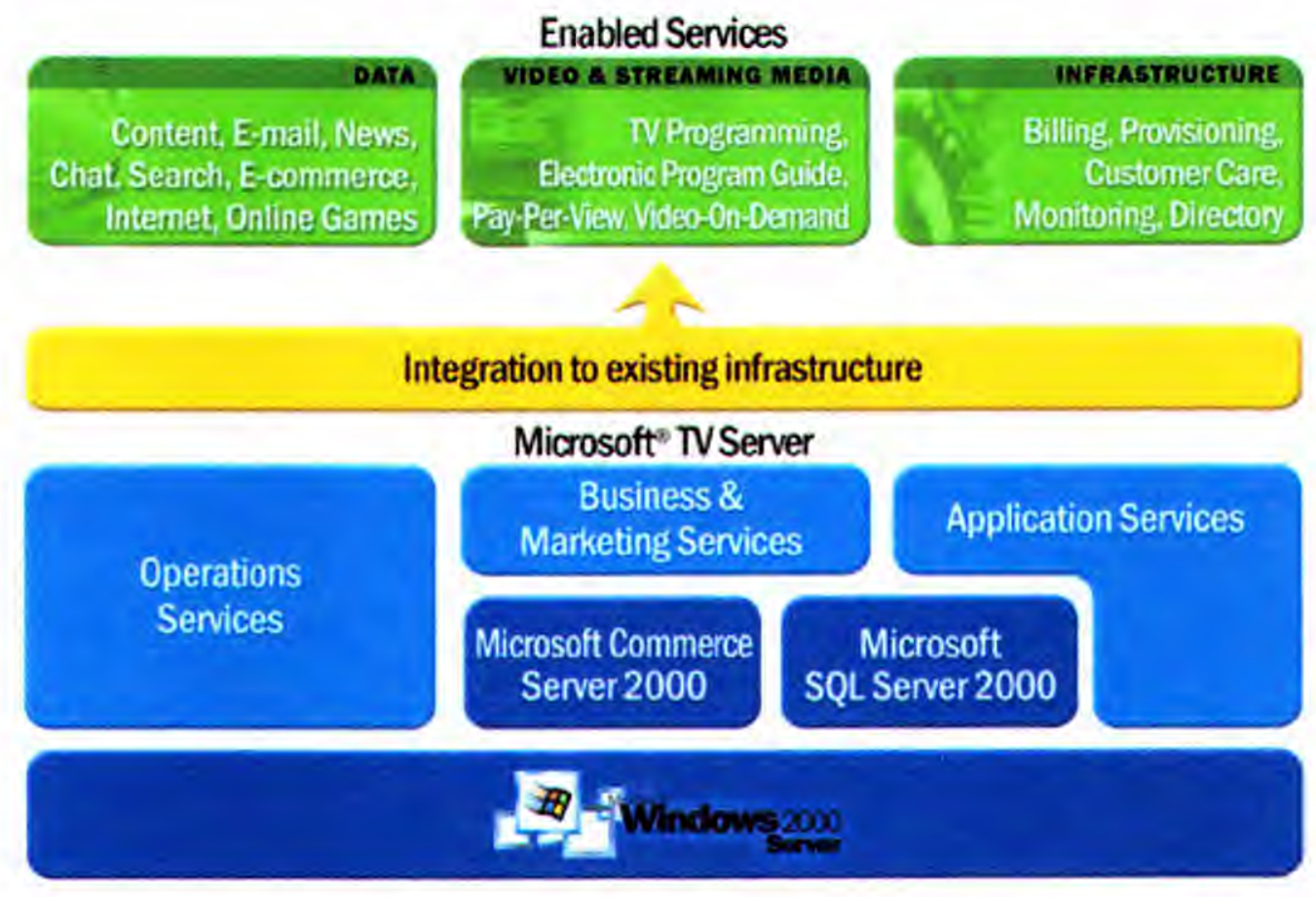

Figura 8 - Estrutura do Microsoft TV Server. Extraída do site da Microsoft TV

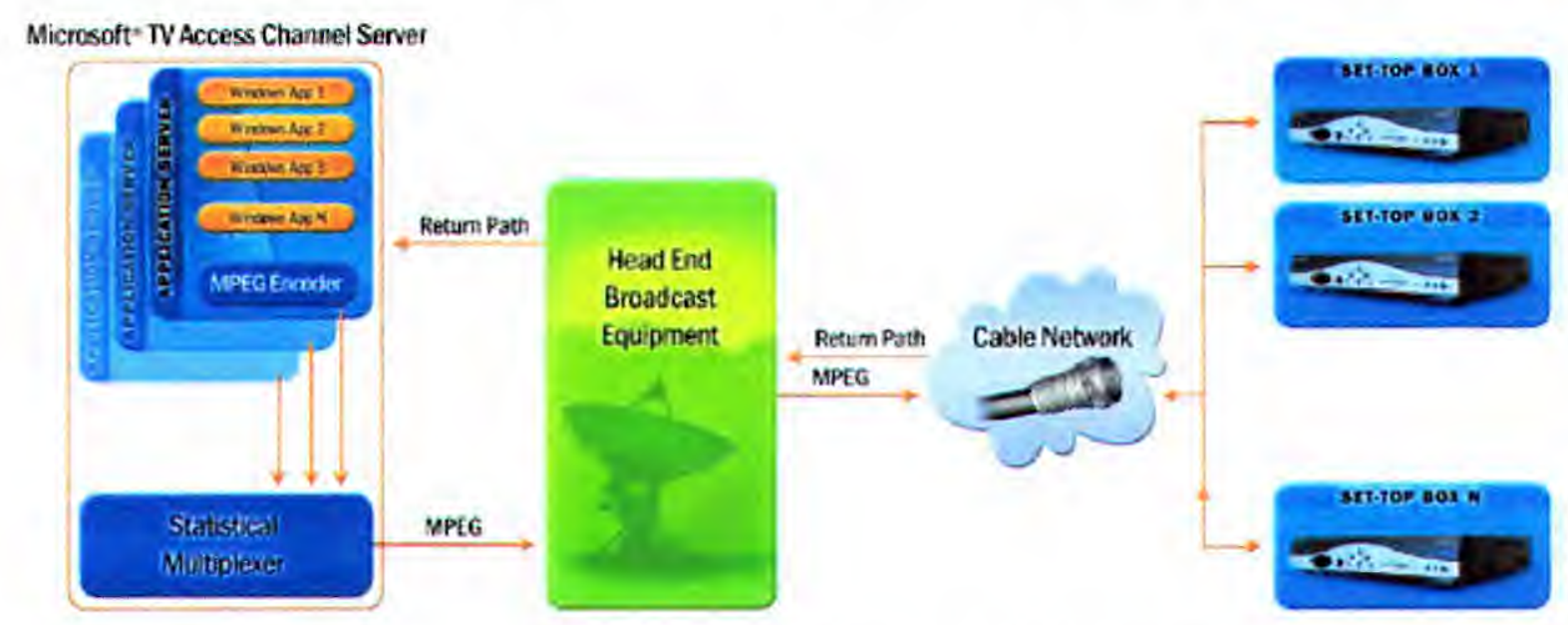

Figura 9 - Infra-estrutura da distribuição do TV Access Channel Server. Extraída do site da Microsoft TV

A operadora de TV a Cabo brasileira NET Brasil está realizando testes do uso da Microsoft TV em Sorocaba, onde estão utilizando a solução Basic Digital para a recepção (é o primeiro teste no mundo), e tanto o TV Server quanto o TV Access Channel Server, para a distribuição. 


\subsubsection{Liberate}

A Liberate ${ }^{18}$ é uma empresa que surgiu há cinco anos, tendo como principais investidores a Oracle e a Netscape, e hoje é uma das líderes no setor de TV Interativa. Ela é uma das empresas fundadoras da ATVEF e é membro do TV-Anytime Forum.

A Liberate possui três linhas de produtos: os servidores (Liberate Connect), os clientes (Liberate TV Navigator - que, atualmente, são baseados no Netscape Navigator, mas a próxima geração utilizará a Gecko Engine) e, por fim, as ferramentas para a edição de programas (Liberate TV Producer). Para a edição de programas interativos, a empresa criou, recentemente, um programa de parcerias tanto na parte de software quanto de hardware, chamado PopTV19.

Existem três tipos de implementação da plataforma TV Navigator, como ilustrado na Figura 10. Nas versões Standard e Compact, o conteúdo transmitido é digital, no entanto, a versão Compact não é compatível com HTML e Javascript, utilizando para a interação uma linguagem chamada CPML (Compact Plataform Markup Language). Já a versão Analog é feita para ser utilizada na televisão analógica e tem funções semelhantes às da versão Standard, sendo que o vídeo é recebido de forma analógica e a interação é feita a partir de uma linha telefônica.

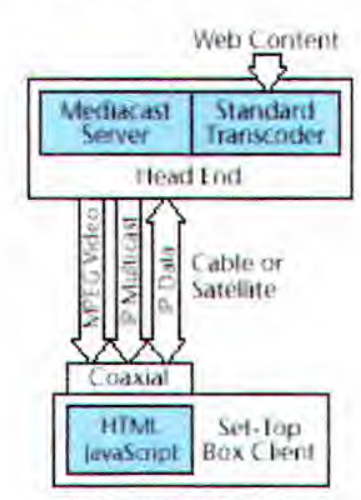

TV Navigator Standard

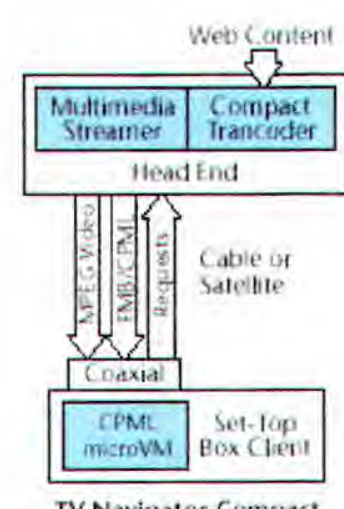

TV Navigator Compact

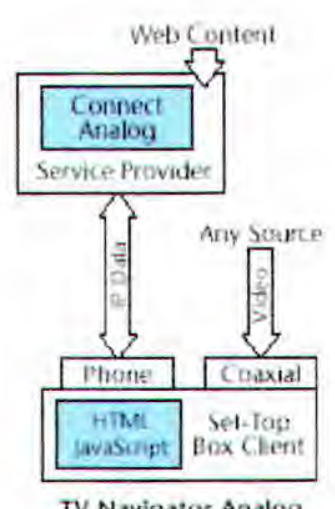

TV Navigator Analog

Figura 10 - Comparação das plataformas do TV Navigator

\footnotetext{
$18 \mathrm{http}: / /$ www.liberate.com/

19 http://partners.liberate.com/
} 
A Liberate é conhecida por suas associações com outras grandes empresas. As três mais importantes associaçōes recentes foram:

- com a Philips, o desenvolvimento de um Set-Top Box com um decoder MPEG-4;

- com a AOL - Time Warner, que utilizará, na AOL TV20, o engine Liberate para a TV analógica;

- com a AT\&T, que utilizará a plataforma Liberate em seu protótipo de TV Interativa.

Por essas características, a Liberate tornou-se uma das empresas mais bem posicionadas no mercado da TV Interativa, principalmente nos EUA. A Liberate, assim como a Microsoft, promete ter seus produtos, em um futuro próximo, totalmente compatíveis com a especificação do ATVEF.

Por meio do programa de parcerias PopTV, a Liberate disponibiliza um programa para a autoria de programas de TV Interativa, chamado TV Producer (que, atualmente, está na versão 1.2.6), que é um plug-in para o software de edição de HTML Macromedia Dreamweaver, e o player, emulador da URD da Liberate, chamado de TV Emulator (cuja versão atual é a 1.2.7).

\subsubsection{Open TV}

A OpenTV21 foi criada, em 1996, como Thompson Sun Interactive e, em 1998, tornou-se OpenTV Corporation. O software da OpenTV roda em mais de 9,3 milhões de Set-Top Boxes em todo o mundo, fazendo dela a empresa de TV Interativa com maior penetração no mercado.

A OpenTV tem como produtos um sistema operacional (OpenTV RunTime), um software servidor (OpenStreamer) e as ferramentas de desenvolvimento de aplicações OpenTV SDK, OpenAuthor e OpenStudio. A empresa possui várias alianças com outras

20 http://www.aoltv.com/

21 http://www.opentv.com/ 
empresas por todo o mundo, em especial com empresas européias, tanto na área de desenvolvimento de software quanto para o desenvolvimento de URDs.

A OpenTV apóia padrões como o DVB-MHP (padrão de TV Interativa da TV Digital européia), a JavaTV e a especificação da ATVEF.

\subsubsection{MyTV}

O MyTV22 é um projeto de um consórcio de empresas lideradas pela Philips e pela Nokia com o objetivo de criar uma aplicação para o padrão DVB-MHP seguindo as especificações do TV-Anytime Forum (que será apresentado na seção 3.4.3). Alguns dos desafios enfrentados pelo projeto são: como transportar dados TV-Anytime Forum no DVB, como anexar metadado ao conteúdo, como tratar múltiplas fontes de informação, além das questões de personalização. A Figura 11 apresenta a estrutura do projeto MyTV.

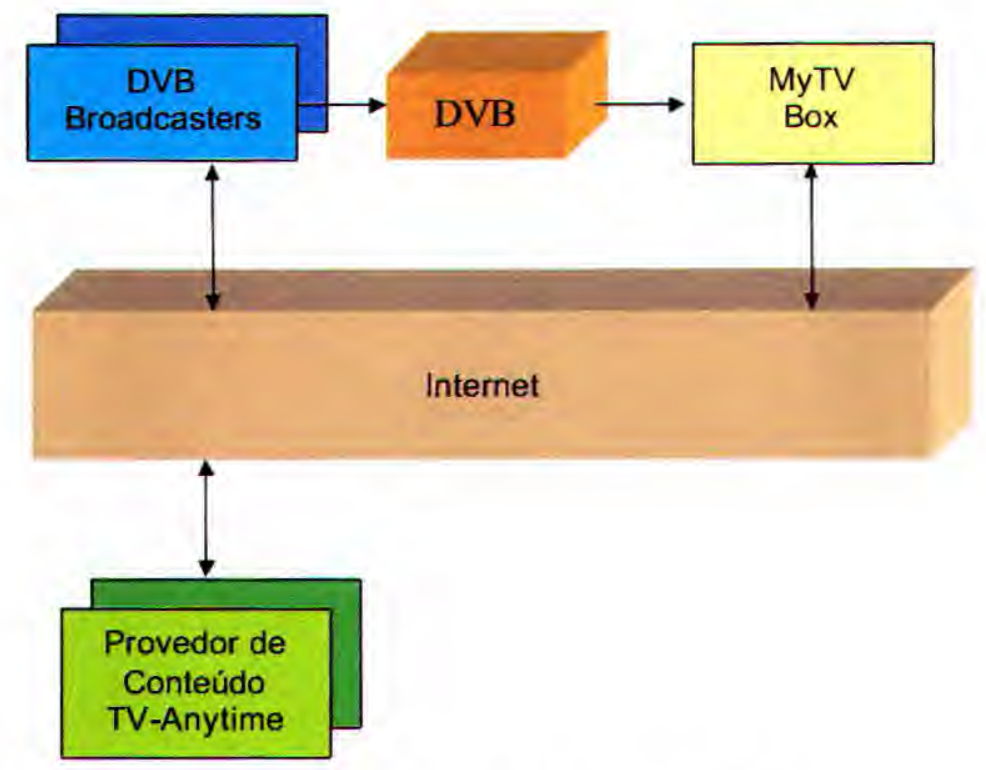

Figura 11 - Estrutura do projeto MyTV

22 http://www.extra.research.philips.com/euprojects/mytv/ 


\subsection{Interactive TV}

A Interactive TV é uma evolução da Enhanced TV, uma vez que não apenas expande as funcionalidades da TV, como cria novos paradigmas de como produzir, transmitir e assistir a TV. Na parte da produção, um impacto bastante grande será sentido porque o produtor terá que se preocupar, não apenas com a produção de uma mídia e, sim, com a produção de várias mídias, seus relacionamentos, e suas alternativas. Com isso, a estrutura do programa de TV ganhou muita complexidade. Na parte da transmissão, o que muda é que, anteriormente, um programa estava inteiro em um stream e, com a TV Interativa, os componentes do programa podem estar separados e podem ter sido transmitidos por diferentes meios, portanto, tanto a emissora quanto a URD devem conter mecanismos para a sincronização do mesmo. Já na parte do usuário (a palavra espectador não se aplica à TV Interativa, uma vez que a interação é esperada), o conceito de assistir um programa de TV irá mudar completamente, pois o programa será personalizado e a interação permitirá que a experiência de assistir tenha outro significado. A Interactive TV pretende possuir todas as funçōes da Enhanced TV somadas a capacidades de VoD, e mudanças de características das mídias apresentadas (como na Individualized TV). A seguir, será apresentado um modelo de Interactive TV, desenvolvido pelo Telecom Italia $\mathrm{Lab}^{23}$, que utiliza o padrão MPEG-4 para a transmissão de seu conteúdo.

\section{AIC / Next TV}

A Next TV24 é um projeto conjunto do Telecom Italia Lab e empresas como a Philips, Sony e Sun Microsystems, entre outras, e tem como objetivo analisar modelos de negócios para a Interactive TV, desenvolvimento de especificaçōes para o transporte e apresentação de mídias, como o MPEG-4 e MPEG-2, além da implementação do hardware e do software necessários para a produção e transmissão de programas interativos. Além disso, a integração dos padrões MPEG com a tecnologia Java e o

23 http://www.telecomitalialab.com/ (antigo CSELT)

24 http://www.extra.research.philips.com/euprojects/nextv/ 
padrão de TV Digital DVB também é alvo de pesquisas. A Next TV se utiliza dos estudos realizados pela AIC-I (Advanced Interactive Content Iniciative), que tem como princípios a distribuição do conteúdo por diversos ambientes de transporte e a utilização dos padrões MPEG-2 e MPEG-4. As Figuras 12 e 13 apresentam a imagem de um programa para a TV Interativa feito para a Next TV, antes e depois da ocorrência de uma interação. Esse programa foi implementado em MPEG-4 e transportado via MPEG2 TS (Transport Stream).

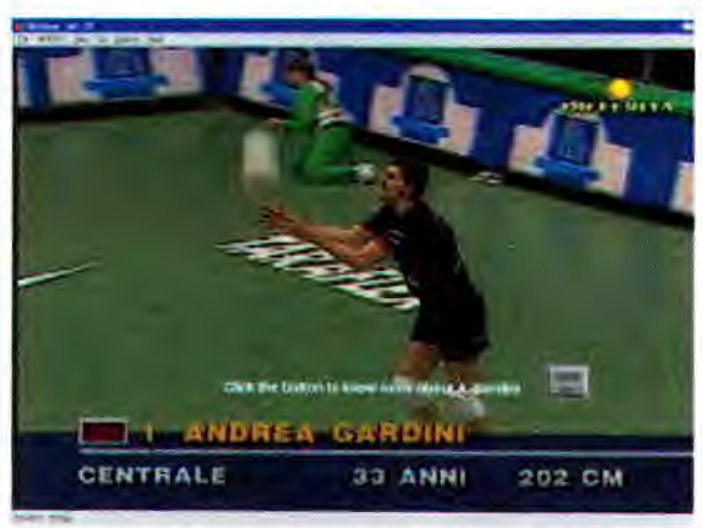

Figura 12 - Programa da NexTV antes da interação

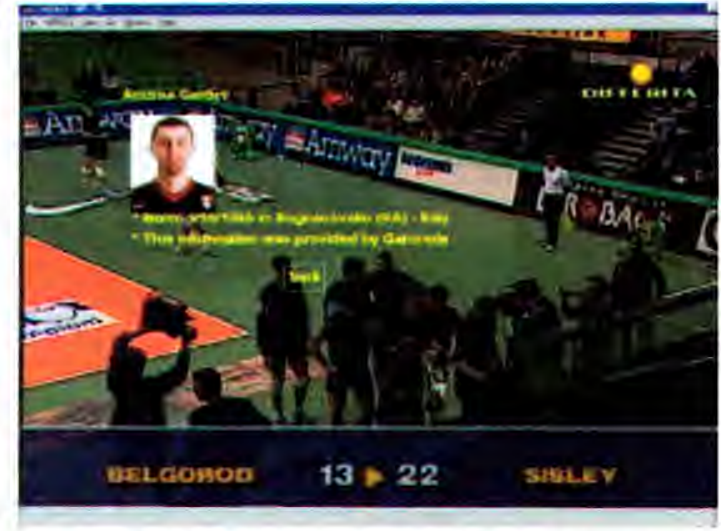

Figura 13 - Programa da NexTV depois da interação

\subsection{Tecnologias para TV Interativa}

Com o advento da TV Digital, diversas tecnologias poderão ser utilizadas para a criação e distribuição de programas para a TV Interativa. Inicialmente, a TV Digital utilizará o padrão MPEG-2 para a codificação de imagens, porém, à medida que a TV passe a ser mais interativa, a demanda de tecnologias mais adequadas surgirá. O sucessor natural do MPEG-2 é o padrão MPEG-4, que foi desenvolvido para ser um padrão multimídia e não somente audiovisual (como o MPEG-2), e já existem estudos para o encapsulamento de streams MPEG-4 em MPEG-2, que é utilizado pelos padrões da TV Digital. Com isso, a implantação da TV-I não será tão onerosa como foi a mudança da TV Analógica para a TV Digital. Como o tráfego já será digital, só será necessária a atualização das URDs ou, então, dos sistemas operacionais das URDs. 
Outra tecnologia que tem grande utilidade na TV Interativa é um outro padrão, também desenvolvido pelo grupo MPEG, o MPEG-7. Esse padrão, ao contrário dos outros, não é relacionado à codificação de áudio e vídeo; sua função é criar um padrão para a descrição de uma cena audiovisual, uma imagem ou sons, que não precisam estar armazenados digitalmente. O MPEG-7 pretende disponibilizar ferramentas (nesse caso, as ferramentas são os descritores, que permitem a criação das descrições) para que a busca em imagens, vídeos e arquivos sonoros seja tão fácil quanto é a busca em textos.

O TV-Anytime Forum pretende especificar o modo como programas de TV Interativa serão descritos utilizando MPEG-7. O DASE e o MHP são os padrões para a apresentação de multimídia nas TVs Digitais americana e européia, respectivamente. $O$ padrão para a apresentação de conteúdo multimídia na TV Digital japonesa está em fase de especificação. A Java TV é uma API Java para as URDs da TV Digital, o MHP utiliza a Java TV em suas especificações. Além dessas tecnologias, será mostrado como a W3C pretende fazer a ligação entre a TV e a WWW.

\subsubsection{MPEG-4}

O padrão MPEG-4 tem como objetivo construir uma cena audiovisual, tratando os dados como objetos de mídia. Esses objetos podem ser vídeo, áudio, objetos sintéticos (imagens e áudio gerados por computador) e objetos Web (documentos na WWW), além de sua relação com o tempo e o espaço. As informações dos objetos, que serão especificados posteriormente, são organizadas em árvores. Outro aspecto do MPEG-4 é permitir a integração da produção, distribuição e do acesso a conteúdo [ISO2001a, Bat1999].

A primeira versão MPEG-4 atingiu o nível de padrão internacional em abril de 1999 [ISO1999a] e a segunda versão tornou-se padrão no início de 2000 [ISO2001a], porém, algumas extensões ainda estão em progresso. 
Uma cena audiovisual MPEG-4 é descrita como a composição de objetos de mídia primitivos. Um objeto de mídia primitivo é, por exemplo, um vídeo da face de uma pessoa ou um áudio de uma voz, e correspondem às folhas em uma árvore descritiva. Já um objeto composto associa esses objetos em sub-árvores, de modo que se pode ter, dentro de um objeto composto, um vídeo de um rosto e o áudio relacionado a uma voz, facilitando a manipulação de vários objetos relacionados.

Dentre as suas características, o MPEG-4 permite [ISO2001a]:

- colocar objetos de mídia em qualquer posição espacial, dadas as suas coordenadas;

- aplicar transformações a objetos, mudando sua geometria ou acústica;

- criar objetos compostos, agrupando objetos primitivos;

- mudar interativamente a visualização e o som de cenas.

Assim como o MPEG-2, o MPEG-4 possui diversos profiles, sendo 8 para vídeo natural, 7 para vídeos sintéticos e híbridos (sintéticos + naturais), 8 para áudio, 3 para gráficos, 4 para descritores de cena, 2 para o MPEG-J e um para a descrição de objetos [ISO2001a]. Além destes, outros profiles estão sendo estudados [ISO2000].

Algumas das aplicações para as quais o MPEG-4 foi desenvolvido são [ISO1999c, Ebr1999]:

- Broadcast: O MPEG4, pelo fato de suportar uma compressão de dados muito alta, permite um uso muito bom da largura de banda disponível; também, por esse motivo, permite que diversos streams de vídeo sejam transmitidos em paralelo. Como foi dito anteriormente, o padrão MPEG-4 trata o vídeo como um conjunto de objetos inter-relacionados e essa característica é bastante interessante para a televisão interativa, uma vez que podemos associar diferentes objetos a diferentes ações. O ISDB (TV Digital japonesa) prevê o uso do MPEG-4 em sua implementação. 
- Visualização de cenas de modo colaborativo: O MPEG4 é bastante apropriado para a organização de cenas envolvendo objetos reais e virtuais, que devem ser transmitidos para participantes dispersos. Isso faz do MPEG-4 uma poderosa ferramenta para a construção de aplicações de trabalho colaborativo, aplicações de realidade virtual e de realidade aumentada (augmented reality).

- Armazenamento e recuperação baseada em conteúdo: Pelo fato do MPEG-4 permitir uma descrição dos objetos, a busca por palavras-chave fica bastante facilitada. Essa característica é tão importante que o uso adequado de metadados (comumente chamados de dados sobre os dados) é o objetivo principal do MPEG-7, que será descrito posteriormente.

- Set-Top Box da Televisão Digital: A TV Digital, como foi dito anteriormente, irá mudar o modo das pessoas assistirem televisão, uma vez que ela possuirá um ambiente mais interativo. Algumas das características que o MPEG-4 possui, que podem ser bastante interessantes para a TV Digital são: a) criação de links entre os comerciais apresentados e suas páginas na Internet; b) acesso à informação na Internet; c) jogos interativos e video on demand.

- Logos: É inegável a popularidade dos jogos de computador nos dias de hoje. A maioria dos jogos utiliza gráficos $3 \mathrm{D}$ tanto para o ambiente quanto para os objetos controlados pelo usuário. O uso de MPEG-4 nos jogos abre novas possibilidades com integração dos objetos sintéticos com os naturais e a animação facial.

- Computacão Móvel: Com a popularização dos Personal Digital Assistants (PDAs) e dos telefones celulares, fica evidente a importância da computação móvel nos próximos anos. O MPEG-4, pelo fato de conseguir transmitir vídeo em redes com pequena largura de banda, mostra-se uma boa solução para a futura transmissão de vídeos para dispositivos móveis.

- Produção de TV: O MPEG-4 apresenta-se como uma interessante evolução em relação ao chroma keying (técnica da TV analógica com a qual é possível colocar um vídeo sobre uma área de outro que possui uma cor bem definida, 
normalmente verde ou azul), permitindo a gravação dos objetos separadamente e com diferentes níveis de qualidade.

O padrão MPEG-4 é dividido em sete partes: Sistemas, Visual, Áudio, Teste de Conformidade, Software de Referência, DMIF e Software Otimizado para as ferramentas MPEG-7 (codificadores de vídeo), que serão apresentadas a seguir.

\section{Parte 1 - Sistema (Systems)}

A parte Systems do padrão define a descrição do relacionamento entre os componentes audiovisuais que formam a cena. Esse relacionamento é descrito em dois níveis principais.

O primeiro descritor é o BIFS (Binary Format for Scenes) [ISO2001a], que descreve o relacionamento espacial e temporal entre os componentes da cena. O BIFS é baseado no conceito do VRML (Virtual Reality Modeling Language) tanto na estrutura quanto na funcionalidade da composição de nós de objetos. O outro descritor é o OD (Object Descriptor), que define o relacionamento entre os Elementary Streams de cada objeto da cena.

Outros aspectos relacionados à parte Systems do MPEG-4 são a interação, a multiplexação, o armazenamento, interfaces com redes e outros equipamentos, representação textual, sincronização e direitos autorais. A interação com e entre os objetos é possível no MPEG-4 de duas formas. O primeiro tipo de interação é o previsto pelo padrão, como o posicionamento espacial e a retirada de objetos da cena. Para que a interação não prevista pelo MPEG 4 com e entre os objetos seja possível existe uma API, a MPEG-J, que é derivada da linguagem Java. A MPEG-J é um sistema de controle flexível e programável que representa uma sessão audiovisual de modo a permitir que a sessão se adapte às características do terminal onde ela será apresentada. A MPEG-J possui duas importantes características: a) a capacidade de permitir uma pequena 
degradação quando os recursos são limitados ou variam de acordo com o tempo; b) a habilidade de responder à interação do usuário e prover funcionalidades multimídia [ISO1999b].

\section{Parte 2 - Visual}

O padrão de vídeo natural do MPEG-4 [ISO1998b, Ebr1999] consiste de uma coleção de ferramentas para as áreas de shape coding (codificação de forma), estimativa e compensação de movimento, codificação de textura, recuperação de erro, sprite coding e escalabilidade.

O shape coding pode ser feito de duas maneiras: a) em modo binário, onde a forma de cada objeto é dada por uma máscara binária; b) pelo modo de grayscale (tons de cinza), onde a forma do objeto é dada de modo similar ao dos canais alpha, permitindo transparência e diminuindo o aliasing (diferença nas bordas das figuras). A estimativa $\mathrm{e}$ a compensação de movimento é baseada em blocos, que podem ser de $8 \times 8$ ou $16 \times 16$ pixels. A codificação da textura é baseada no 8X8 DCT (Discrete Cosine Transform). Com algumas modificações, a codificação de texturas estáticas pode ser feita utilizando transformadas wavelet [Dau2000].

As mais importantes características do padrão de codificação visual do MPEG-4 são [Ebr1999, Bat1999]:

- Eficiência na compressão: a compressão eficiente foi um dos principais objetivos tanto do MPEG-1 quanto do MPEG-2. O MPEG-4 pretende, a partir de uma codificação melhorada e da codificação de múltiplos streams de mídia concorrentes, melhorar ainda mais essa compressão e, com isso, aumentar o número de aplicações e produtos que utilizam esse padrão; 
- Interacão baseada em conteúdo: codificando e representando objetos de vídeo ao invés de quadros de vídeo, o MPEG-4 permite a criação de aplicações baseadas em conteúdo;

- Acesso universal: as duas últimas funcionalidades do MPEG-4 são a robustez e a escalabilidade permitindo, assim, a transmissão de vídeos, de acordo com a largura de banda disponível. O padrão definiu três faixas de bitrates: abaixo de 64 $\mathrm{Kb} / \mathrm{s}$, entre 64 e $384 \mathrm{~Kb} / \mathrm{s}$ e entre 384 e $4 \mathrm{Mb} / \mathrm{s}$, cobrindo, assim, as necessidades de diferentes aplicações.

Uma cena visual do MPEG-4 é composta por um ou mais objetos de vídeo. Cada objeto de vídeo possui informação temporal e espacial através de sua forma, movimento e textura.

Um bitstream MPEG-4 tem uma divisão hierárquica (Figura 14), sendo dividido em:

- Seqüência de Objetos Visuais (VS); a cena completa, que pode conter objetos 2De 3D;

- Objeto de Vídeo (VO): um objeto de vídeo é necessariamente 2D, e ele pode ter um formato retangular ou, utilizando máscaras, irregular;

- Camada do Objeto de Video (VOL): um objeto de vídeo pode ser composto por diversas camadas, por exemplo, com diferentes níveis de compressão e quantização.

Cada objeto de vídeo é dividido em frames, chamados Video Object Plane (VOP), que podem ser agrupados em Groups of Video Object Planes (GOV). 


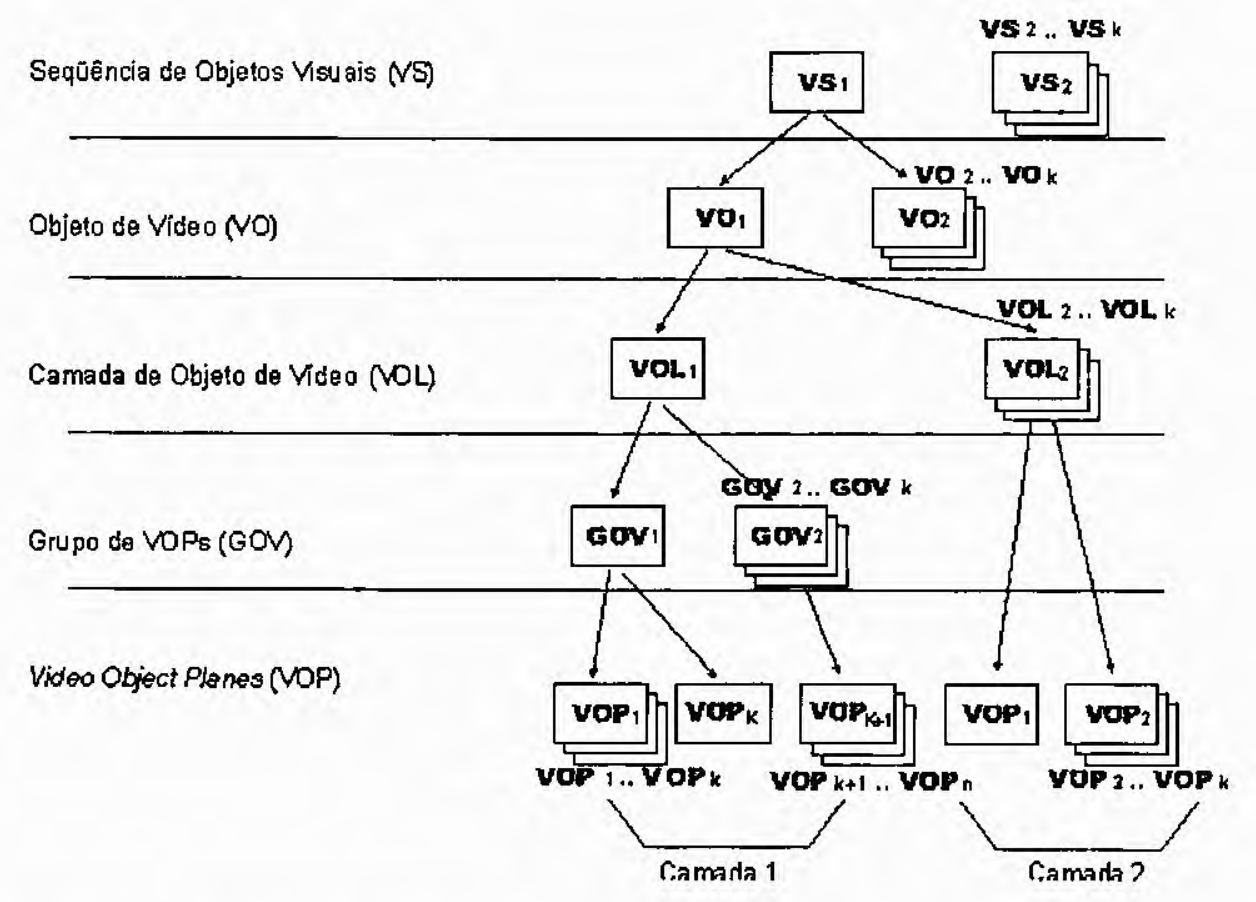

Figura 14 - Exemplo da estrutura de um bitstream MPEG 4. Extraída de [Ebr1999]

\section{Parte 3 - Áudio}

A parte de áudio do MPEG-4 é referente tanto à codificação de áudio, com diversos Profiles e Levels, quanto à apresentação de voz sintética, incluindo a sincronização labial e a informação sobre os fonemas.

\section{Parte 4 - Teste de Conformidade (Conformance Test)}

O teste de conformidade visa estabelecer regras para que futuros softwares que utilizem o padrão MPEG-4 possam ser testados.

\section{Parte 5 - Software de Referência}

O software de referência é um software que deve ser utilizado para o teste de streams MPEG-4. O software desenvolvido se chama IM1-2D e pode ser encontrado no site do CSELT 25 .

25 http://www.cselt.it/ufv/im1/ 


\section{Parte 6 - Framework para a Integração da Entrega Multimídia (DMIF)}

Outro componente importante do MPEG-4 é o DMIF (Delivery Multimedia Integration Framework) [ISO1999b]. O DMIF é um protocolo para o gerenciamento de streams multimídia sobre tecnologias de transporte. Ele é semelhante ao FTP, sendo que a principal diferença é que enquanto o FTP retorna dados, o DMIF retorna ponteiros para onde obter os streams de dados, ajustando a QoS do objeto às condições da rede [ISO2001a].

\section{Parte 7 - Software Otimizado para as Ferramentas MPEG-7}

A sétima parte do padrão pretende fazer um software que se utilize das ferramentas MPEG-7.

\section{Players}

Não existem muitos players de MPEG-4 disponíveis. O mais conhecido é o IM1-2D feito pelo CSELT (atual Telecom Italia Lab). O IM1-2D foi feito para ser o software de referência, relativo à parte 5 do padrão. A última versão disponível para download é a versão 2.7. Ela apresenta os streams MPEG-4 e vem com um codificador. No entanto, não foi possível implementar um exemplo de TV Interativa, pois foram encontrados problemas para realizar a codificação do vídeo. A Figura 15 apresenta a tela do player IM1-2D. 


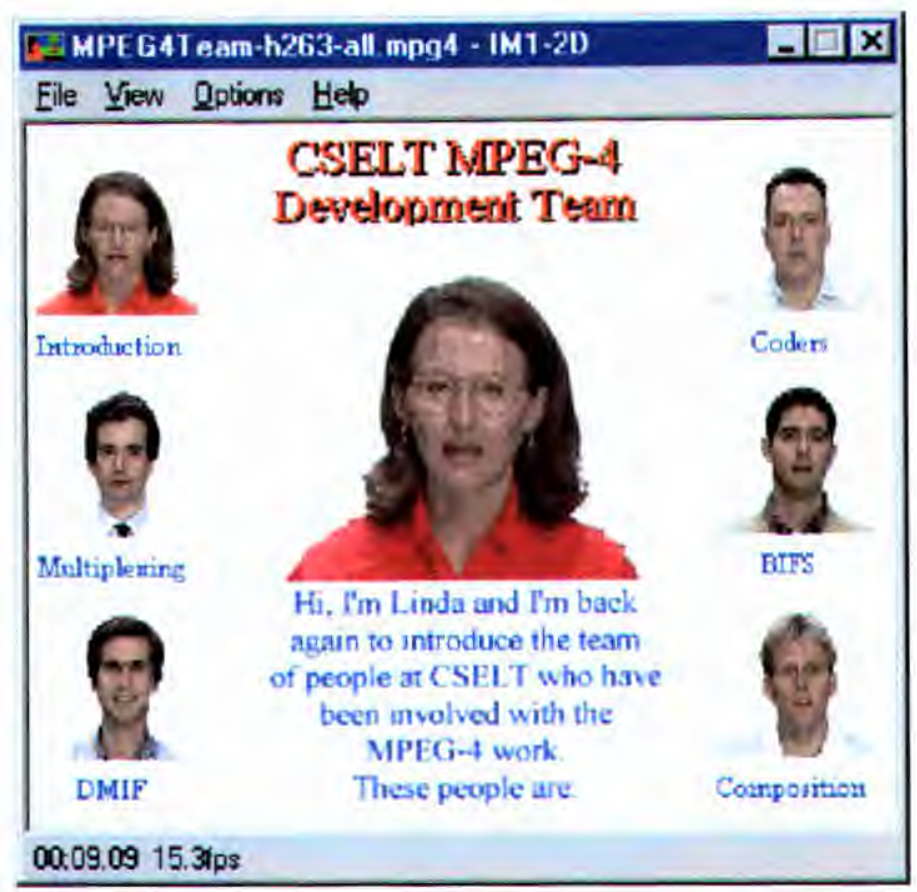

Figura 15 - Tela do IM1-2D

Existem codecs que implementaram somente a codificação do vídeo MPEG-4, no entanto, eles não são compatíveis com o IM1-2D. Esses codecs são o MPEG-4 video codec da Microsoft e o da DivX. Os vídeos codificados dessa forma podem ser visualizados no Windows Media Player ou no The Playa ${ }^{26}$, player de vídeo feito pela equipe que desenvolveu o DivX.

\section{Ferramentas de autoria}

Ainda não existem muitas ferramentas de autoria para o MPEG-4. Uma ferramenta avaliada foi a desenvolvida pelo Instituto Superior Técnico de Portugal. O IST MPEG-4 Video Compliant Framework ${ }^{27}$ implementou diversas funcionalidades do padrão, entre elas a codificação separada dos objetos. A Figura 16 apresenta uma tela do software na qual pode ser notada a presença da árvore de objetos, à esquerda, e da Timeline, abaixo.

\footnotetext{
${ }^{26}$ http://download2.divx.com/videoplayers/theplaya/DivX4FullInstaller.exe 27 http://www.img.Ix.it.pt/ImageGroup/IST_MPEG4_Video_Framework/tutorial.htm
} 


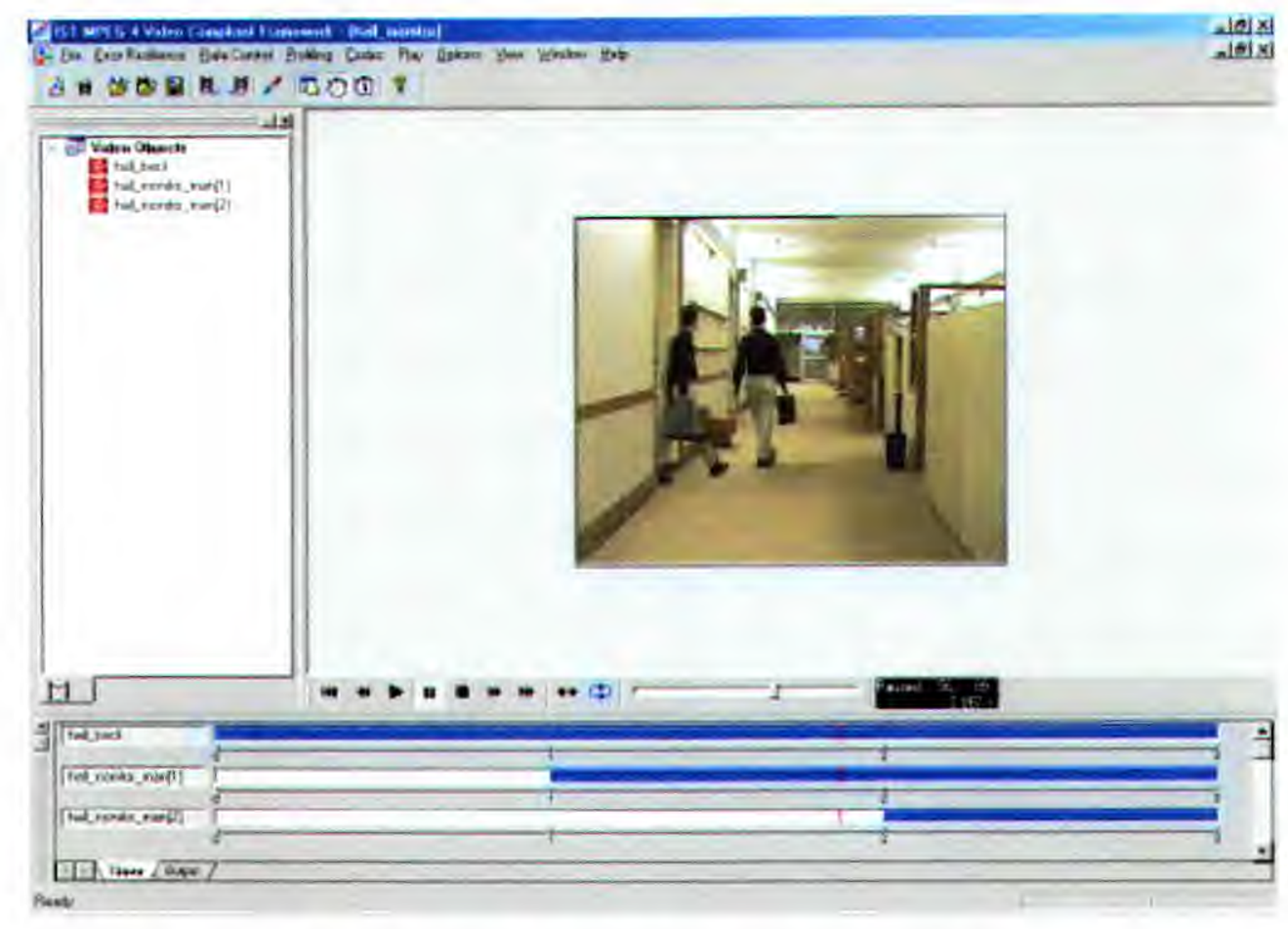

Figura 16 - Tela do IST MPEG -4 Video Compliant Framework

O software foi testado, porém, ele só trabalha com objetos já codificados, e os codificadores disponíveis não eram compatíveis com ele, bem como os streams gerados por ele não eram compativeis com os players.

O CSELT está em fase final de desenvolvimento do Sinfonia, um software que compreenderá um player, uma ferramenta de autoria e um servidor de streams, porém, só tivemos acesso a um plug-in para o Netscape Communicator para a apresentação dos vídeos no formato MPEG-4.

\subsubsection{MPEG-7}

Com o uso crescente de informação audiovisual, um modo de descrever o conteúdo dessas informações fez-se necessário, uma vez que as buscas nesses dados não eram "eficientes". Para isso, foi utilizado o conceito de metadados, também conhecido como "dados sobre os dados". Diversos trabalhos nessa linha de pesquisa já foram feitos no grupo Intermídia do $\mathrm{ICMC}^{28}$, como, por exemplo, o trabalho de Goularte [Gou1998]. O

${ }^{28} \mathrm{http}: / /$ www.intermidia.icmc.sc.usp.br/ 
uso de metadados em conteúdo audiovisual tornará possível a busca minuciosa em grandes bases de dados, em um tempo bastante curto, semelhante à busca em texto. No entanto, para que seja possível essa busca, o conteúdo audiovisual deve ser descrito de uma forma padronizada.

O MPEG-7 [ISO1998a, ISO2001c], formalmente conhecido como "Interface de Descrição do Conteúdo Multimídia", tem como objetivo especificar um conjunto padrão de descritores de vários tipos de informaçōes multimídia. Essa descrição será associada ao conteúdo permitindo, assim, um modo de procura eficiente para o material de interesse do usuário.

Em termos de padronização, pretende-se definir com o MPEG-7:

- Tipos de Dados (Datatypes): elementos de descrição não específicos ao domínio audiovisual, que correspondem ao reuso de tipos básicos ou estruturas, utilizados por múltiplos Descritores e Esquemas de Descrição;

- Descritores (D): representam as características e definem a sintaxe e a semântica de cada representação de características;

- Esquemas de Descrição (DS): especificação da estrutura e da semântica dos relacionamentos entre seus componentes, que podem ser Ds ou DSs.

- Uma Linguagem de Definição de Descrição (Definition Description Language) (DDL): para permitir a criação de novos DSs (ou mesmo novos Ds) e permitir a extensão e modificação dos mesmos.

O MPEG-7 não especifica como é feita a extração das descrições/características do objeto, bem como não especifica um mecanismo de busca que faça uso das descrições [ISO2001c].

O MPEG-7 tem como principais áreas de aplicação [Nac1999a]:

- Educação;

- Jornalismo; 
- Informação turística;

- Serviços culturais (museus, galerias de arte e exposições);

- Entretenimento (jogos);

- Sistemas geográficos;

- Aplicações biomédicas;

- Home-Shopping (busca por palavras-chave);

- Arquivos de filmes, vídeo e rádio (permitindo, assim, uma busca por assunto).

O ISDB (TV Digital Japonesa) já prevê o uso do MPEG-7 como modo de descrever seus programas e, com isso, tem trabalhado em conjunto com o TV-Anytime Forum na especificação de como utilizar o MPEG-7 na TV Interativa [TVA2000c].

O padrão MPEG-7 é dividido em sete partes: Sistemas, Linguagem de Definição de Descrição, Visual, Áudio, Esquemas de Descrição Multimídia, Software de Referência e Teste de Conformidade, que serão apresentadas a seguir.

\section{Parte 1 - Sistemas (Systems)}

A primeira parte do padrão MPEG-7 é o Systems [ISO2001d]. É a arquitetura padrão do sistema, que especifica as funcionalidades para a comunicação das descrições do conteúdo multimídia. O objetivo do MPEG-7-Systems é criar uma especificação não ambígua que permita aos desenvolvedores e usuários de MPEG-7 o desenvolvimento de decodificadores MPEG-7 e o preparo de Descrições MPEG-7 para o transporte e armazenamento.

A Figura 17 apresenta a arquitetura do MPEG-7. A camada mais baixa é o meio de transmissão/armazenamento (Transmission/Storage Medium), referente às camadas de distribuições da infra-estrutura. O stream MPEG-7 pode ser transportado de diversas maneiras, como MPEG-2, ATM, IP ou MPEG-4, sendo que na Camada de Transmissão (Delivery Layer) é especificado como isso ocorrerá. A Camada de Transmissão entregará 
streams elementares de MPEG-7 para a Camada de Compressão (Compression Layer). Esses streams elementares podem ser compostos por Esquemas de Descrição ou por Descrições, que podem estar representados ou no formato textual ou no formato binário (BiM - Binary Format for MPEG-7), dependendo da aplicação que o utilizará.

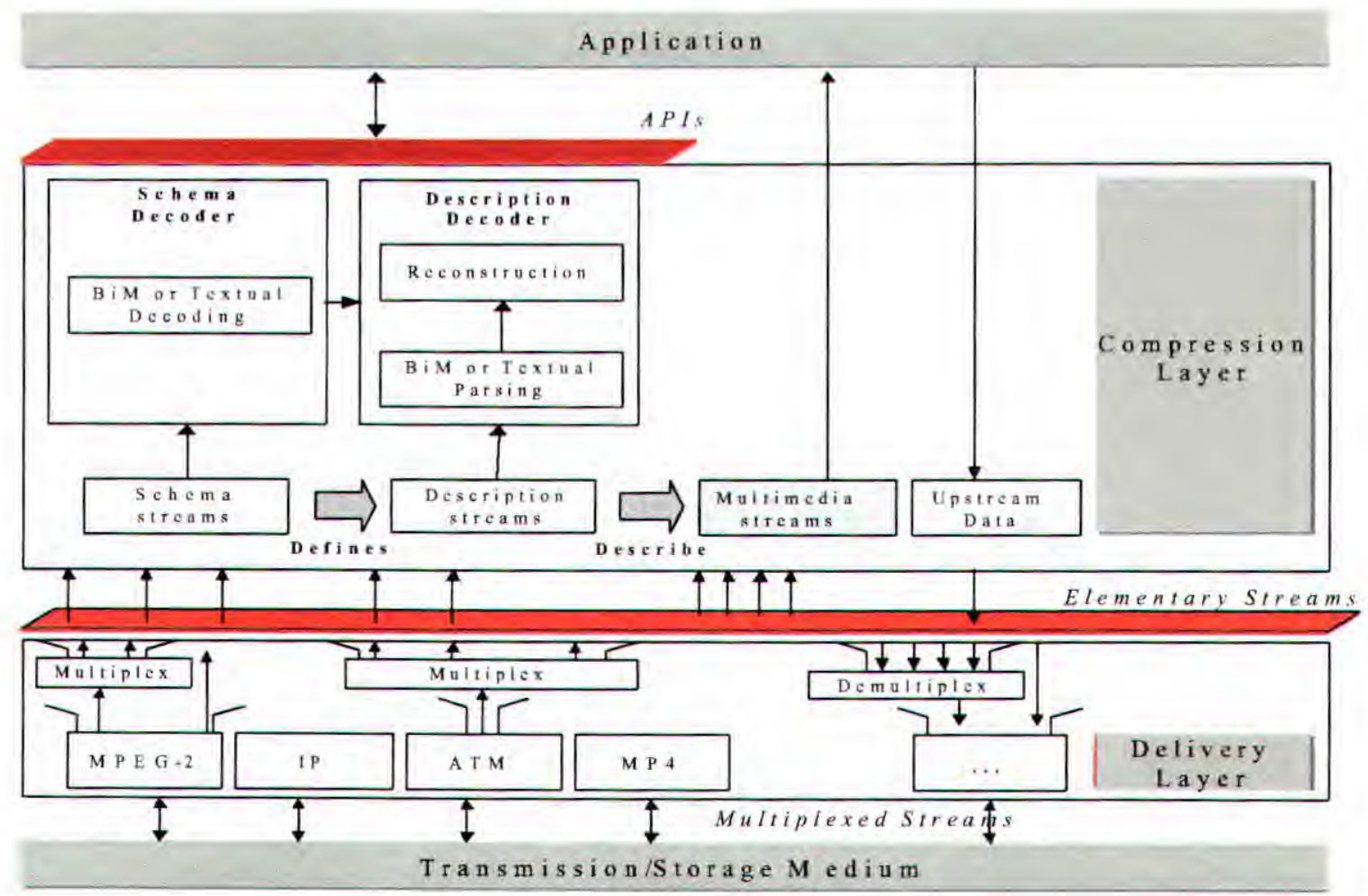

Figura 17 - Arquitetura MPEG-7. Extraida de [ISO2001d]

\section{Parte 2 - Linguagem de Definição de Descrição (DDL)}

Para que as Descrições e Esquemas de Descrição sejam feitos, é necessária a definição de uma linguagem para a criação dessas descrições. O MPEG Group decidiu recentemente pela adoção da linguagem XML Schema [W3C2001a, W3C2001b, W3C2001c], por ser um padrão bastante difundido no mundo. Porém, como o XML Schema não foi feito especificamente para o conteúdo audiovisual, foram criadas extensões para o MPEG-7. Essas extensões são relativas à representação de matrizes e vetores e a tipos de dados relativos a tempo. Com isso, a DDL do MPEG-7 foi dividida em três partes: a linguagem 
estrutural do XML Schema, os tipos de dados do XML Schema e as extensões feitas, que podem ser encontradas no documento que especifica a DDL MPEG-7 [ISO2001b].

\section{Parte 3 - Visual}

A terceira parte do padrão [ISO2001e] especifica ferramentas (descritores) para a descrição do conteúdo visual, como imagens, vídeo e imagens em 3D. Essas ferramentas são definidas a partir de sua sintaxe em DDL e representação binária (BiM). Elas permitem a descriçāo das características visuais, como cor, textura, formato e movimento, assim como permitem a descrição da localização dos objetos descritos em uma imagem ou sequiência de vídeo.

\section{Parte 4 - Áudio}

Esta parte do padrão MPEG-7 [ISO2001f] especifica ferramentas para a descrição do conteúdo sonoro. $O$ formato de codificação ou o meio de transmissão não são fatores limitantes, bem como não é limitado à descrição de músicas, discursos, efeitos especiais e trilhas sonoras. Também foram descritos os timbres de instrumentos e as saídas de mecanismos de reconhecimento de voz. Através desses descritores pretende-se que seja possível a localização de áudio por semelhança.

\section{Parte 5 - Esquemas de Descrição de Multimídia (MDS)}

A quinta parte do padrão MPEG-7 especifica as ferramentas para a descrição de informações multimídia. Essas ferramentas podem ser divididas em elementos básicos (Basic Elements), elementos de descrição de conteúdo (Content Description), elementos de gerenciamento (Content Management), organização de conteúdo (Content Organization), navegação e acesso (Navigation $\mathcal{E}$ Access) e interação do usuário (User Interaction), como podemos ver na Figura 18. 


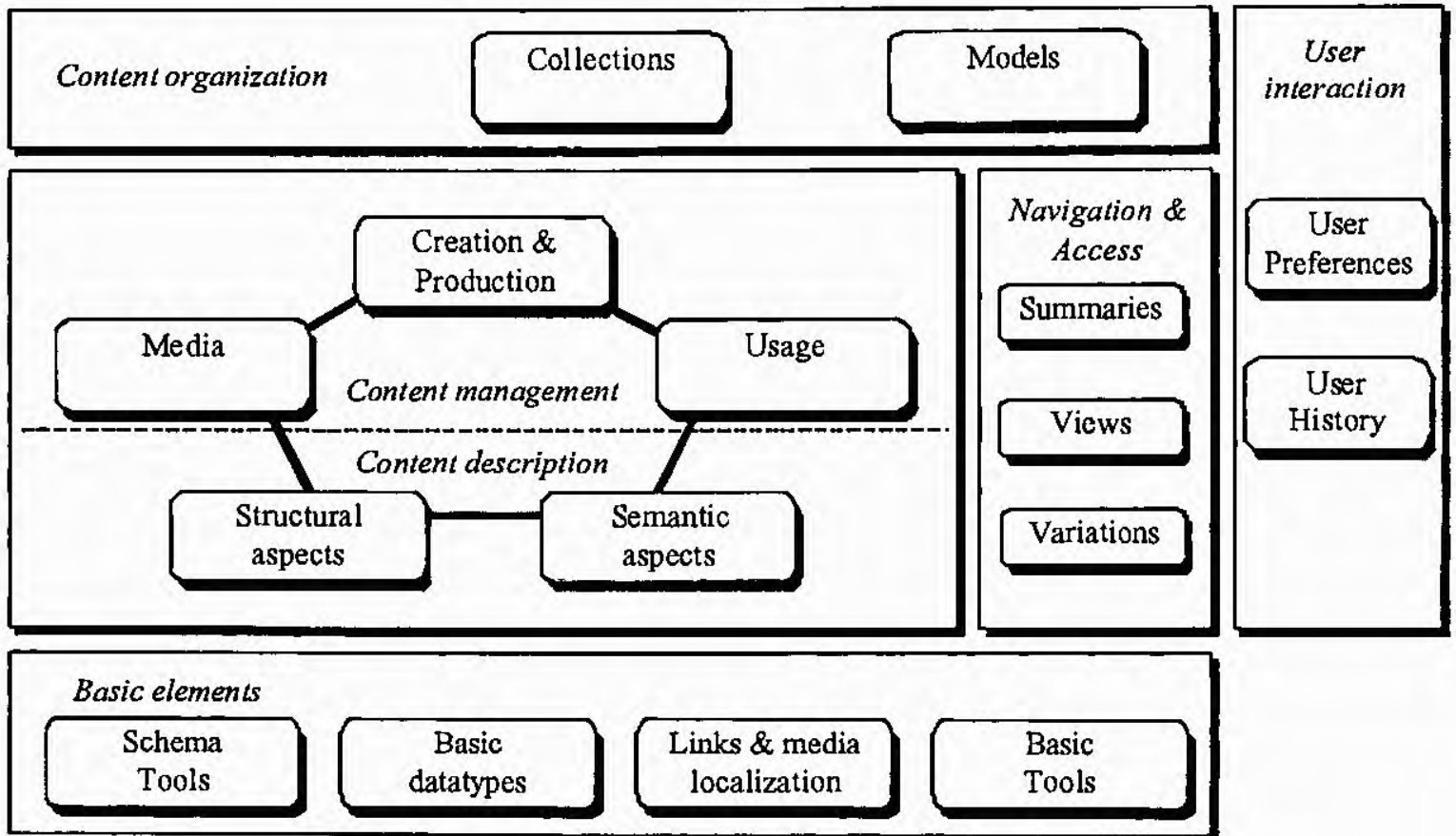

Figura 18 - Estrutura do MDS. Extraída de [1SO2001g]

\section{Parte 6 - Software de Referência}

A sexta parte do padrão é a criação de um software de referência. Esse software é dividido em quatro partes:

- Um parser de DDL;

- Descritores visuais - o software deve criar descriçōes padrões do conteúdo visual;

- Descritores sonoros - o software deve criar descrições padrões do conteúdo sonoro;

- Esquemas de Descrição Multimídia - o software deve possuir esquemas de descrição multimídia padrões.

No entanto, ainda não foi otimizada a aquisição automática de características sonoras, visuais ou multimídia [ISO2001h].

\section{Parte 7 - Teste de Conformidade (Conformance Test)}

A última parte do padrão definirá guias e procedimentos para o teste de conformidade com o padrão das implementações. 


\section{Exemplo de descrição de um vídeo em MPEG-7}

Um exemplo da descrição de um vídeo utilizando o MPEG-7 MDS é apresentado na Figura 19.

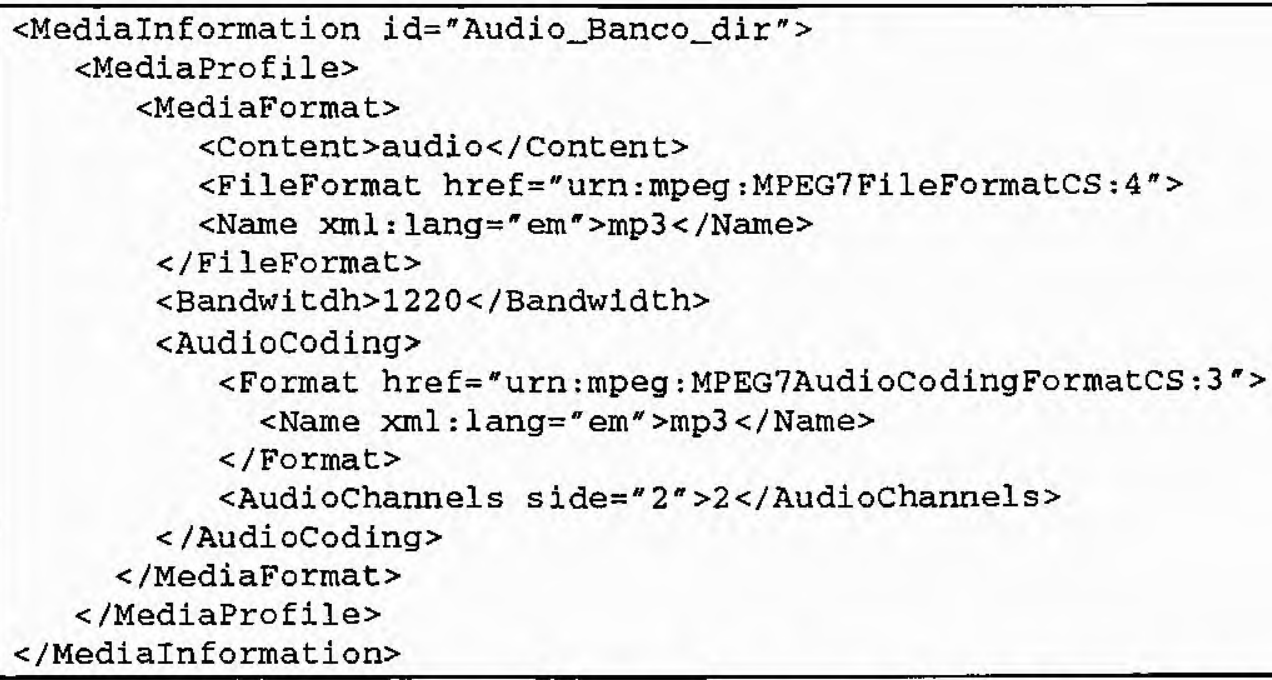

Figura 19 - Exemplo de uma descrlção de um vídeo em MPEG -7

\subsubsection{TV-Anytime Forum}

O TV-Anytime Forum foi criado em setembro de 1999 com o objetivo de mapear os diferentes requisitos da TV Interativa e, a partir destes, criar especificações de equipamentos para a geração, recepção e a distribuição de conteúdo.

O TV-Anytime Forum focalizou o seu trabalho em três áreas: a definição de como utilizar os metadados, como fazer as referências entre o conteúdo e como garantir o direito autoral. A partir dessas três áreas pretende-se fornecer informação para as URDs sobre os programas, e também fornecer dados para os EPGs.

Em setembro de 2000 foi escrita a versão final dos requisitos da TV Interativa (Requirements Series), que foi dividida em 5 documentos:

- O 10. Documento [TVA2000a] sugere os modelos de TV Interativa que o TVAnytime permitirá; 
- O 20. Documento [TVA2000b] mostra como a TV Interativa pode ser implementada tecnicamente;

- O3०. Documento [TVA2000c] mostra como os metadados devem ser tratados;

- O 4 ${ }^{\circ}$. Documento [TVA2000d] apresenta modos de criar referências ao conteúdo;

- O 50. Documento [TVA2000e] diz respeito ao gerenciamento dos direitos autorais.

Hoje em dia, o TV-Anytime Forum trabalha na especificação da TV Interativa (Specification Series), também dividida em 5 documentos: o primeiro documento é chamado de Benchmark Applications [TVA2001a] e apresenta os modelos de negócios interativos, além de mostrar como o modelo do TV-Anytime Forum adequar-se-á a cada um deles; o segundo documento (System Description) [TVA2001b] descreve o comportamento do sistema e como ele deve utilizar as especificações do TV-Anytime Forum; o terceiro documento (Metadata) [TVA2001c] é o primeiro documento de especificação e especifica como as ferramentas MPEG-7 podem ser utilizadas em conjunto com as criadas pelo TV-Anytime Forum; o documento seguinte [TVA2001d] especifica como a referência ao conteúdo deve ser feita; o último documento da especificação, e o único sem uma versão preliminar disponível, é o relativo aos direitos autorais.

O sistema do TV-Anytime Forum é centrado na figura do Personal Digital Recorder (PDR), que poderá ser incorporado em aparelhos de DVD, DVD-R, Videogames, TVs, entre outros.

\subsubsection{Multimedia Home Plataform}

Em 1997, o consórcio DVB sentiu a necessidade da criação de uma especificação para a apresentação de multimídia, que foi chamada de Multimedia Home Plataform (MHP). Essa é a única especificação multimídia para a TV Digital já concluída. Nessa especificação, uma parte importante é a API (Application Programming Interface), que 
permite o acesso tanto às funções da URD quanto do programa interativo sendo apresentado.

O MHP definiu três perfis de aplicações e níveis de interatividade, que são mostrados na Figura 20. O primeiro nível é o "Enhanced Broadcast", que é o mais básico e tem o nível de interatividade encontrado hoje em dia nas soluções de Enhanced TV sem canal de retorno. O perfil "Interactive Broadcast" incorpora outros modos de interatividade, com o canal de retorno e o perfil "Internet Access", que poderá acessar conteúdo presente na Internet para a utilização nas apresentações multimídia.

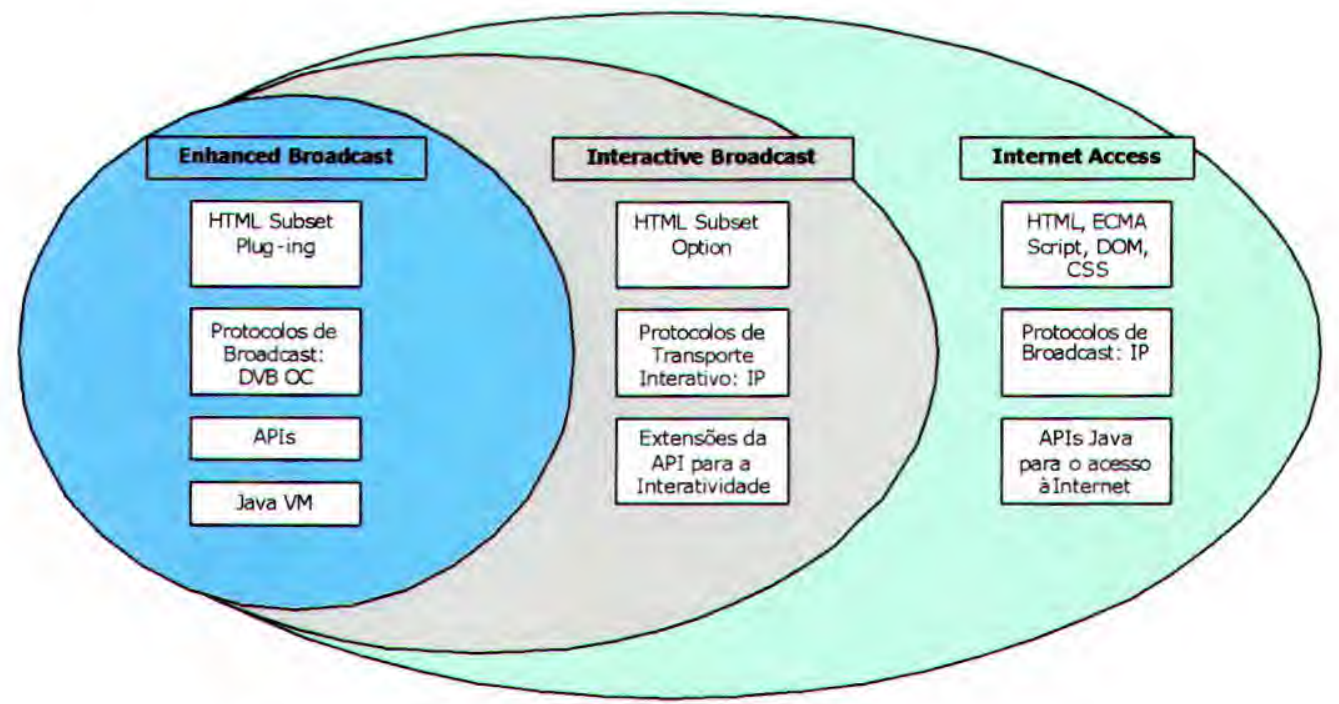

Figura 20 - Perfis de interatividade definidos no MHP

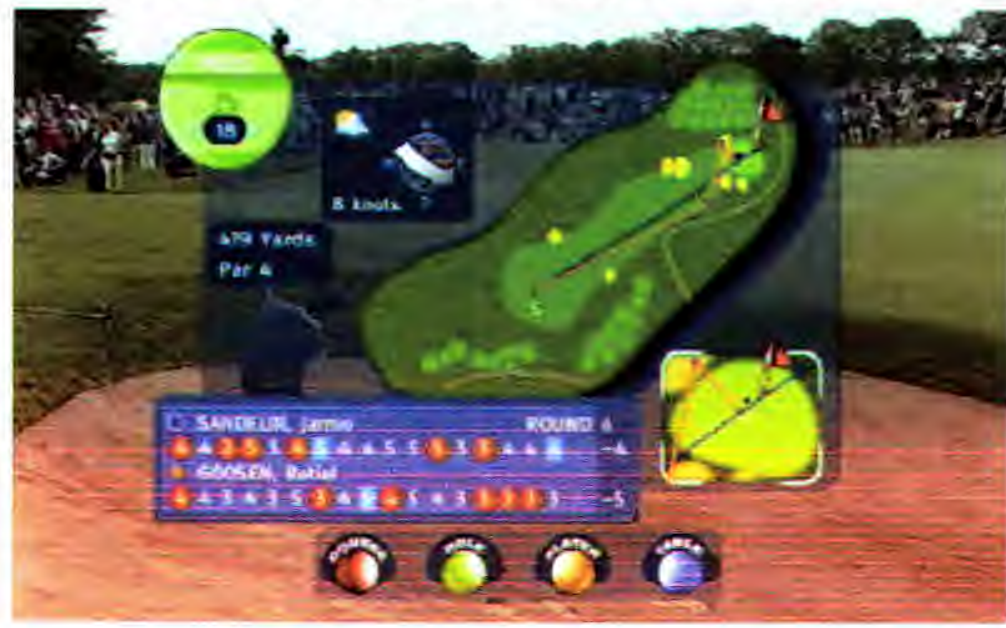

Figura 21 - Exemplo de aplicação sincronizada com o conteúdo. Apresentada no seminário do DVB em Taipei (fevereiro de 2001) 
Através do MHP, podem ser apresentados: páginas HTML, apresentações Flash e objetos MPEG4, entre outros. A Figura 21 apresenta um exemplo de um programa utilizando MHP, sincronizado com a transmissão de vídeo DVB.

\subsubsection{DTV Application Software Environment}

O ATSC, padrāo americano para a TV Digital, permite a transmissão de dados, porém ,não diz como esses dados devem ser apresentados. O DASE (DTV Application Software Environment) é um padrão que pretende especificar características e comportamentos para que uma URD possa apresentar os dados corretamente.

O padrão DASE é dividido em 8 partes:

- Parte 1 - Introdução, Arquitetura e Funcionalidades (Introduction, Architecture, and Common Facilities) - Apresenta uma introdução do padrão, apresenta a arquitetura e define quais as funcionalidades que o padrāo terá, como, por exemplo, quais decodificadores;

- Parte 2 - Aplicações Declarativas e o Ambiente (Declarative Applications and Environment) - Apresenta como aplicaçōes declarativas devem ser processadas. Uma aplicação declarativa é uma aplicação feita em uma linguagem de marcadores (markup language). Por exemplo, um documento XML ou uma página HTML;

- Parte 3 - Aplicaçōes Procedurais e o Ambiente (Procedural Applications and Environment) - Apresenta como aplicações procedurais devem ser apresentadas. As aplicações procedurais são programas Java ou Flash;

- Parte 4 - Application Programming Interface - Especifica uma API para a criação de programas interativos;

- Parte 5 - Recursos para a Portabilidade de Fontes (Portable Font Resource) Especifica como fazer o download de fontes especiais;

- Parte 6 - Segurança (Security) - Especifica como os aspectos relacionados à segurança devem ser tratados; 
- Parte 7 - Application Reference Model - Especifica como as informaçōes do DASE devem ser tranportadas pelo padrão ATSC.

- Parte 8 - Conformidade (Conformance) - Especifica como devem ser feitos os testes de conformidade das implementações.

As versões atuais das especificações podem ser encontradas no site do DASE29.

A Figura 22 apresenta a arquitetura DASE, mostrando que aplicações declarativas são tratadas de modo diferente das aplicaçōes procedurais e independente do formato do conteúdo, já que este é decodificado independentemente.

\section{Conteúdo DASE}

(XHTML, CSS. ECMAScript, JavaTV Xlet,...)

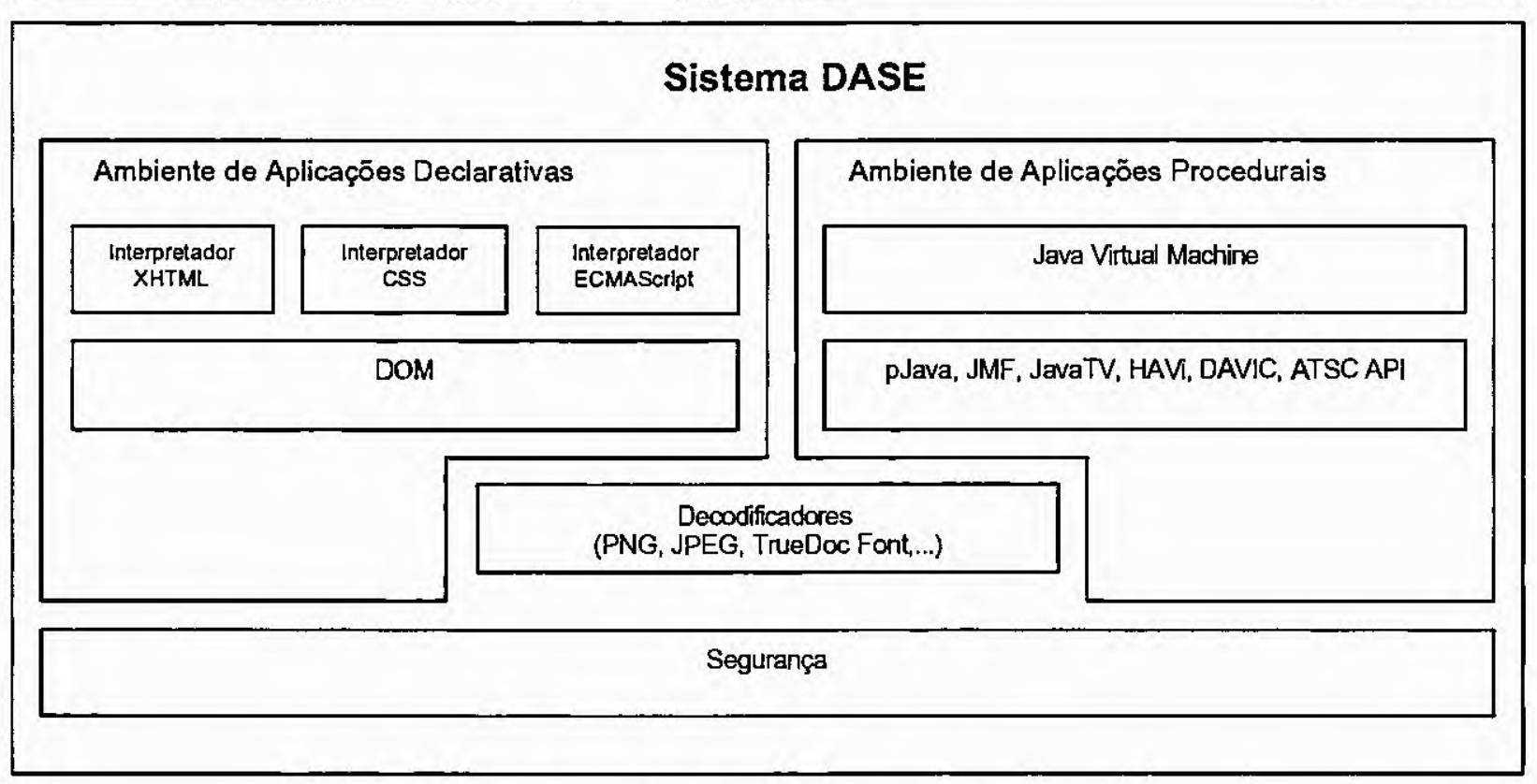

Figura 22 - Arquitetura DASE

\subsubsection{JavaTV}

A Sun Microsystems é mais uma empresa interessada na TV Interativa, pretendendo ampliar o mercado de sua linguagem de programação Java. Para isso, a Sun ${ }^{29}$ http://www.atsc.org/S17page.htm। 
desenvolveu uma API Java para a TV Digital, chamada de JavaTV30, com funcionalidades como:

- áudio/vídeo streaming;

- acesso condicional;

- acesso a serviços de informações;

- controle de turner para a mudança de canais;

- controle de gráficos na tela.

A Figura 23 mostra o ambiente Java e a API JavaTV, implementado em uma URD.

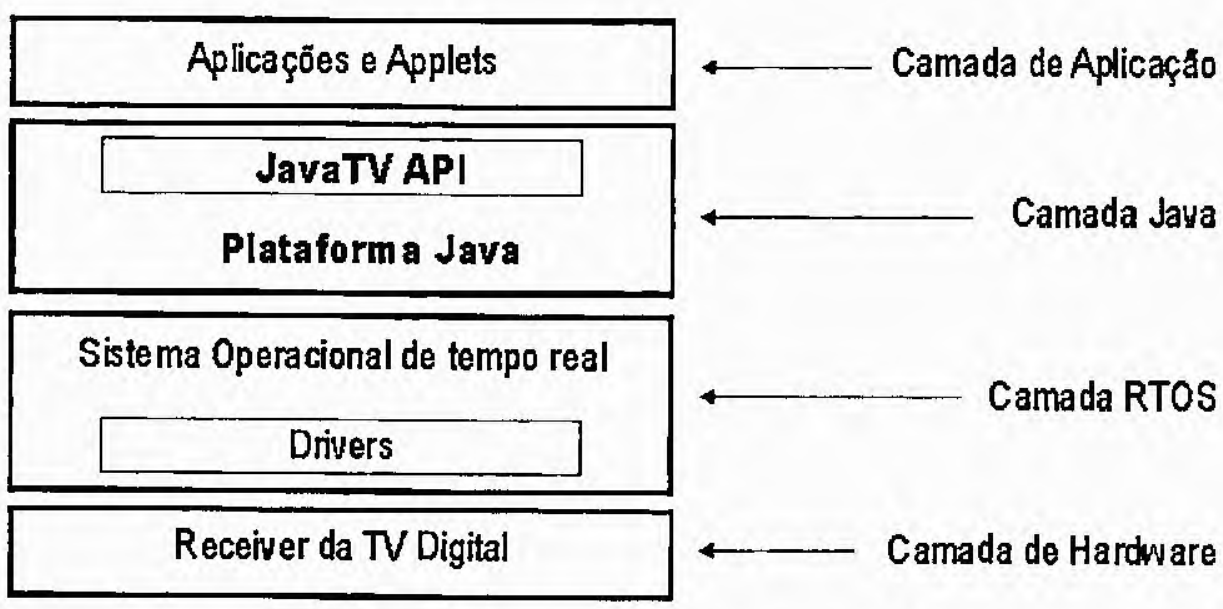

Figura 23 - Pilha de software em um STB. Extraída do site JavaTV

A Sun já firmou muitas parcerias com empresas como Sony, Philips e OpenTV, tornando a sua JavaTV uma grande promessa no mercado de TV Interativa. Além dessas empresas, o consórcio DVB-MHP pretende utilizar o Java TV.

\subsubsection{W3C}

Em junho de 1998 foi realizado o workshop "Television and the Web"31, durante o qual ficou evidente a necessidade da padronização de tecnologias para integrar a Web e a

30 http://java.sun.com/products/javatv/

31 http://www.w3.org/Architecture/1998/06/Workshop/program.html 
televisão [Kat1998, Rod1998]. Com isso, foi criado o "Television and Web" Interest Group ${ }^{32}$ na W3C (World Wide Web Consortium).

Na comunidade da televisão, existia um desejo de adaptar certas especificações da W3C antes de usá-las em aplicações TVWeb [Bac1998]. Pretendia-se que somente uma parte das especificaçōes da W3C fosse suportada e que novas características fossem implementadas. Com isso, membros desse Interest Group representaram os interesses das televisões nos Working Groups do HTML (Hypertext Markup Language) e do CSS (Cascading Style Sheets).

O grupo trabalhou durante um ano (setembro de 1998 até setembro de 1999) e gerou a especificação da URI " $t v$ " [Vic2000, Fin2000], além de gerar mais discussōes e idéias sobre a TV Interativa.

\subsubsection{Tecnologias para a distribuição}

\section{Internet}

A WWW [Ber1994] mostra-se uma ótima candidata quando o objetivo é distribuir informação, portanto, torna-se óbvia a sua utilização para a transmissão de vídeo. No entanto, existem diversos problemas tecnologicos que, atualmente, limitam a difusão de seu uso para distribuição de vídeo.

O principal problema é a largura de banda, e esse problema existe tanto do lado dos servidores quanto do lado dos usuários. Do lado dos servidores, distribuir vídeo digital significa a necessidade de uma conexão através de uma banda bastante larga, uma vez que transmitirá ao mesmo tempo diversos vídeos (ou o mesmo, porém em tempo diferente). Do lado dos usuários existe a limitação da conexão ao provedor, normalmente via modem, limitando bastante a banda; isso está mudando com a

32 http://www.w3c.org/TV/ 
disponibilidade das conexões de banda larga. Existem pesquisas de conexão rápida sem fio para a próxima geração de telefones celulares (UMTS33).

Apesar destas limitações, a distribuição de vídeo via Internet tem crescido em uma velocidade impressionante. Sites como $\mathrm{CNN}^{34}$, $\mathrm{UOL}^{35}$ e Globo.com ${ }^{36}$ possuem canais de televisão que utilizam a tecnologia de streaming de vídeo, e em sites como Ifilm ${ }^{37}$ e AtomFilms ${ }^{38}$ é possível ver curta metragens na tela do computador, também utilizando a tecnologia de streaming de vídeo. As empresas que disputam o mercado de streaming de vídeo são a Real Networks ${ }^{39}$ com o Real Player, A Microsoft com o seu Media Player e a Apple ${ }^{40}$ com o QuickTime.

A última novidade na área de distribuição de vídeo na Internet é a compressão MPEG4, que tornou possível a transmissão (ou o download) de um filme inteiro com a qualidade de DVD (500 linhas de resolução). Já que uma hora de vídeo ocupa cerca de $350 \mathrm{MB}$, percebemos a grande diferença ao compararmos com o MPEG-2. Com tal compressão, muitas vezes um filme de duas horas não cabe em um DVD com somente uma camada (4.7 GB). Essa distribuição de filmes na Internet deve-se principalmente a duas coisas: à quebra do código de segurança dos DVDs e ao aparecimento do DivX ${ }^{41}$, que faz a codificação em MPEG-4. Essa área vem preocupando a indústria cinematográfica, uma vez que já apareceu uma versão do Napster (software popular para a troca de arquivos mp3 na Internet) para o MPEG-4: a rede Fast Track ${ }^{42}$, que permite a troca de arquivos na Internet livremente.

\footnotetext{
33 http://www.umts-forum.org/

34 http://www.cnn.com/

35 http://www.uol.com.br/

36 http://www.globo.com/

37 http://www.ifilm.com/

38 http://www.atomfilms.com/

39 http://www.real.com/

$40 \mathrm{http}: / /$ www $a p p l e . c o m /$

41 http://www.divx.com/

42 http://www.fasttrack.nu/
} 
O W3C e o IETF (Internet Engineering Task Force), vendo a importância da integração entre a Internet e a Televisão, vêm se esforçando para definir padrões para essa integração.

\section{TV a Cabo}

Atualmente, já é possível acessarmos a Internet via Cabo através dos Cable Modems, utilizando um protocolo desenvolvido pelo Cable Labs. No Brasil, a NET e a TVA já possuem esse tipo de serviço. As principais vantagens da Internet via Cabo são a velocidade e a conexão ininterrupta (sem a necessidade da "discagem" ao provedor).

Pelo fato de já combinar o acesso à Internet com a transmissão de vídeo, a TV a Cabo deve logo tornar-se interativa. Os novos padrões da TV Digital e da TV Interativa pretendem utilizá-la como um meio de distribuição.

\section{Telefonia}

A telefonia está presente em todos os modelos de televisão interativa hoje existentes. É através do telefone que o usuário recebe os dados para o EPG, navega na Internet e faz o upload dos dados necessários para a interação. Porém, nem todos os dados da TV Interativa são recebidos via telefone; a imagem $\mathrm{e}$ os triggers são recebidos analogicamente, uma vez que a transmissão de vídeo é inviável com a atual velocidade dos modems.

Com a finalidade de permitir uma maior velocidade para a transmissão de dados, foram desenvolvidas tecnologias como a ADSL para os consumidores finais, e ATM para os provedores. 
A $\operatorname{ADSL}^{43}$ permite velocidades de até $2 \mathrm{Mb} / \mathrm{s}$ para o downstream e o upstream, além de reservar um canal de $4 \mathrm{KHz}$ analógico para a linha telefônica. A Telefônica, operadora de telefonia do estado de São Paulo, já está disponibilizando linhas ADSL com velocidades entre $256 \mathrm{~Kb} / \mathrm{s}$ até $2 \mathrm{Mb} / \mathrm{s}$, em várias cidades do estado. A utilização de uma linha ADSL para a implementação da TV Interativa já é bastante utilizada.

As redes ATM (Asyncronous Transfer Mode) [Bou1992] mostram-se uma excelente solução na transmissão de vídeo de alta qualidade a longas distâncias e para vários receptores, uma vez que permitem conexões de $622 \mathrm{Mb} / \mathrm{s}$, ou mais, e ainda possuem Qualidade de Serviço, que para a transmissão de vídeo é bastante interessante. O ATM também é uma excelente solução para a interligação entre os provedores, aumentando, assim, a largura de banda.

${ }^{43}$ http://www.adsl.com/ 


\section{Implementação de um programa de TV Interativa}

Como foi visto anteriormente, existem diversas implementações e definições de TV Interativa. Neste trabalho consideramos como TV Interativa a TV que possui as seguintes características:

- Recepção digital dos sinais de áudio e de vídeo;

- Canal de retorno dedicado;

- Possibilidade de transmissão e recepção de dados;

- Possibilidade de comunicação com outros equipamentos eletrônicos;

- Possibilidade de interação na rede e na aplicação via agentes.

Utilizando essas características, uma aplicação de TV Interativa foi modelada e implementada. Nas seçōes seguintes serão apresentados, respectivamente, os aspectos de consciência de contexto relevantes à TV Interativa, a infra-estrutura necessária para a distribuição, os requisitos para a produção, a modelagem do ambiente de TV-I consciente de contexto, e a modelagem e implementação de uma aplicação, no caso um evento esportivo.

\subsection{Aspectos de consciência de contexto aplicados à TV Interativa}

Tradicionalmente, eventos e relacionamentos são analisados e modelados no desenvolvimento de interfaces para aplicações em ambientes computacionais. No entanto, quando se consideram aspectos como a ubiquidade, o projeto de interface exige requisitos que vão além dos eventos e relacionamentos, uma vez que a interface deve ser dotada de capacidades reativas, tanto ao nível do usuário quanto em termos da infra-estrutura formada pela própria aplicação e pela rede de comunicação, por exemplo. Adicionalmente, aspectos de consciência de contexto acrescentam novas possibilidades de interação aos usuários, aplicações e infra-estrutura. 
Em linhas gerais, entende-se por contexto qualquer informação que possa ser usada para caracterizar a situação de uma entidade. Uma entidade, por sua vez, pode ser uma pessoa, um lugar ou objeto relevante para a interação entre um usuário e uma aplicação, incluindo-se o próprio usuário e a aplicação em si [Dey2000]. Assim, um sistema é consciente de contexto se utiliza o contexto para oferecer informaçōes relevantes e/ou serviços ao usuário, sendo que a relevância depende das tarefas que o usuário realiza [Abo1999].

A criação de ambientes que utilizem as informaçōes de contexto para fornecer informações relevantes e/ou ações específicas para cada usuário, conforme o grau de liberdade definido pelo projetista, é uma tarefa que precisa ser parametrizada pela aplicação. Essa parametrização é obtida com base em cinco questionamentos: a) onde o usuário está (WHERE); b) quem é o usuário (WHO); c) como o usuário está utilizando os recursos (HOW); d) quando se pode realizar determinada operação (WHEN); e) o que o usuário está fazendo (WHAT). No contexto da execução automática de tarefas e ações, podem-se considerar as quatro entidades de conscienncia definidas por Dey e Abowd [Dey2000], a partir dos questionamentos citados: a) localização (WHERE); b) identidade (WHO); c) atividade (WHAT + HOW); d) tempo (WHEN).

Aspectos de consciência de contexto podem ser importantes quando associados ao ambiente no qual uma aplicação está inserida, oferecendo as informações do contexto em que o usuário se encontra, as possibilidades de adaptação e informações sobre recursos disponíveis em um determinado momento. Esse é o ponto-chave para a definição do conceito de perfil apresentado neste trabalho, e que se encontra detalhado na seção 4.5.2. A Figura 24 apresenta um esquema de representação que permite o mapeamento conceitual das entidades de consciência de contexto em parâmetros de definição de perfis.

Um ponto importante é que palavras como HOW, WHERE, WHAT, WHO e WHEN expressam semânticas que podem ser tão complexas quanto seja necessário a uma aplicação. Assim, a semântica HOW, por exemplo, ao se referir a "quais recursos estão 
em uso", expressa implicitamente "como o usuário está utilizando esses recursos". Neste ponto, implementando um mecanismo avaliador (agente + filtros, por exemplo) que apresente e/ou monitore uma lista dos recursos em uso, pode-se ter uma indicação de como o usuário está se sentindo no ambiente (contribuição para emotional interfaces). De forma complementar, a proposta de junção das semânticas HOW e WHAT oferece suporte à formação da entidade "atividade" que, em suma, é um elemento formador do conceito de perfil, visto que para se ter atividade é necessário ter recursos em uso, quer seja ao nível do usuário quer seja ao nível da infra-estrutura.

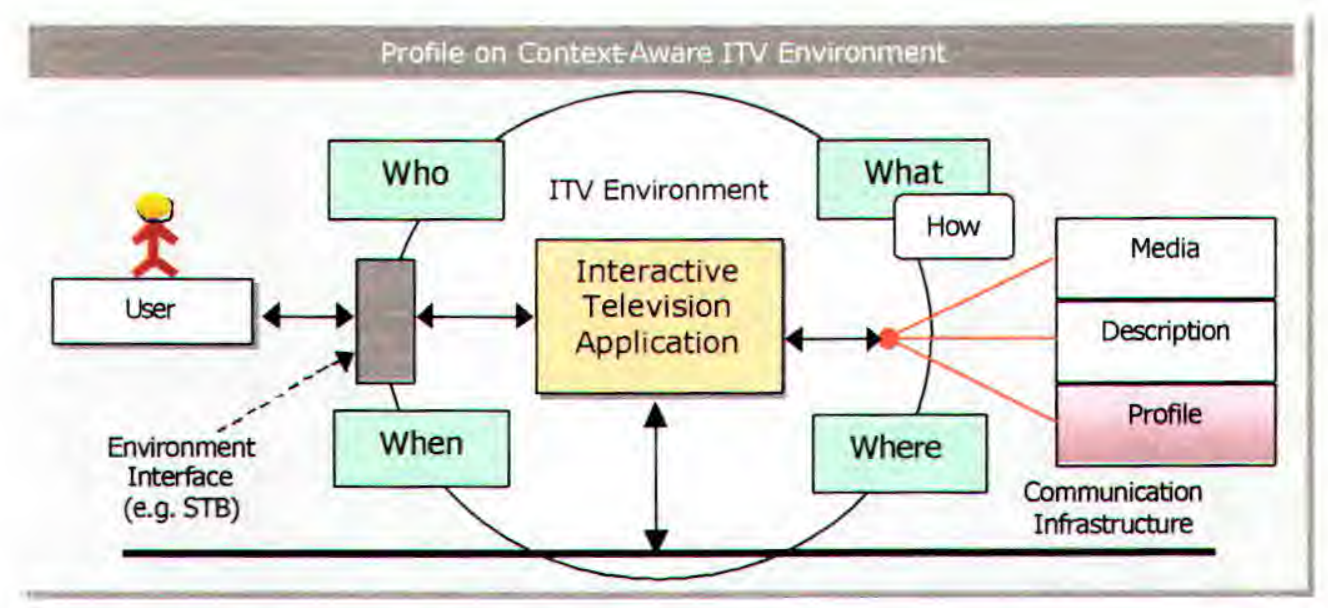

Figura 24 - Mapeamento de entidades de consciência de contexto em elementos de perfis de aplicações de TV-I

No contexto proposto por este trabalho para as aplicações de TV-I, a execução automática de tarefas e ações é de extrema importância. Nesse sentido, agentes podem ser usados para permitir a implementação dos aspectos de consciência de contexto, considerando-se, por exemplo, as quatro entidades de consciência definidas por Dey e Abowd [Dey2000].

A definição fundamental de agente, dotida da literatura, diz que um agente é capaz de colaborar, através da troca de dados com outros agentes e programas, para a resolução de problemas complexos [Ket1994]. Complementando, pode-se dizer que um agente computacional é um componente de software capaz de se comunicar e cooperar com outros agentes usando uma linguagem de comunicação. 
No contexto da TV-I, observa-se que dispositivos como URDs (Unidades ReceptorasDecodificadoras) acrescentam novas possibilidades de interação que vão além dos dispositivos tradicionais de interação, como mouse e o teclado; e a interação com o ambiente (consciência de contexto), no qual a aplicação está inserida passa a ser tão importante quanto a interação direta do usuário com uma aplicação.

O desenvolvimento de perfis para aplicações de TV-I é, então, uma forma de categorização que caracteriza a situação de uma entidade em uma aplicação, bem como uma forma de se obter informações sobre o comportamento dessa entidade no tempo [Dey2000]. Assim, com o uso de perfis em conjunto com informações de contexto, uma aplicação pode realizar ações e reações, como as seguintes:

- a apresentação de informações e serviços para o usuário, como, por exemplo, a apresentação de mídias disponíveis e que estão relacionadas com o contexto do usuário;

- a execução automática de serviços, como, por exemplo, o disparo de eventos relacionados com a localização corrente de uma entidade;

- a associação do contexto com a informação para posterior recuperação, como, por exemplo, o armazenamento de informações contextuais durante uma sessão de vídeo interativo, relacionando observações do(s) usuário(s) com o(s) assunto(s)-chave que faz(em) parte da descrição de uma ou mais cenas desse vídeo.

As definições de consciência de contexto oferecem condições para o desenvolvimento de aplicações altamente adaptativas, o que é relevante em ambientes interativos, como é o caso da TV-I.

O grau de consciência (awareness) de um objeto em relação a outro quantifica a importância subjetiva ou relevância do objeto para um determinado ambiente ou mesmo para uma determinada mídia utilizada em uma aplicação. No contexto da TV-I, como exemplo, o grau de consciência pode ser mapeado para o volume de um canal de 
áudio ou para o nível de detalhe de imagem de uma seqüência de objetos formadores de uma cena em um vídeo.

Outro ponto importante reside no fato de que um objeto, em uma interação, pode afetar os níveis de consciência de outro objeto, exigindo, portanto, procedimentos de negociação. $O$ objeto que observa (ou receptor) pode focar sua atenção em áreas ou objetos específicos, enquanto o objeto observado (ou transmissor) pode controlar sua "visibilidade" de forma que objetos em algumas áreas sejam mais conscientes que em outras áreas. Esse aspecto é relevante no acesso a conteúdo de mídias em uma determinada cena, representada com tecnologias como MPEG-4, por exemplo.

\subsection{Infra-estrutura para a Distribuição}

Este projeto foi feito tendo como base uma infra-estrutura para a distribuição, desenvolvida especialmente para a TV-I. Essa arquitetura segue o modelo clienteservidor e possui, no lado do cliente, um ambiente consciente de contexto. A Figura 25 apresenta essa infra-estrutura, que pode ser dividida em:

- Server: O servidor tem como função armazenar e distribuir programas de TV-I. Esses programas são compostos por objetos multimídia, como vídeo, áudio, imagens, animaçōes, gráficos e textos, entre outros. Além disso, um programa deve possuir um script indicando como esse programa deve ser apresentado, sua estrutura e as relações espaciais e temporais entre seus objetos. Em outras palavras, um programa é composto por conteúdo e estrutura;

- Network: Existem duas redes no ambiente apresentado, isto é, a rede que faz a ligação entre o servidor e a rede caseira (home network), e a própria rede caseira. A primeira rede deve ser capaz de mudar seu comportamento de modo a transmitir os dados eficientemente, mudando dinamicamente seus protocolos e algoritmos. Já a rede caseira deve ser capaz de realizar a comunicação entre os diferentes equipamentos (e sensores) e o terminal; 
- Client: O Cliente é composto pelo terminal e seus agentes. O terminal é composto por um computador pessoal conectado à rede e deve exibir os programas de TVI. Esse terminal também deve rodar um player compatível com o padrão MPEG-4.

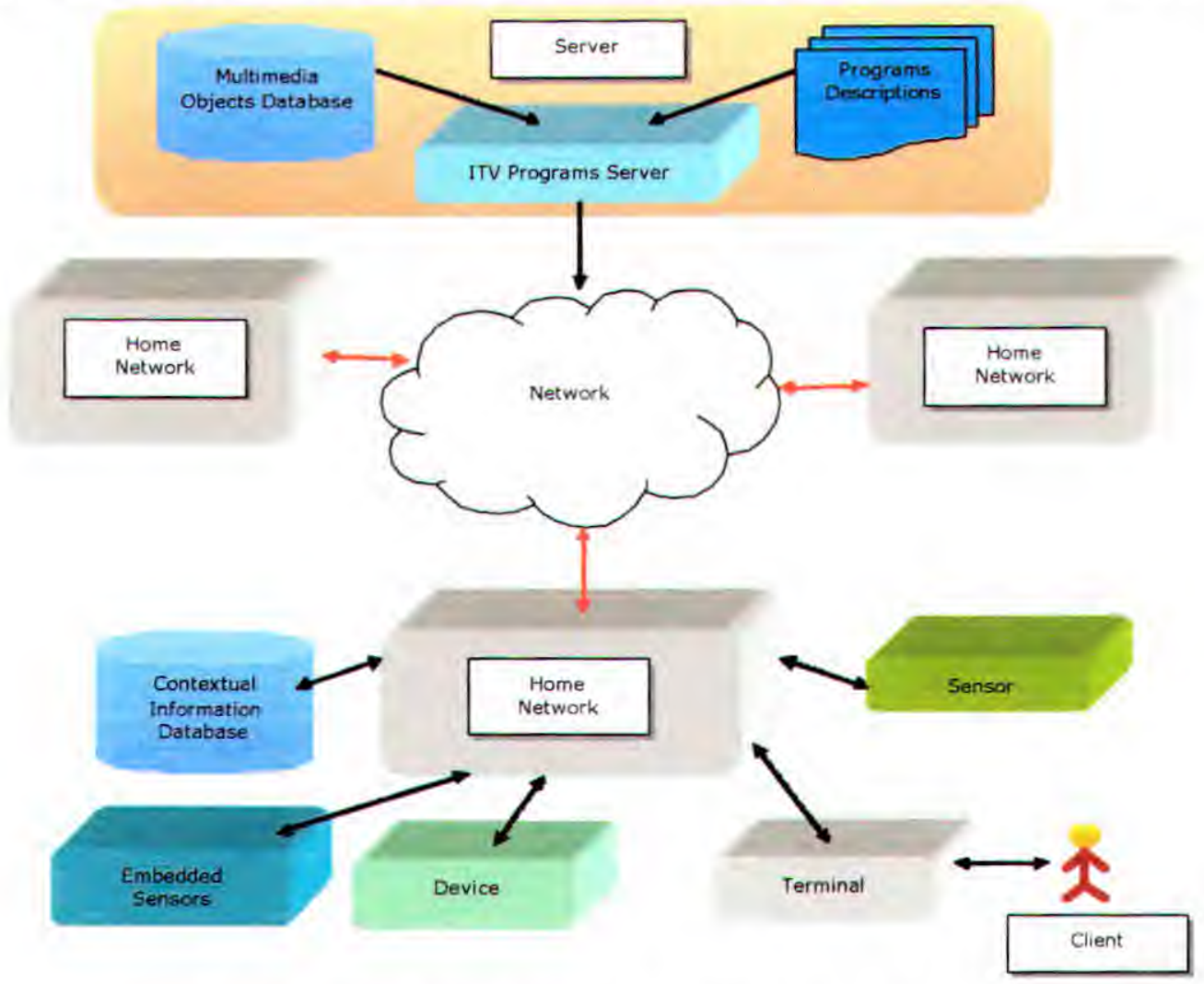

Figura 25 - Ambiente consciente de contexto para a TV Interativa

\subsection{Requisitos Necessários para a Produção do Programa de TV Interativa}

Este projeto foi feito de modo a minimizar as mudanças na infra-estrutura, necessárias para a produção de um programa de TV-I em relação a um programa para a TV Digital. Com isso, além dos equipamentos presentes em um estudio de TV Digital, como câmeras e VTRs digitais, somente são necessários dois softwares.

O primeiro é uma ferramenta para a edição dos streams MPEG4; essa ferramenta deve possuir a capacidade de lidar com vários objetos. O segundo software necessário é um editor de metadados que suporte o MPEG-7 e os elementos especificados pelo TVAnytime Forum e por este projeto (que serão apresentados na seção 4.5). Esse segundo 
software, preferencialmente, seria integrado a um editor ou player de streams MPEG-4, de modo a facilitar a inserção de metadados.

A maior mudança está no modo de criar os programas, já que na TV-I, além da produção do conteúdo audiovisual tradicional, é necessária a produção de conteúdo audiovisual alternativo, dos metadados e de como será a interação do usuário.

\subsection{Modelagem da Aplícação de TV Interativa}

A aplicação de TV Interativa foi dividida em três grandes componentes e outros dois componentes que estão relacionados a todas as partes. A modelagem, apresentada na Figura 26, segue uma linguagem com sintaxe semelhante à UML Unified Modeling Language). A UML [Boo1996] é utilizada na modelagem das classes de objetos, em uma aplicação de TV Interativa consciente de contexto, para permitir a especificação formal dessas classes e seus relacionamentos, em termos das ações que são geradas durante o uso da aplicação pelo usuário.

Os três principais componentes desse modelo são:

- Program Model: O objeto central de uma aplicação de TV Interativa é o programa (program), que é ligado às principais partes dos outros modelos (profile e terminal). Essas ligaçōes existem porque o terminal recebe informações de um perfil de programa (program profile), porém, como toda essa informação está no program model, ele se comunica com o objeto program. A Seção 4.5.1 apresentará o Program Model de modo mais completo;

- Profile Model: Cada programa é composto (e apresentado) por um ou mais perfis. Um perfil pode ser visto como uma "cara" diferente de um programa. A seção 4.5.2 apresentará o conceito de perfil de programa e o Profile Model com mais detalhes;

- Terminal Model: O objeto central desse componente é o terminal. Este está conectado ao Sistema Adaptativo (Adaptive System) e aos sensores de movimento e equipamentos ubíquos (Ubiquitous and Mobile Sensor), que incluem todos os 
sensores e equipamentos que podem prover informação contextual útil. $\mathrm{O}$ terminal pode possuir equipamentos embutidos, como decodificadores (de vídeo e de áudio) e acessórios para a interação (por exemplo, teclados e joysticks). Outro objeto que está presente no Terminal Model é a pessoa (person). O person é o objeto onde toda a informação relevante sobre todos os usuários do sistema é armazenada. Exemplos de informações relevantes são idade, gênero, salário, canais e programas favoritos, restrições de acesso, volume do som e ajustes da imagem. $\mathrm{O}$ Adaptive System é referente às informações relacionadas à rede. $\mathrm{O}$ Ubiquitous / Mobile Sensor é composto por objetos (devices) representando os equipamentos que tornam possível a consciência de contexto e a ubiqüidade, como sensores e suas características. O Terminal Model é pesquisado em outros trabalhos realizados no laboratório Intermídia.

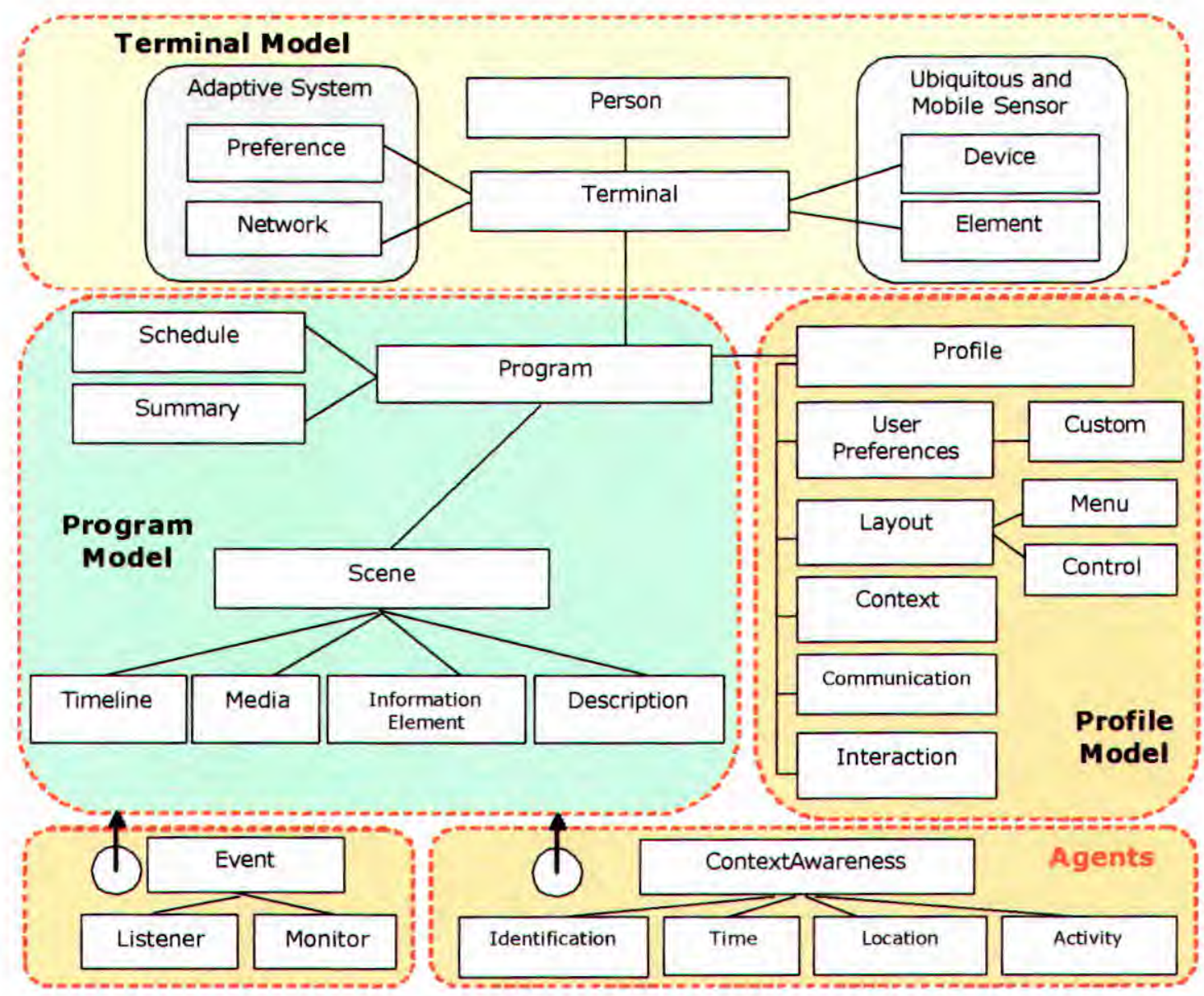

Figura 26 - Diagrama de Classes de uma Aplicação de TV Interativa. Extraída de [San2001] 
Os outros componentes são os referentes à consciência de contexto e aos eventos que ocorrem durante o programa. Esses componentes serão estudados por outros trabalhos realizados no grupo Intermídia.

\subsection{Estrutura e implementação de um programa de TV Interativa}

A abordagem atual da TV Interativa, em nível mundial [ATV2000; DVB2000; TVA2001a], prevê somente a adição de alguns aspectos de interatividade aos tradicionais programas de televisão. No entanto, com a mesma tecnologia que esses modelos utilizam, é possível obter um resultado com maior grau de adaptabilidade ao consumidor e que também permita uma melhor definição do público-alvo pela emissora de televisão. Nesse ponto, observa-se que é possível adaptar um mesmo programa, com pequenas modificações, a espectadores com diferentes interesses, conforme ilustra a Figura 27.

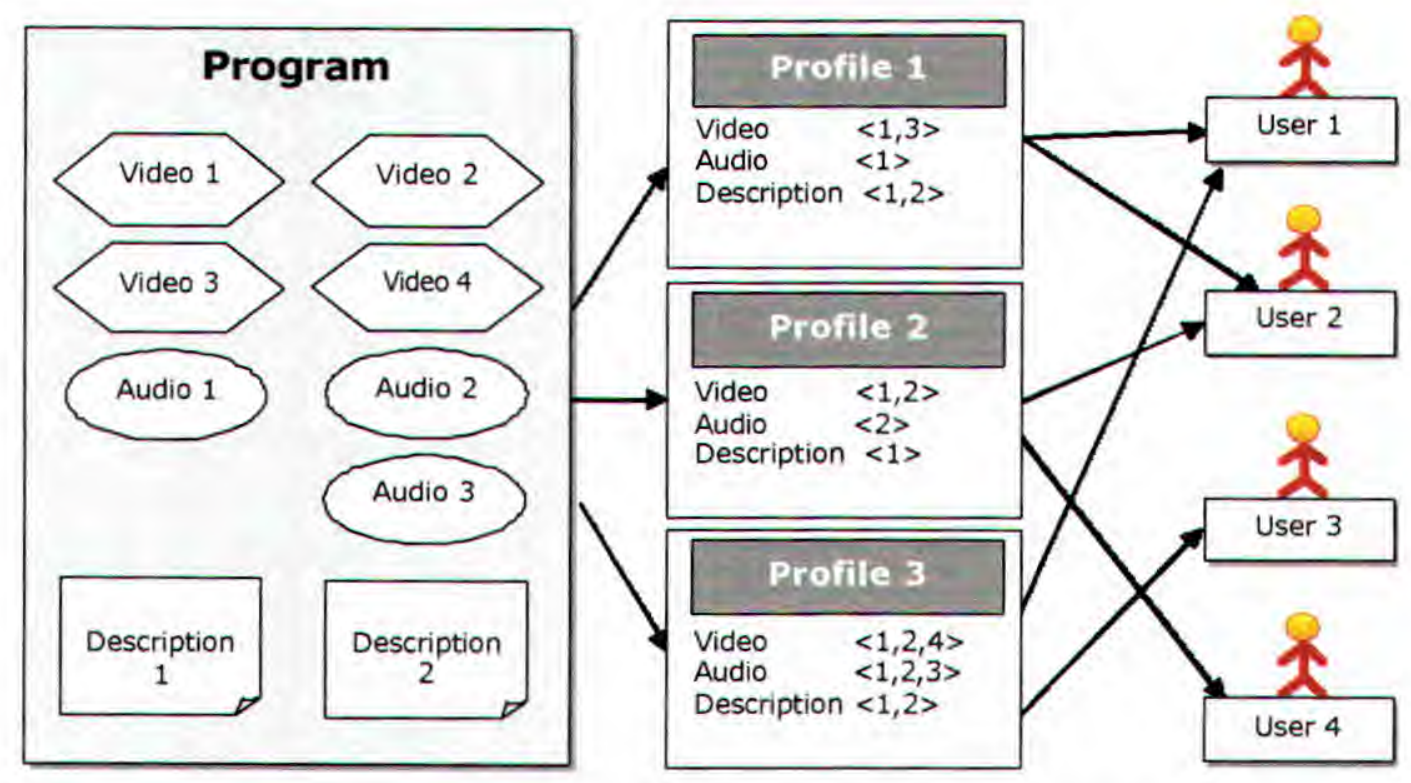

Figura 27 - Estrutura proposta para um programa de TV-I

Na Figura 27 é apresentado um programa com seus diversos objetos, porém, para cada usuário ele será mostrado de uma forma diferente, dependendo dos perfis que esse usuário tem à disposição. Na seção 4.5 .3 será mostrado um exemplo de aplicação desses conceitos em um programa de TV-I. 
Nesse contexto, é importante ressaltar que esse tipo de adaptação, considerando-se uma estrutura particular para um programa de TV Interativa, pode ser feito com o uso de aspectos de consciência de contexto, conforme apresentado na seção 4.1. As seções 4.5.1 e 4.5.2 apresentam definições de programa e de perfil, respectivamente.

\subsubsection{Programa}

O programa é o elemento central da TV Interativa. O programa pode ser definido como o conjunto de todas as mídias (e suas descrições), cenas (e suas descrições), um sumário (ou sinopse) e sua programação, conforme mostra a Figura 28.

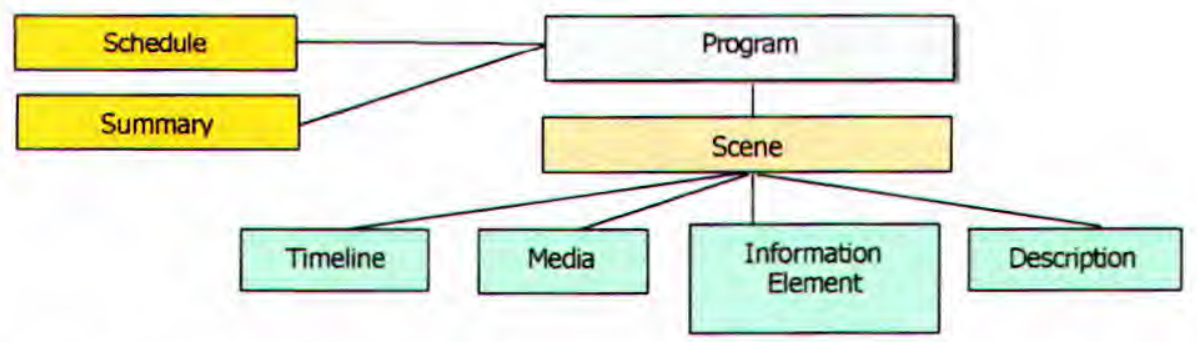

Figura 28 - Entidades que compōem um programa em uma aplicação de TV-I

O programa é estruturado usando a DDL MPEG-7 [ISO2001b] e utiliza as descrições multimídia definidas pelo MPEG-7 [ISO2001c]. As entidades Schedule e Summary são definidas pelo TV-Anytime Forum [TVA2001b; TVA2001c], e, por isso, não serão apresentadas aqui com maior detalhamento. A Tabela 7 apresenta os elementos de um programa.

Tabela 7 - Elementos do Programa

\begin{tabular}{|c|c|}
\hline Nome & Definição \\
\hline Program & $\begin{array}{l}\text { É o principal elemento de um programa. É do tipo } \\
\text { ProgramType }\end{array}$ \\
\hline ProgramType & $\begin{array}{l}\text { É um complexType, dentro do qual estão a cena, a } \\
\text { programação (Schedule) e a sinopse (Summary) }\end{array}$ \\
\hline Information & Apresenta informações sobre o programa \\
\hline ProgramInformationType & $\begin{array}{l}\text { É um simpleType que contém informações sobre o } \\
\text { programa }\end{array}$ \\
\hline name & Nome do programa. É do tipo mpeg7:TitleType \\
\hline id & $\begin{array}{l}\text { Identificação única do programa - é utilizado o } \\
\text { identificador de programas do TV Anytime Forum } \\
\text { CRIDType }\end{array}$ \\
\hline
\end{tabular}




\begin{tabular}{ll}
\hline Scene & Descreve os objetos presentes na cena. É do tipo SceneType \\
\hline Summary & Apresenta a sinopse do programa - foi definido pelo TV \\
& Anytime Forum como o tipo SynopsisType \\
\hline Schedule & E um elemento que apresenta a programação do programa. \\
& Edo tipo tva:ScheduleEventType \\
\hline
\end{tabular}

O Schema de descrição do programa é apresentado na Figura 29.

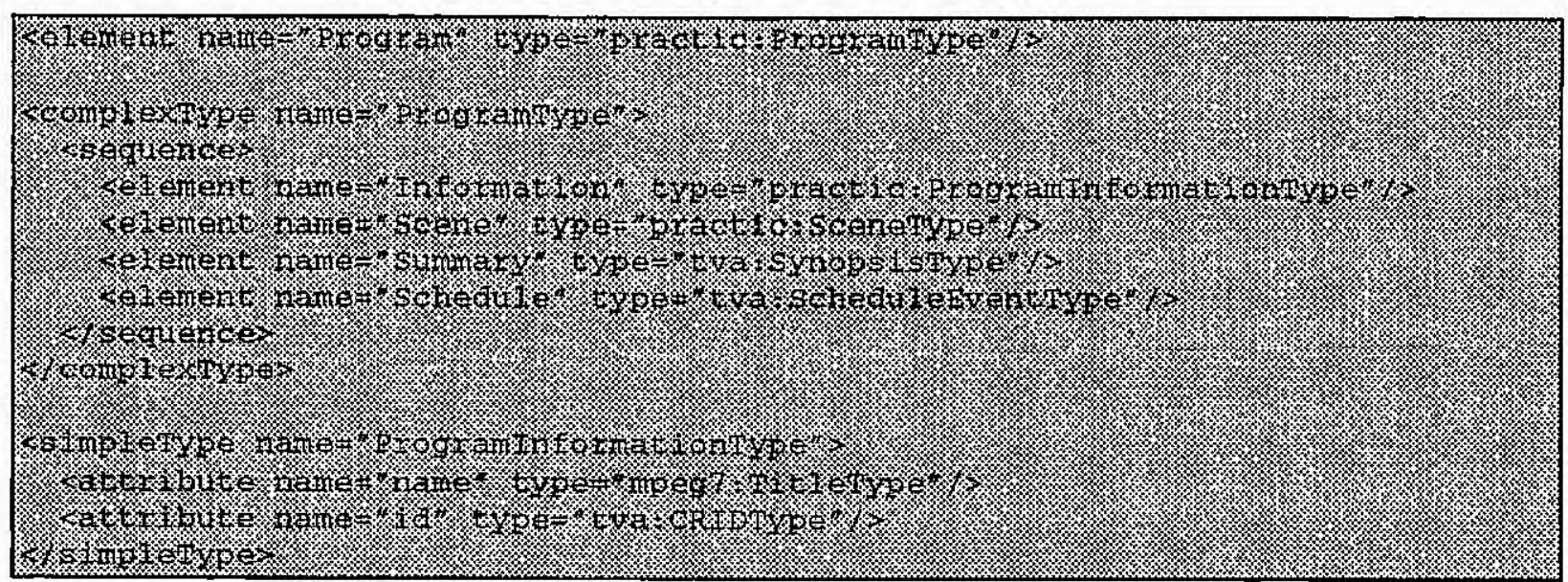

Figura 29 - Exemplo de Schema para o elemento program

O programa deve ser definido e disponibilizado pela emissora, de modo que seja possível sua apresentação de diferentes maneiras. No programa estão presentes as informações fundamentais para o funcionamento do mesmo, bem como a sua composição por mídias, que podem ser descritas em MPEG-7. Um exemplo do uso do cabeçalho é apresentado na Figura 30.

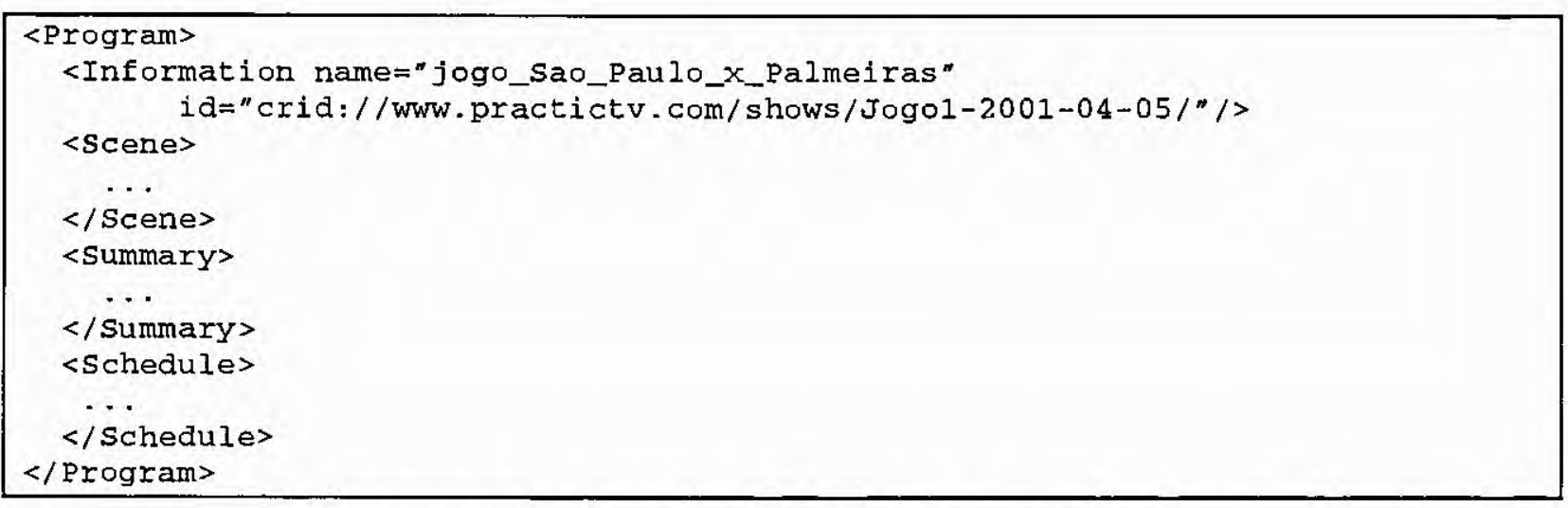

Figura 30 - Exemplo de cabeçalho de um programa

Como foi mostrado na Figura 28, um programa é composto por diversos sub-elementos, cuja definição, bem como de seus atributos, é apresentada na Tabela 8. 
Tabela 8 - Sub-elementos do programa

\begin{tabular}{ll}
\hline Nome & Definição \\
\hline SceneType & É o tipo de dado que possui as informações sobre a cena \\
\hline Media & É um elemento que indica o tipo de mídia existente na cena e \\
& sua.localização. É do tipo Media Type \\
\hline Timeline & É um elemento que indica a localização da descrição da linha do \\
& tempo da cena. É do tipo TimelineType \\
\hline Ielement & É o elemento responsável pela interação via Information \\
& Element, e é nesse elemento que estão as ações que devem ser \\
& feitas de acordo com o contexto. Esse elemento, bem como seus \\
& sub-elementos, estão em fase de especificação em outro projeto \\
& do grupo Intermídia. É do tipo IelementType \\
\hline Description & É um elemento destinado à descrição de mídias independentes \\
& ou da cena. É um tipo de dado MPEG-7, que pode ser um XML \\
& ou um HTML, e seu tipo é indicado na descrição da cena. Esse \\
& elemento deve ser retirado de IPCTMimeTypeCS [ISO2001g] \\
& (seção 17.1.2.1.2)
\end{tabular}

O Schema de descrição de uma cena é apresentado na Figura 31.

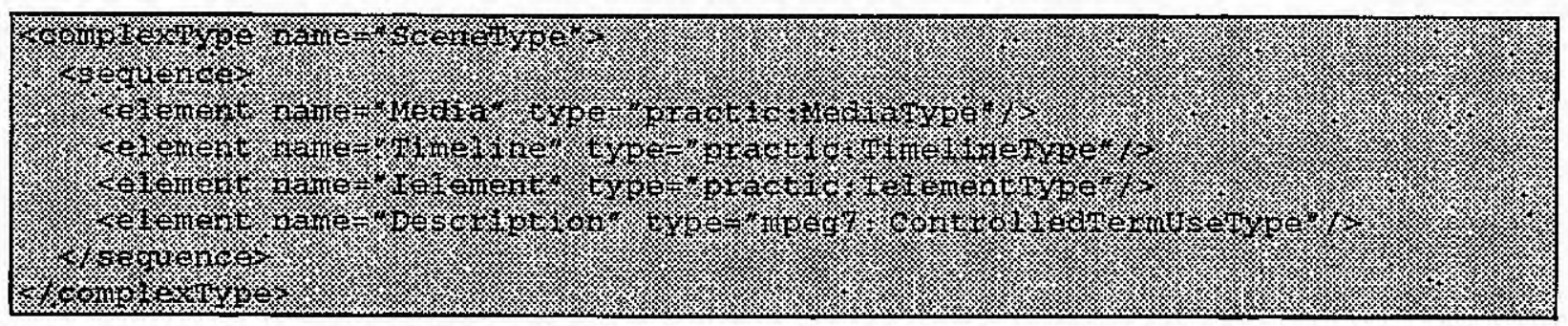

Figura 31 - Exemplo do Schema para descrever a cena

O programa pode ser composto por vários objetos de mídia, que devem ser descritos. A descrição desses objetos de mídia é apresentada na Tabela 9, e o seu Schema de representação é apresentado na Figura 32.

Tabela 9 - Sub-elementos de mídia

\begin{tabular}{ll}
\hline Nome & Definição \\
\hline MediaType & É o tipo de dado que descreve as características da mídia \\
\hline MediaID & $\hat{E}$ o identificador do objeto de mídia. $\hat{E}$ do tipo \\
& mpeg7:UniqueIDType. É utilizado para a ligação a dados \\
& relacionados à mídia descritos em MPEG-7 \\
\hline ObjectID & $\begin{array}{l}\text { É o identificador do objeto de mídia. É do tipo PracticIDType. É } \\
\text { utilizado para a manipulação do objeto mídia no layout }\end{array}$ \\
\hline FileFormat & $\hat{E}$ um elemento que indica o formato da mídia. É um tipo de \\
& dado MPEG-7 que deve ser retirado de MPEG7FileFormatCS \\
& [ISO2001g] (seção17.1.2.1.1) \\
\hline Location & Informa a localização do arquivo. É do tipo
\end{tabular}




\begin{tabular}{|c|c|}
\hline & mpeg7:MediaLocatorType \\
\hline Filesize & Informa o tamanho do arquivo \\
\hline System & $\begin{array}{l}\text { Informa o tipo de sistema de cores utilizado, por exemplo, PAL, } \\
\text { NTSC e DVB. E um tipo de dado MPEG-7 que deve ser retirado } \\
\text { de MPEG7SystemCS [ISO2001g] (seção 17.1.2.3.1) }\end{array}$ \\
\hline Bandwidth & $\begin{array}{l}\text { Informa a largura de banda necessária para a mídia ser } \\
\text { apresentada }\end{array}$ \\
\hline Bitrate & Informa a taxa de bits necessária para a apresentação da mídia \\
\hline variable & Utilizado se a taxa de bits é variável \\
\hline minimum & $\begin{array}{l}\text { Indica a taxa de bits mínima necessária para a apresentação da } \\
\text { mídia }\end{array}$ \\
\hline average & Indica a taxa de bits média para a apresentação da mídia \\
\hline maximum & $\begin{array}{l}\text { Indica a taxa de bits máxima necessária para a apresentação da } \\
\text { mídia }\end{array}$ \\
\hline AudioAttributes & Descreve as características sonoras da mídia \\
\hline coding & $\begin{array}{l}\text { Indica o tipo de codificação utilizado na mídia. E um tipo de } \\
\text { dado MPEG-7 que deve ser retirado } \\
\text { MPEG7AudioCodingFormatCS [ISO2001g] (seção 17.1.2.6.1) }\end{array}$ \\
\hline Channels & Indica o número de canais sonoros da mídia em cada posição \\
\hline front & Número de canais de áudio frontais \\
\hline rear & Número de canais de áudio traseiros \\
\hline side & Número de canais de áudio laterais \\
\hline $1 \mathrm{fe}$ & Número de canais de áudio de baixa freqüência \\
\hline track & Número de faixas nas quais o som está gravado \\
\hline MixType & $\begin{array}{l}\text { Indica o tipo de mixagem utilizado pela mídia. É um tipo de } \\
\text { dado MPEG-7 que deve ser retirado de } \\
\text { MPEG7AudioPresentationCS [ISO2001g] (seção 17.1.2.5.1) }\end{array}$ \\
\hline VideoAttributes & Descreve as características visuais da mídia \\
\hline Coding & $\begin{array}{l}\text { Indica o tipo de codificação utilizado na mídia. É um tipo de } \\
\text { dado MPEG-7. E um tipo de dado MPEG-7 que deve ser retirado } \\
\text { de MPEG7VideoCodingFormatCS [ISO2001g] (seção 17.1.2.4.1) }\end{array}$ \\
\hline$\overline{\text { Scan }}$ & $\begin{array}{l}\text { Indica o tipo de "scan" utilizado pela mídia (por exemplo, } \\
\text { progressivo, entrelaçado). É um tipo de dado tva:ScanType }\end{array}$ \\
\hline Horizontalsize & Indica a tamanho horizontal (em pixels) da mídia \\
\hline Verticalsize & Indica a tamanho vertical (em pixels) da mídia \\
\hline AspectRatio & $\begin{array}{l}\text { Indica o aspecto da imagem (a proporção do tamanho horizontal } \\
\text { e do vertical). É um tipo de dado tva:AspectRatioType }\end{array}$ \\
\hline Color & $\begin{array}{l}\text { Indica como é a coloração da mídia (branco e preta, colorida } \\
\text { artificialmente...). E um tipo de dado tva:ColorType }\end{array}$ \\
\hline
\end{tabular}

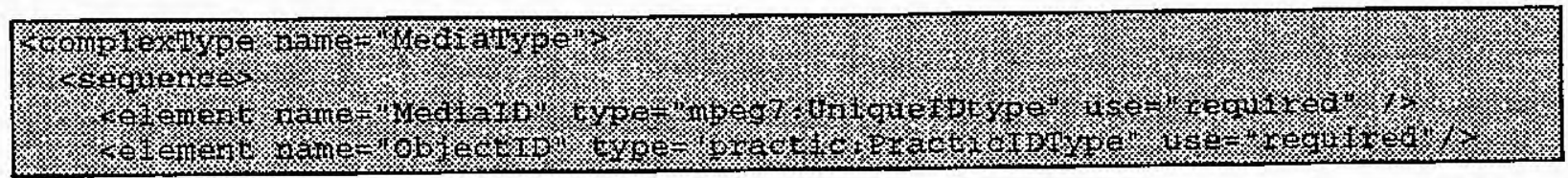




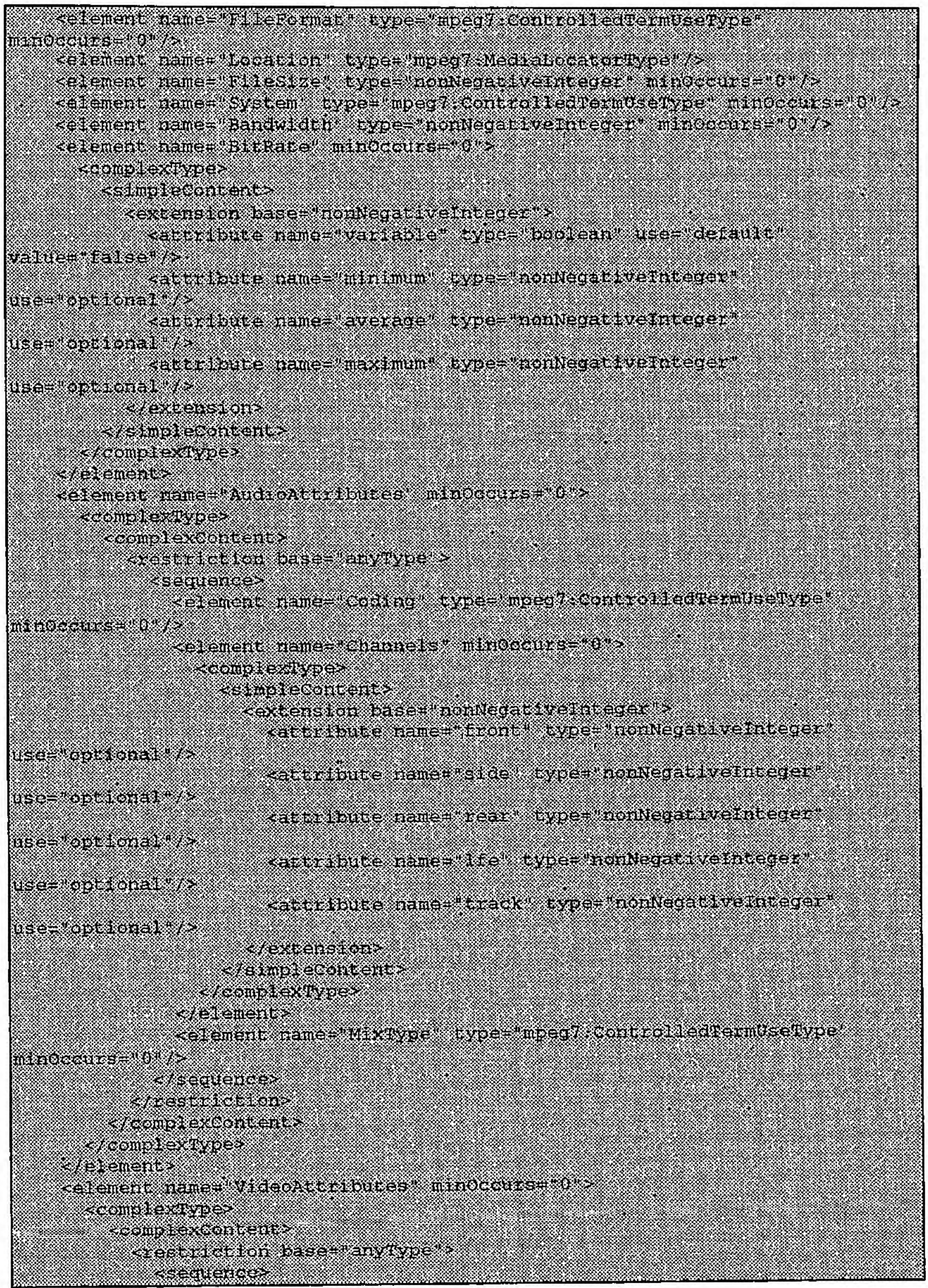




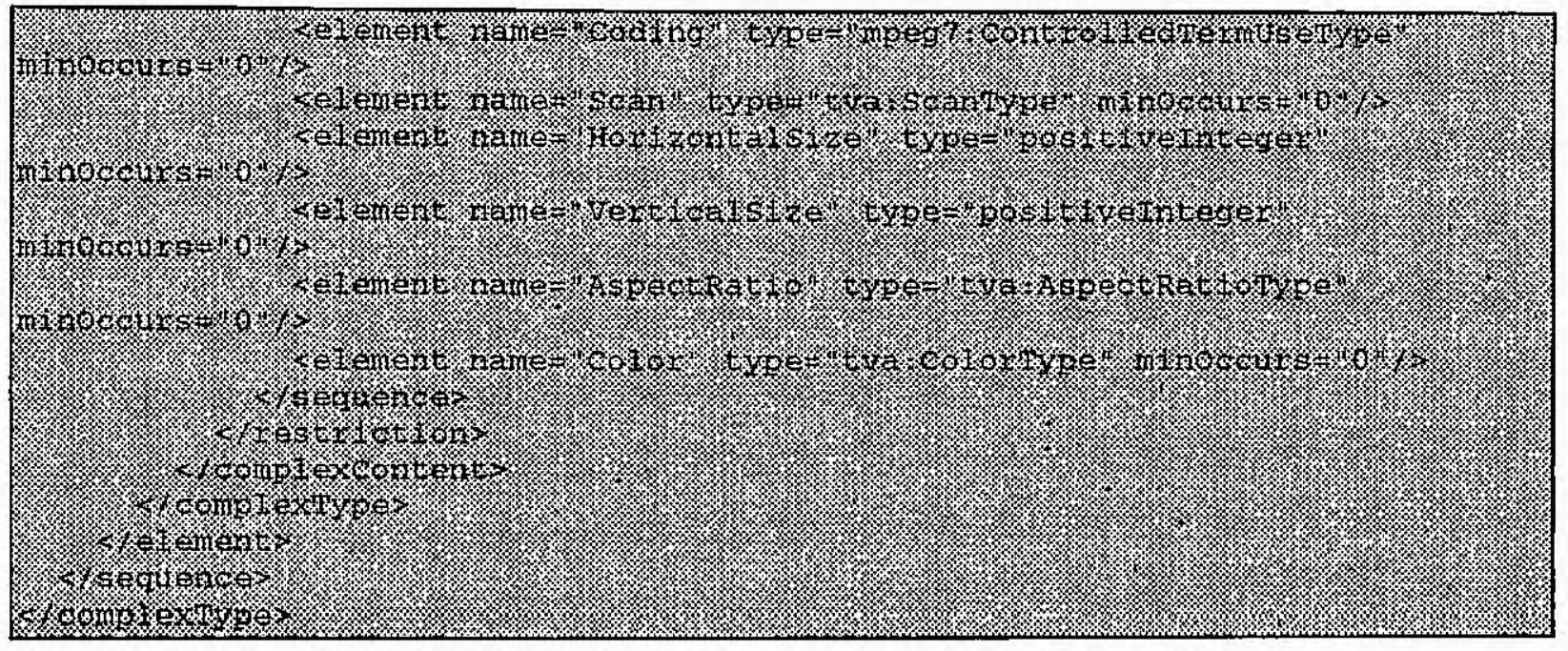

Figura 32 - Exemplo do Schema para a descriçāo das mídias

A partir das mídias e suas descriçōes, é possível construir diferentes interfaces, ou modos de apresentação, para um programa. A essa possibilidade dá-se a denominação de perfil. Para a codificação das mídias e das cenas, essa proposta considera o uso da tecnologia MPEG-4, que é bastante flexível e eficiente para a compactação de vídeo e de áudio. Como característica fundamental do MPEG-4, pode-se citar o fato dos componentes de uma cena estarem separados como objetos, permitindo, assim, incrementos nas formas de manipulação desses componentes. Essa característica é bastante significativa para o caso da implementação de diferentes perfis de programas de TV-I. É importante salientar que apesar deste trabalho considerar o uso de MPEG-4 para a apresentação e transmissão do programa, a estrutura apresentada é independente do mecanismo de transporte, podendo utilizar os padrões da TV Digital [ATS2001; DVB1999; ARI1998], bem como o Multimedia Home Plataform [DVB2000] para a apresentação do conteúdo multimídia.

As descrições das cenas e das mídias permitem a criação de ferramentas de busca em vídeos, áudio e nas cenas. Pelo fato deste trabalho utilizar o padrão MPEG-7 para a descrição destas, deve-se observar que ferramentas de busca para MPEG-7 poderão ser utilizadas.

Outro elemento importante da cena é o Timeline, a linha do tempo, que informa a posição temporal das mídias na cena. Esse elemento é do tipo TimelineType, que tem seus elementos apresentados na Tabela 10 e seu Schema, na Figura 33. 
Tabela 10 - Sub-elementos de linha do tempo

\begin{tabular}{ll}
\hline Nome & Definição \\
\hline Timelinetype & $\begin{array}{l}\text { É o tipo de dado que possui as informações sobre a linha do } \\
\text { tempo da cena }\end{array}$ \\
\hline Tobject & $\begin{array}{l}\text { É um elemento que indica o objeto que terá sua ação temporal } \\
\text { descrita }\end{array}$ \\
\hline \multicolumn{1}{c}{ ID } & É um identificador do objeto. É do tipo PracticIDType \\
\hline MediaTime & $\begin{array}{l}\text { É um elemento que informa o ponto em que a mídia deve } \\
\text { começar e sua duração. É um elemento MPEG-7 do tipo } \\
\text { mpeg7:MediaTimeType }\end{array}$ \\
\hline SceneTimePoint & $\begin{array}{l}\text { Eum elemento que indica o instante da cena em que o objeto } \\
\text { deve ser inserido. É um elemento MPEG-7 do tipo } \\
\text { mpeg7:TimePointType }\end{array}$ \\
\hline
\end{tabular}

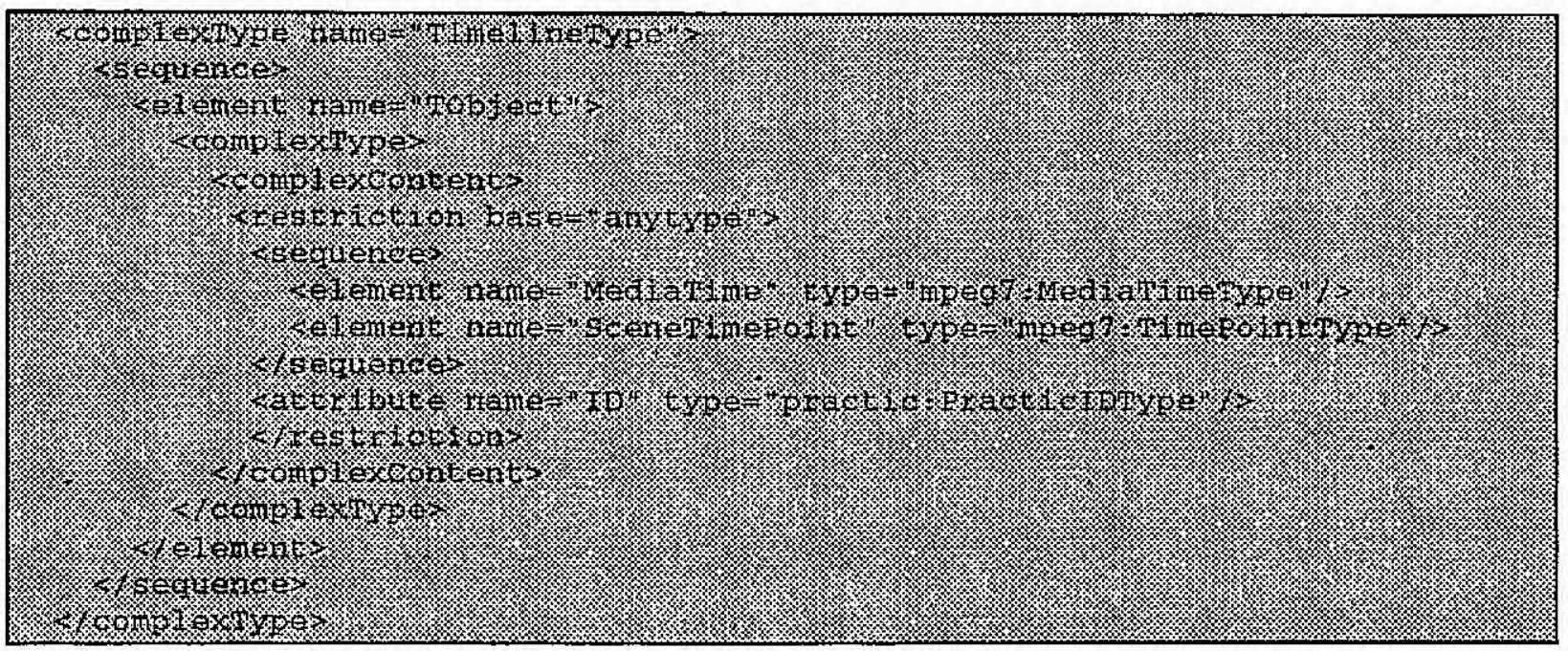

Figura 33 - Exemplo do Schema para os elementos da linha do tempo

O sumário e o schedule têm uma destacada importância para aplicações do tipo EPG (Electronic Program Guides), uma vez que é a partir do uso de EPGs que o usuário escolherá o que assistir e o que pretende gravar. Com as informações do sumário, o usuário pode escolher exatamente os programas a serem assistidos/gravados; com a informação do schedule, o usuário não precisa se preocupar com o horário de início do programa, uma vez que sua URD fará isso de forma transparente. Outro relevante uso do schedule reside no fato de que, em um ambiente consciente de contexto e ubíquo, a URD pode informar a um equipamento telefônico ou PDA (Personal Digital Assistant) o horário de início de um determinado programa. 


\subsubsection{Perfil de programa}

Um programa precisa de uma especificação de um modo de apresentação. Pelo fato de existir uma vasta quantidade de mídias disponíveis, o número de diferentes formas de apresentação desse programa tende a ser igualmente grande. Quem disponibiliza os perfis são as emissoras geradoras de programas, porém, esses perfis podem ser personalizados pelos usuários. Ao fazer-se com que as produtoras disponibilizem os perfis, impede-se a incompatibilidade entre um perfil e um programa, além de permitirse que diferentes perfis possam ser disponibilizados, de acordo com o tipo e/ou categoria de usuário (por exemplo, o plano de canais interativos que um determinado usuário possui).

Este trabalho utiliza o padrão MPEG-7 para a criação de novos elementos e para descrever alguns aspectos de layout, requisitos e contexto, relevantes a esse perfil e suas interações, conforme ilustra a Figura 34.

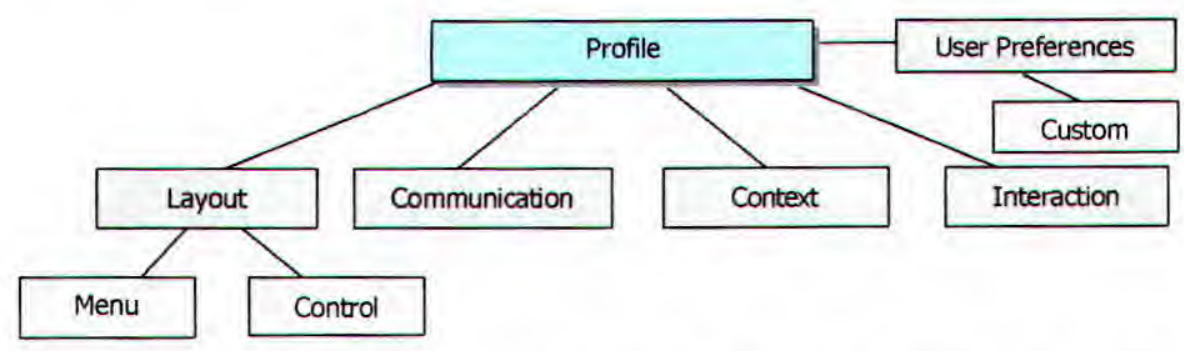

Figura 34 - Entidades que compõem um profile em uma aplicação de TV-I

As informações relativas a um perfil estão dentro de um elemento profile. Esse elemento, por sua vez, é composto por outros elementos, que terão suas funcionalidades apresentadas na Tabela 11 e seu Schema, na Figura 35.

Tabela 11 - Elementos de perfil

\begin{tabular}{ll}
\hline Nome & Definição \\
\hline Profile & $\begin{array}{l}\text { É o elemento que descreve as características do perfil do } \\
\text { programa. É do tipo ProfileType }\end{array}$ \\
\hline ProfileType & É um complexType, dentro do qual estão todos os elementos do \\
\hline
\end{tabular}




\begin{tabular}{ll}
\hline Layout & perfil. \\
& $\begin{array}{l}\text { E um elemento, dentro do qual estará especificada a disposição } \\
\text { dos elementos na tela. É do tipo LayoutType }\end{array}$ \\
\hline Communication & $\begin{array}{l}\text { É um elemento que informa as características necessárias para a } \\
\text { transmissão e visualização do perfil. É do tipo } \\
\text { CommunicationType }\end{array}$ \\
\hline Context & $\begin{array}{l}\text { E um elemento que informa como devem ser tratadas } \\
\text { informações de contexto relevantes }\end{array}$ \\
\hline name & Identifica o nome do perfil \\
\hline id & Identificador único do programa. É do tipo PracticIDType \\
\hline programid & $\begin{array}{l}\text { Indica o id do programa ao qual aquele perfil pertence. É do tipo } \\
\text { tva:CRIDType }\end{array}$ \\
\hline
\end{tabular}

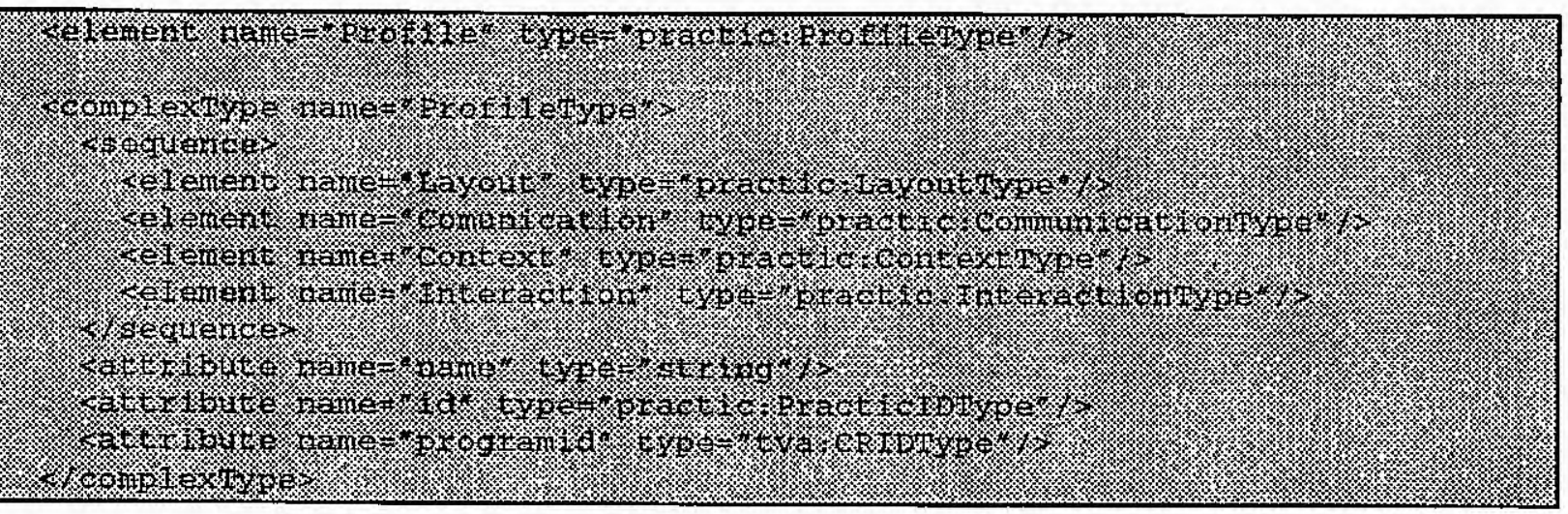

Figura 35 - Exemplo do Schema para o elemento profile

Um exemplo do uso do cabeçalho é apresentado na Figura 36.

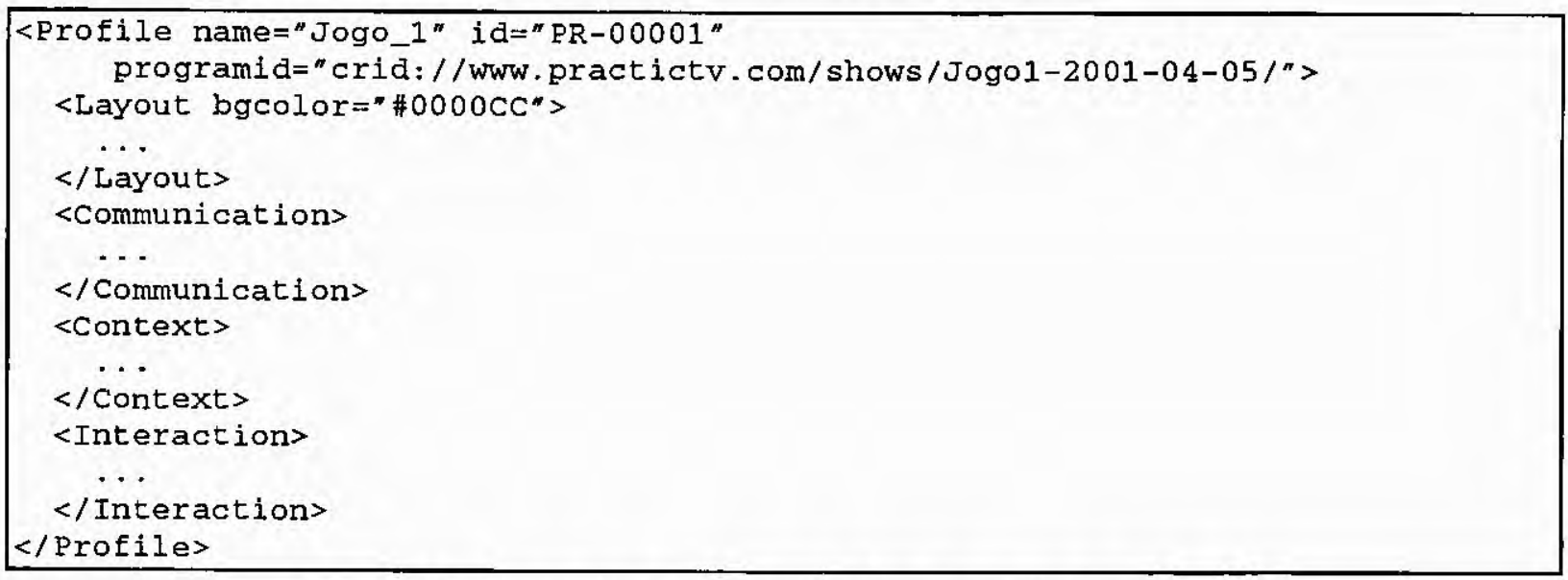

Figura 36 - Exemplo do cabeçalho de um perfil de programa

Os aspectos de apresentação definidos, que fazem parte do elemento Layout, são relativos às cores de fundo, às fontes e posições das múdias. Dentro do layout ainda, têm-se os controles de mídia possíveis para um determinado perfil, o tipo de menu e seu conteúdo. Uma versão simplificada do Schema de descrição do elemento Layout é 
apresentada na Figura 37 e a descrição de seus sub-elementos, na Tabela 12. A versão completa do Schema é apresentada no Apêndice B.

Tabela 12 - Sub-elementos de layout

\begin{tabular}{|c|c|}
\hline Nome & Definição \\
\hline LayoutType & $\begin{array}{l}\text { E um complexType que indica as características do layout do } \\
\text { perfil }\end{array}$ \\
\hline bgcolor & Indica a cor de fundo padrão. É do tipo hexadecimal \\
\hline object & $\begin{array}{l}\text { É o elemento que indica um objeto na cena. Um objeto pode ser } \\
\text { um elemento de mídia ou uma descrição }\end{array}$ \\
\hline Ia & Identificador único de objetos. É do tipo PracticIDType \\
\hline xposition & Indica a posição horizontal do objeto \\
\hline yposition & Indica a posição vertical do objeto \\
\hline volume & Indica o volume do objeto \\
\hline effect & Indica o efeito sonoro aplicado àquele objeto \\
\hline Button & Esse é um elemento que apresenta um botão padrão na tela \\
\hline id & E um identificador do botão. É do tipo PracticIDType \\
\hline action & Indica a ação que deve ser disparada quando o botão é clicado \\
\hline xposition & Define a posição na tela da margem esquerda do botão \\
\hline yposition & Define a posição na tela da margem acima do botão \\
\hline Menu & $\begin{array}{l}\text { É o elemento responsável pelo menu do programa. É do tipo } \\
\text { MenuType }\end{array}$ \\
\hline Control & $\begin{array}{l}\text { São os controles do programa (play, stop, rewind, forward, } \\
\text { replay, change subtitle, change language...) }\end{array}$ \\
\hline name & $\begin{array}{l}\text { É o nome do comando. É um tipo de dado MPEG-7 que deve ser } \\
\text { retirado de MPEG7ActionTypeCS [ISO2001g] (seção 17.4.1.1.1) }\end{array}$ \\
\hline id & E o identificador do comando \\
\hline Action & É a ação disparada quando o comando é executado \\
\hline MenuType & $\begin{array}{l}\text { E um complex type que define um tipo de menu disponível para } \\
\text { aquele programa de TV-I }\end{array}$ \\
\hline Selector & E um tipo de menu. É do tipo MenuSelector \\
\hline Popup & E um tipo de menu. É do tipo MenuPopup \\
\hline Bar & E um tipo de menu. É do tipo MenuBar \\
\hline type & Identificador do tipo de menu (popup, selector...) \\
\hline position & Indica a posição do menu (top, down, left, right) \\
\hline color & Indica a cor do menu. É do tipo hexadecimal \\
\hline
\end{tabular}

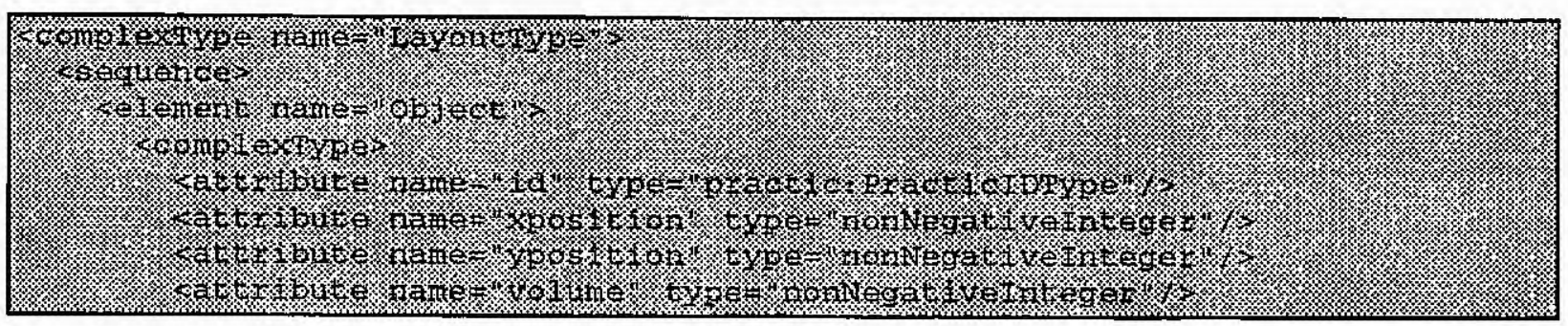




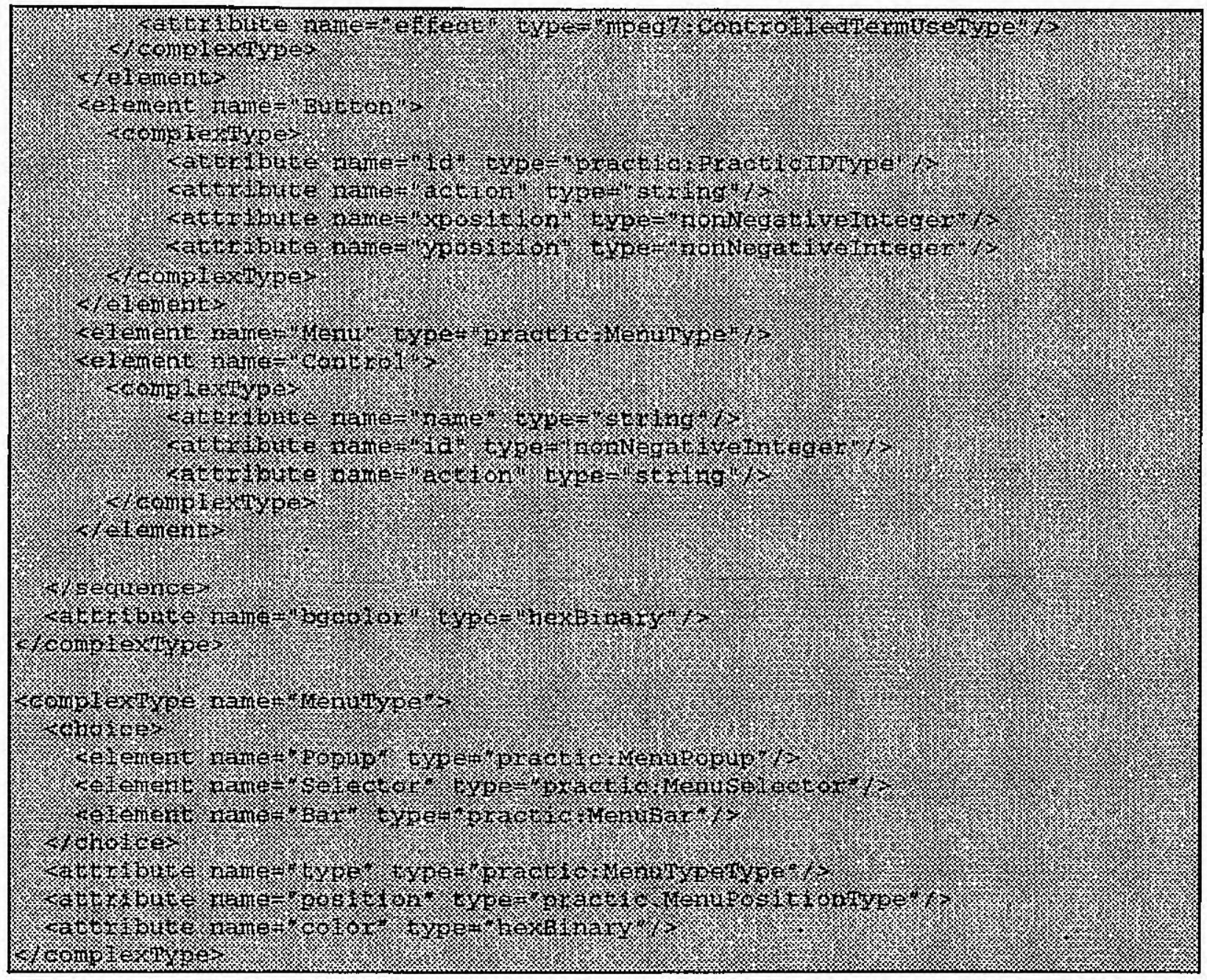

Flgura 37 - Exemplo do Schema para o elemento layout

Os requisitos do perfil ficam especificados e armazenados dentro do elemento communication, onde estão os requisitos de comunicação de cada mídia, os decodificadores necessários para cada uma dessas mídias e requisitos técnicos da URD. Na Tabela 13 são apresentados os sub-elementos do elemento communication e na Figura 38 é apresentada uma versão simplificada do Schema de descrição do tipo CommunicationType.

Tabela 13 - Sub-elementos de comunicação

\begin{tabular}{ll}
\hline Nome & Definição \\
\hline CommunicationType & $\begin{array}{l}\text { É um complexType que contém elementos que indicam as } \\
\text { características necessárias para a apresentação do perfil }\end{array}$ \\
\hline CommRequirements & $\hat{\text { É um complexType onde estão os requisitos de cada mídia }}$ \\
\hline Bandwidth & $\begin{array}{l}\text { Quantidade de banda de rede necessária para a apresentação } \\
\text { do perfil }\end{array}$ \\
\hline codec & Decodificadores e codificadores necessários para a a
\end{tabular}


apresentação da mídia. É um tipo MPEG-7 que deve ser retirado de MPEGTVideoCodingFormatCS [ISO2001g] 17.1.2.4.1 ou de MPEG7AudioCodingFormatCS [ISO2001g] 17.1.2.6.1

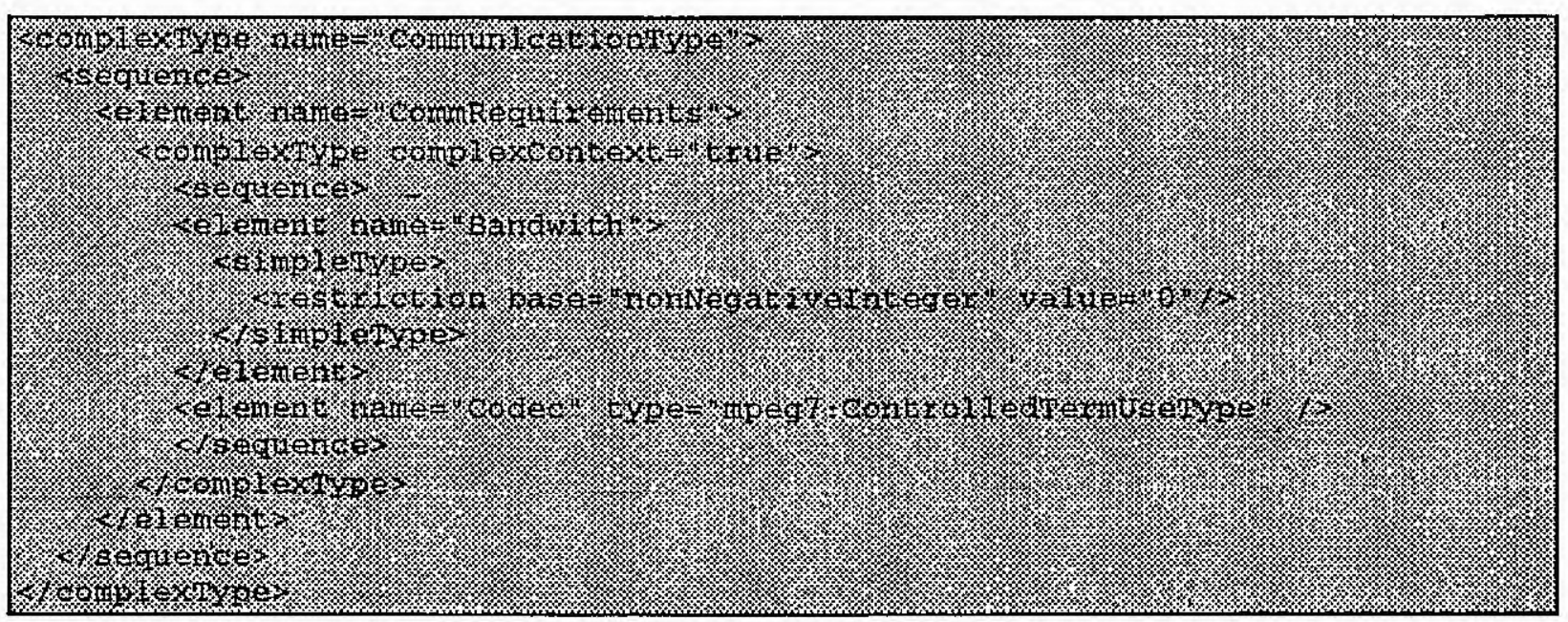

Figura 38 - Exemplo de Schema para o elemento Communication

Dentro do elemento context, insere-se todo o tipo de informação de contexto que pode ser relevante para um determinado perfil. Esse elemento foi definido a partir de variáveis relevantes em consciência de contexto, tais como who, where, when e what [Dey2000], e apresentadas na Seção 4.1. Esse elemento possui as ações que devem ser realizadas em determinadas situações. A Tabela 14 apresenta a descrição desses elementos, a Figura 39 apresenta um exemplo de como utilizar o Schema para a utilização em consciência de contexto apresentando o tipo ContextType.

Tabeia 14 - Sub-elementos de consciêncla de contexto

\begin{tabular}{ll}
\hline Nome & Definição \\
\hline Who & $\begin{array}{l}\text { Elemento que indica quem (é utilizado para a ação dos agentes } \\
\text { no ambiente) e dependendo deste realizará uma ação }\end{array}$ \\
\hline RefId & Identificador de who. É um tipo mpeg7:UserIdentifierType \\
\hline Where & $\begin{array}{l}\text { Elemento que indica localização e dependendo desta realizará } \\
\text { uma ação }\end{array}$ \\
\hline RefId & Identificador do local \\
\hline When & $\begin{array}{l}\text { Elemento que indica tempo e dependendo deste realizará uma } \\
\text { ação }\end{array}$ \\
\hline RefId & Identificador de tempo. É um tipo mpeg7:TimeType \\
\hline What & $\begin{array}{l}\text { Elemento que indica o que está sendo feito e dependendo deste } \\
\text { realizará uma ação }\end{array}$
\end{tabular}




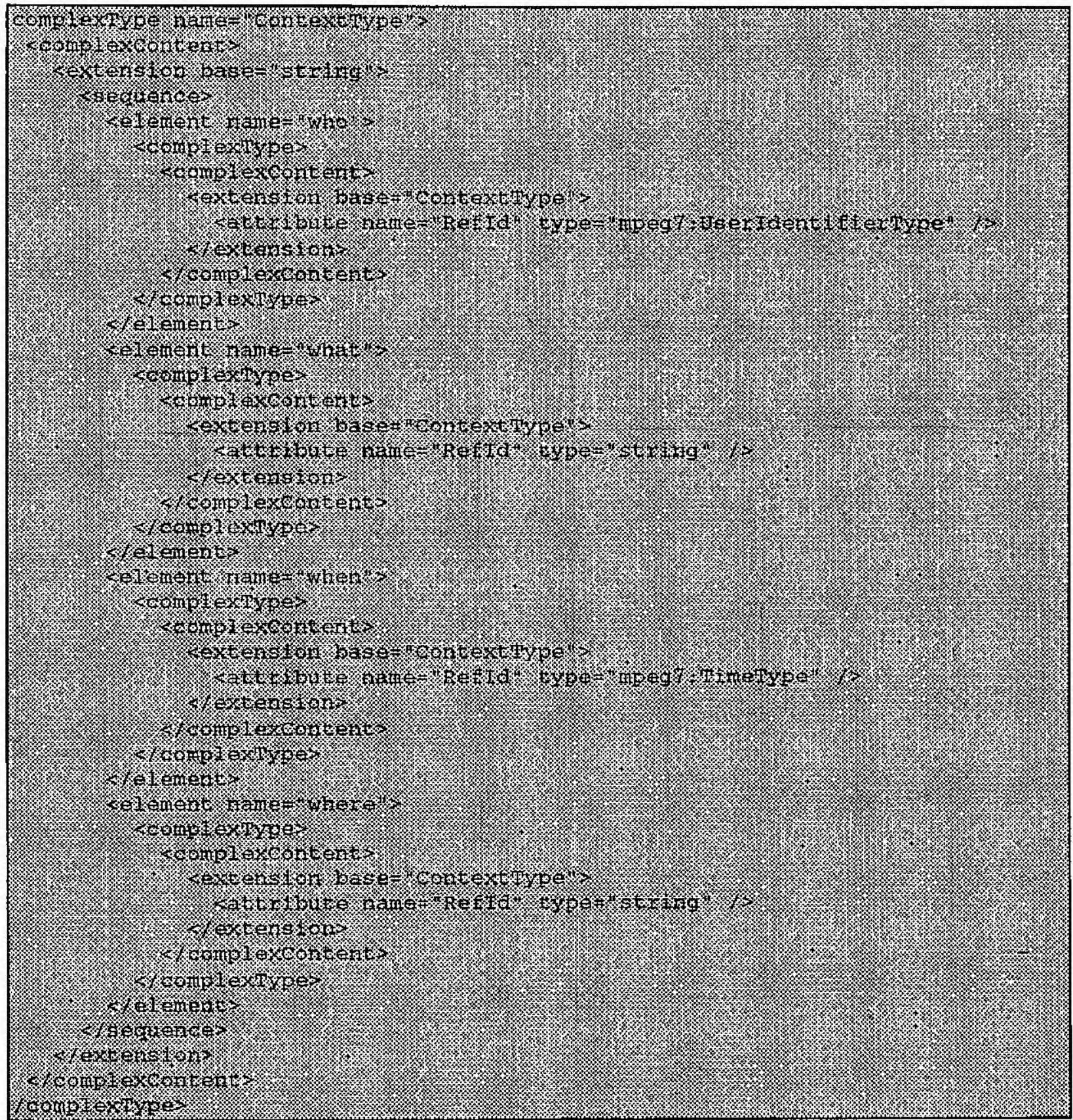

Figura 39 - Exemplo de Schema para os elementos de consciência de contexto

A utilização dos sub-elementos do elemento context se dá através do aninhamento dos mesmos, de modo semelhante à utilização do if, them e else em linguagens de programação. Desse modo, é possível associar ações às situações relevantes que acontecem no ambiente. Um exemplo é mostrado na Figura 40. 


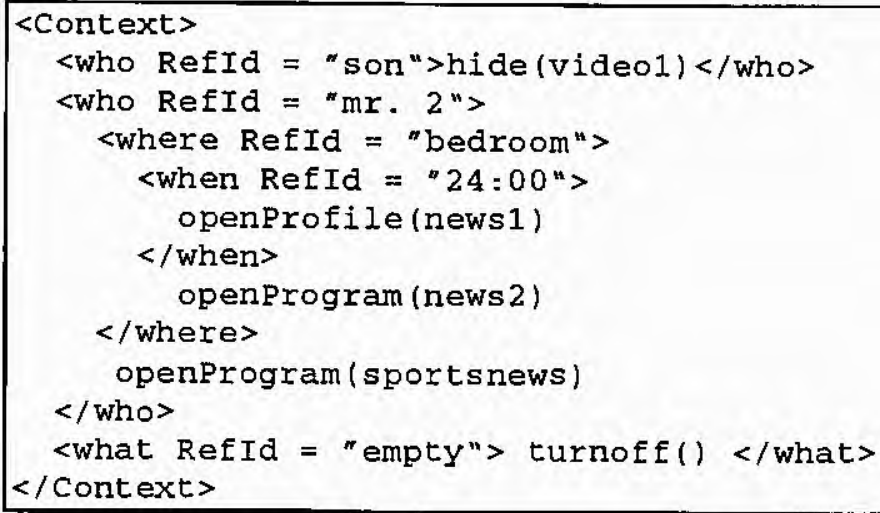

Figura 40 - Exemplo do uso dos elementos de consciência de contexto

No exemplo anterior é mostrado o uso da consciência de contexto dentro de um perfil, no entanto, os elementos de consciência de contexto podem ser utilizados tanto no elemento <program> quanto no elemento user preferences, indicando qual é o perfil mais adequado daquele programa para aquela pessoa. No elemento <user preferences>, o elemento <context> é utilizado com a mesma sintaxe e, no caso do programa, ele será parte do Information Element, que está em fase de especificação.

O último importante elemento é o Interaction, no qual estarão todas as ações que devem ser realizadas para cada interação definida para um perfil. Essas interações são descritas segundo a Tabela 15 e na Figura 41 são mostrados os elementos de interação.

Tabela 15 - Sub-eiementos de interaçāo

\begin{tabular}{ll}
\hline Nome & Definição \\
\hline InteractionType & $\begin{array}{l}\text { É um complexType, que possui a sequência de interações dadas } \\
\text { pelo elemento IT. }\end{array}$ \\
\hline IT & É o elemento necessário a cada interação. É do tipo ITType \\
\hline ITType & $\begin{array}{l}\text { É um complexType que descreve o que deve ser feito quando } \\
\text { uma ação é realizada }\end{array}$ \\
\hline on & $\begin{array}{l}\text { É um atributo que indica que tipo de interação foi feita (click, } \\
\text { move, double-click ...) }\end{array}$ \\
\hline media & É um atributo que indica a mídia com a qual ocorreu a interação \\
\hline button & $\begin{array}{l}\text { É um atributo que indica o botão (de um controle remoto) com o } \\
\text { qual ocorreu a interação }\end{array}$ \\
\hline action & É a ação que deve ocorrer (função que será chamada) \\
\hline
\end{tabular}




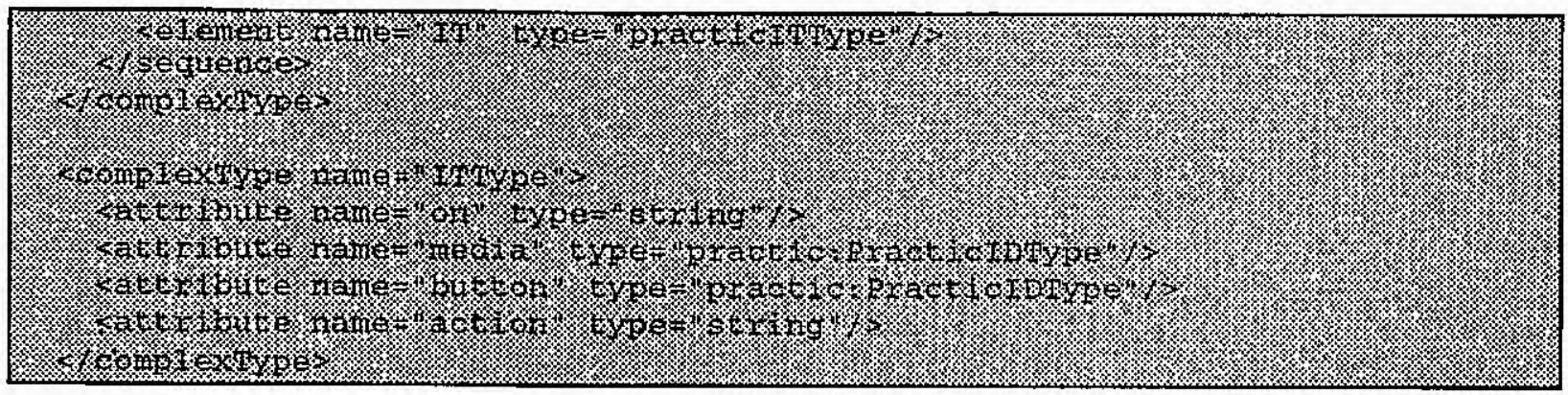

Figura 41 - Exemplo do Schema para os elementos de interação

No exemplo da Figura 42, o atributo move é uma descrição MPEG-7, o atributo video3 foi apresentado no programa e descrito em MPEG-7 e a ação moveMedia(video3) representa um comando que será dado à URD para realizar a tarefa. É importante notar que esse comando depende do Sistema Operacional presente na URD e das aplicaçōes que estão presentes no mesmo, tais como MHP ou JavaTV [Sun2000].

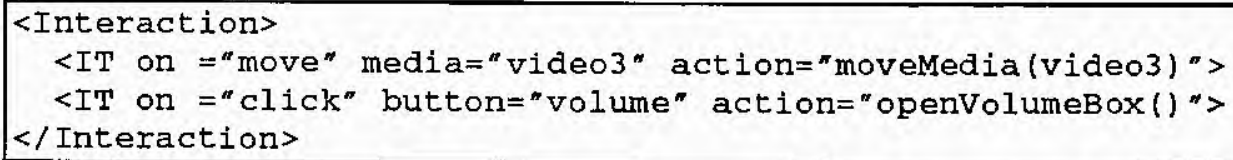

Figura 42 - Exemplo do uso dos elementos de interação

Além desses, existe mais um elemento que segue a sintaxe dos perfis, denominado Userpreferences. O elemento UserPreferences, diferentemente dos outros elementos, fica armazenado na URD; nele estão armazenadas algumas personalizações feitas pelos usuários para um determinado perfil, de um determinado programa. Os elementos de personalização do usuário são descritos na Tabela 16, o Schema é apresentado na Figura 43 e um exemplo de uso desses elementos é apresentado na Figura 44.

Tabela 16 - Elementos de personalizaçăo do usuário

\begin{tabular}{ll}
\hline Nome & Definição \\
\hline UserPreferences & $\begin{array}{l}\text { É um elemento que armazenará as personalizações dos } \\
\text { perfis e programas }\end{array}$ \\
\hline UserPreferencesType & $\begin{array}{l}\text { É um complexType onde serão armazenadas todas as } \\
\text { personalizaçōes de perfis, de programas e de hábitos para } \\
\text { assistir televisão }\end{array}$ \\
\hline user & $\begin{array}{l}\text { É um atributo com o nome do usuário. É um tipo de dado } \\
\text { mpeg7:UserIdentifierType }\end{array}$ \\
\hline Profile & $\begin{array}{l}\text { É elemento que conterá as mudanças no perfil. É do tipo } \\
\text { ProfileType }\end{array}$ \\
\hline Custompreferences & $\begin{array}{l}\text { É um elemento que informa outras personalizações não } \\
\text { relativas somente a um programa ou perfil, e sim }\end{array}$ \\
\hline
\end{tabular}


relacionadas a situações ou, então, personalizações válidas para todos os perfis e/ou programas.

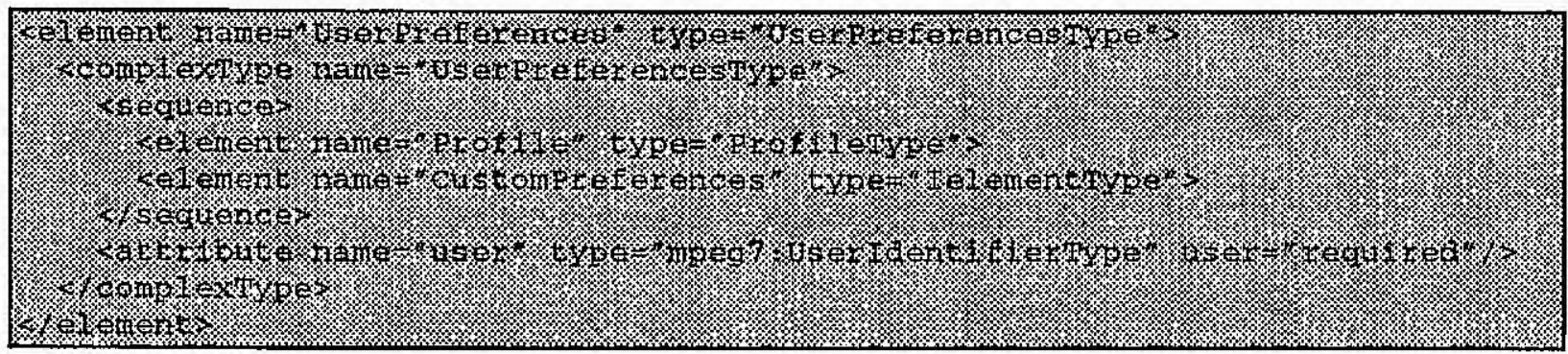

Figura 43 - Exemplo de Schema para os elementos de preferências do usuário

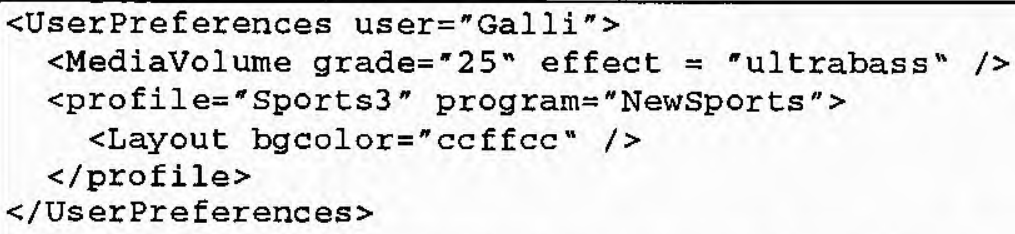

Figura 44 - Exemplo do uso dos elementos de preferênclas do usuário

Com os elementos apresentados e utilizando as descrições do MPEG-7 [ISO2001g] e do TV-Anytime Forum [TVA2001b; TVA2001c], pode-se especificar um amplo conjunto de características singulares, além de personalizações para os perfis e programas.

\subsubsection{Utilização dos perfis em um programa de TV Interativa}

A utilização de perfis permite, inicialmente, uma melhor adequação de um determinado programa ao seu espectador. Esse conceito pode ser utilizado em ambientes com ou sem a presença de consciência de contexto. A Figura 45 apresenta um diagrama de seqüência, em sintaxe gráfica baseada em UML [Boo1996], que mostra o funcionamento básico da ação dos perfis para a apresentação de um programa em um ambiente não consciente de contexto.

Observando-se a Figura 45, percebe-se que a seqüência de eventos tem início quando o usuário decide qual programa irá assistir; escolhido o programa, a URD requisita à emissora quais são os perfis possíveis e permitidos para aquele usuário; a emissora, então, retorna esses perfis para a URD, que apresenta as opções para o usuário; o usuário 
escolhe o perfil e suas modificações, e então o URD faz a requisição, junto à emissora, dos streams de vídeo, áudio, dos metadados e do stream de controle da cena; por fim, a emissora enviará o programa e o perfil desejados para o usuário.

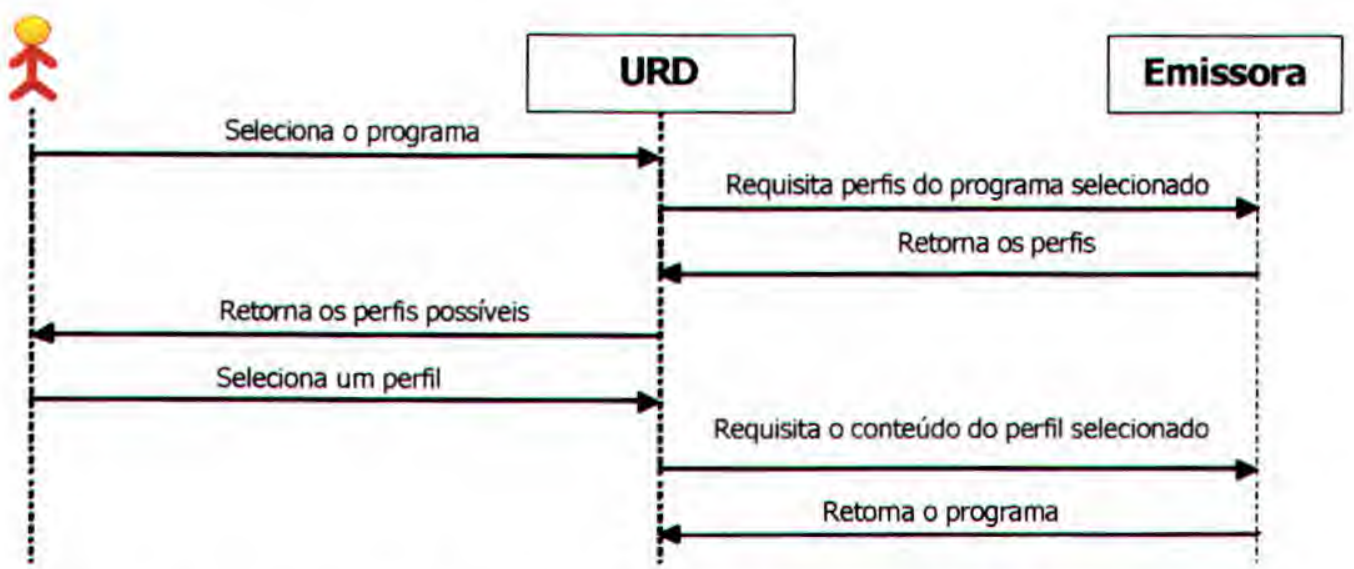

Figura 45 - Diagrama de seqüência UML para as entidades de um programa de TV-I

A outra utilização do conceito de perfis é em um ambiente consciente de contexto. Nesse tipo de ambiente, agentes fornecem à URD as informações que podem ser relevantes ao perfil, conforme descrito na Seção 4.1. A URD, por sua vez, utiliza essas informações, descritas no elemento context, para a adaptação do perfil de programa. A Figura 46 apresenta um diagrama de colaboração de um exemplo do uso desse conceito.

A seqüência apresentada na Figura 46 inicia-se com o usuário ligando o terminal e escolhendo um programa (1); em seguida, o terminal fará, simultaneamente, a captura de informação sobre o ambiente, começando por informações sobre os dispositivos ligados e suas propriedades (2.1), seguindo com a captura das informações dadas pelos sensores (2.2) e as informações contextuais, como dia, horário e eventos relacionados (2.3). Depois disso, com as informações capturadas, o terminal recebe o perfil do programa adequado para aquele contexto (3). Então, as informações são passadas para a aplicação de TV Interativa, que configurará o programa de TV-I para ser recebido (4). Em seguida, as descrições do programa são recebidas (5), seguidas pelo estado atual da rede (6); então, serão definidas as melhores características para a transmissão do programa na rede (7) e o estado do servidor é recebido. Finalizando, a aplicação envia o 
programa para o terminal apresentar. Existem ainda os agentes de eventos, que têm a função de capturar eventos durante a transmissão e que podem mudar algumas características do programa (10).

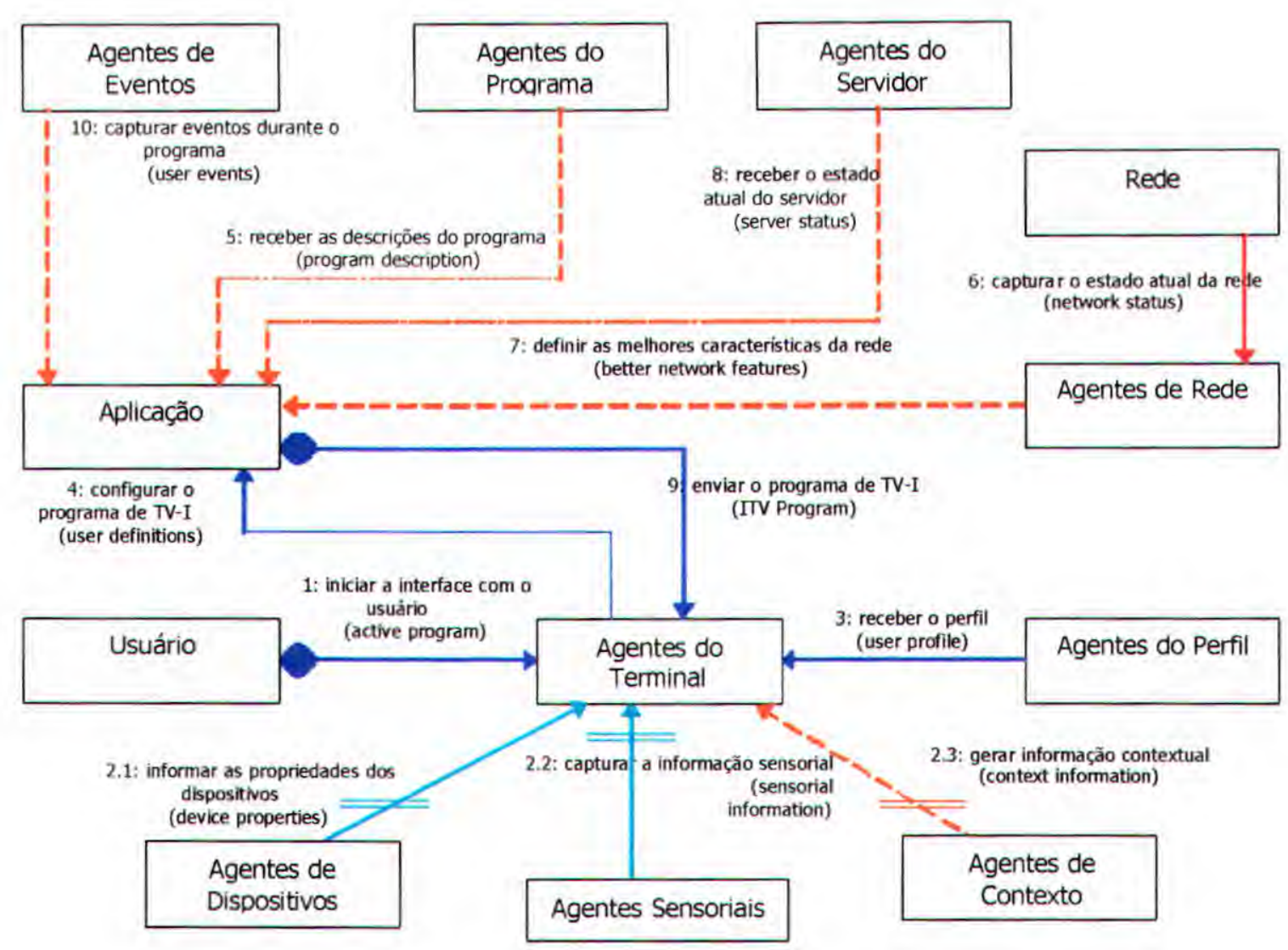

Figura 46 - Diagrama de Seqüência UML para uma aplicação de TV-I consciente de contexto baseada em agentes

Na seção 4.5.4 será apresentado um exemplo de programa interativo com o uso de perfis.

\subsubsection{Exemplos de programas de TV Interativa}

A linguagem visual para a TV Interativa terá características da linguagem já utilizada nos programas da televisão tradicional, da utilizada nos PDRs, e da presente em sites da WWW. Com isso, os programas adaptar-se-ão às novas funcionalidades disponíveis. A 
seguir, serão apresentados alguns exemplos de programas da TV e algumas mudanças que serão possíveis.

Em um evento, como um jogo de futebol, vôlei ou basquete, na parte visual, a presença de múltiplas câmeras fornecendo vários ângulos da partida; na parte de áudio, a escolha da narração entre os vários narradores disponibilizados pela emissora do programa, ou o áudio original, se o programa for estrangeiro; na parte de dados relacionados, links para dados dos jogadores, dos times, das partidas e dos campeonatos, sendo que alguns links apareceriam em determinados momentos, como após um gol em uma partida de futebol, links para replay, dados do jogador e da partida, entre outros. Alguns desses exemplos já estāo disponíveis na Enhanced TV, porém, de uma forma diferente e muito limitada.

No caso dos filmes, as possíveis mudanças seriam múltiplos ângulos, cenas alternativas e dados relacionados ao filme e aos atores. Esse tipo de interação já é possível e, em alguns casos, comum, nos DVDs. Comandos como retroceder e avançar um filme, comuns nos PDRs, também poderiam ser disponibilizados pela emissora. Como complemento, as produtoras de filmes poderiam fazer um novo tipo de merchandising criando links aos seus produtos à medida que eles aparecem na tela, ou, então, mudando os produtos de acordo com as características do usuário.

Telejornais poderiam ter diversas "caras", privilegiando imagens, privilegiando notícias relacionadas, programas relacionados ou links na WWW relacionados com cada notícia. Cada notícia também poderia ter uma versão expandida com maior duração que aquela mostrada no telejornal. O usuário também poderia limitar seu telejornal a alguns assuntos de seu interesse.

Outro tipo de programa tradicional que poderia mudar são os programas infantis, que poderiam incentivar a interação das crianças para a resposta de perguntas ou oferecerem mais informaçōes sobre objetos na tela, tornando-se, assim, educativos. Já existem programas infantis para a Enhanced TV em transmissão nos EUA. 
Um programa educativo poderia utilizar as técnicas, já bastante estudadas, da educação por computador à distância e adaptá-las para a tela de TV e para os diferentes controles da TV Interativa. A TV pode ser uma interface mais interessante e acessível às pessoas do que um computador.

Programas de Home Shopping com certeza poderão sofrer uma melhora significativa de qualidade e eficiência com a interação, uma vez que será mais fácil para o consumidor obter informações sobre o produto e comprá-lo. Além disso, será possível personalizar o canal de Home Shopping, de modo a oferecer produtos atraentes, segundo o perfil do usuário. Os programas de Home Shopping podem ser adaptados para serem chamados a partir do link nos produtos em filmes, comerciais, notícias e outros programas de TV.

Jogos Interativos também são uma parte motivadora da TV Interativa; os novos aparelhos, como o Xbox, PlayStation 2 e o Game Cube, já têm características para jogos em redes e seus fabricantes pensam em adaptá-los para a TV Interativa. Gameshows são outros programas que podem ter um ganho bastante grande com a possibilidade de interação. Já existem programas interativos nos quais o usuário pode responder às perguntas ao mesmo tempo em que o participante do programa real e, no final do mês, o telespectador que mais acumular pontos ganha prêmios. Esses programas se utilizam dos recursos da Enhanced Television e, para a interação (que é bastante limitada), utilizam a linha telefônica. Com a TV Interativa com um canal dedicado, muitas outras características podem surgir, como a formação de equipes para competir, auxílio da rede para o participante, entre outras.

A propaganda para a TV Interativa deve ter um novo paradigma, uma vez que diversas novas variáveis serão introduzidas, como a propaganda direcionada (só alguns recebem a propaganda), a propaganda adaptável (dependendo de quem está assistindo, a propaganda é diferente) e a possibilidade de interação com o produto, e mesmo compra via TV. 


\subsubsection{Aplicação dos conceitos de Programa e de Perfil a um programa de evento esportivo}

Nesta seção, é apresentada uma proposta para um programa esportivo que tenha como conteúdo uma partida de futebol, que representa a aplicação dos conceitos de perfis em um programa de televisão interativa. A situação proposta para esse programa permite visualizar as possibilidades que 0 uso de perfis pode acrescentar aos aspectos de interação do usuário em TV-I, evidenciando que tanto o usuário quanto a própria aplicação interagem com a infra-estrutura descrita na seção 4.2 .

Na exibição de um evento esportivo em TV-I, algumas características são esperadas no contexto da interação do usuário, dentre as quais pode-se destacar: a) oferta de diferentes ângulos de câmeras; b) oferta de várias opções de áudio, tais como diferentes locutores e idiomas; c) acesso a informações estatísticas dos times que estão jogando, do próprio jogo e dos jogadores; d) oferta de situações de replay, além do convencional; e) oferta de informaçōes sobre assuntos relacionados, como outros jogos simultâneos, por exemplo; f) acesso a informações sobre o programa (sumário) e a programação; g) oferta de programas relacionados, como jogos do mesmo time na programação do mês, por exemplo.

Em termos de construção da aplicação, essas características devem ser implementadas e descritas segundo os elementos do programa e do perfil apresentados na Seção 4.5. Cada perfil pode possuir características únicas que devem ser especificadas. Nesse ponto, alguns exemplos de variáveis de um perfil podem ser como os seguintes:

- layout: aspectos de cor de fundo e das imagens/figuras; estilo dos botões, estilo de menu, posição do menu, posição das mídias na interface do usuário (quando possível), quais mídias devem ser apresentadas, quais mídias podem ter suas posições mudadas e quais podem ser as posiçōes finais;

- comunication: quais são os codecs necessários para cada mídia, bem como as taxas de largura de banda necessárias para cada mídia; 
- context: quais são os comandos de decisão que utilizam as variáveis de contexto, tais como quem está usando, qual o horário de uso, quais outros aparelhos estão ligados e/ou conectados, o que já foi visto até um determinado momento;

- interaction: quais são as mudanças em relação às mídias e ao layout, por exemplo, a partir da interação do usuário com determinados grupos de botões/controles/menus associados a essas mídias e layout.

Vale ressaltar que a definição de uma instância de um programa, como é o caso de um evento esportivo, não limita a aplicação do conceito de perfis em TV-I. Deve-se observar que tanto a infra-estrutura como os perfis podem ser aplicados, por exemplo, em ambientes interativos diferentes da TV-I, como é o caso da videoconferência em um ambiente de ensino-aprendizagem.

\section{Definindo o Programa}

Os componentes do programa de evento esportivo são apresentados na Tabela 17.

Tabela 17 - Componentes do programa

\begin{tabular}{ll}
\hline Objeto & Descrição \\
\hline Video_Principal & $\begin{array}{l}\text { E o stream de vídeo principal da transmissão, semelhante à } \\
\text { transmissão atual de jogos de futebol. Composto por imagens } \\
\text { de diversas câmeras }\end{array}$ \\
\hline Video_Topo & $\begin{array}{l}\text { É o stream de vídeo das imagens da câmera que fica acima do } \\
\text { estádio, em um dirigível }\end{array}$ \\
\hline Video_Gol_esq & $\begin{array}{l}\text { É o stream de vídeo da imagem do gol da esquerda. São } \\
\text { utilizadas mais de uma câmera para esse stream de vídeo: uma } \\
\text { atrás da trave, uma acima da trave e uma lateralmente (para } \\
\text { escanteios e impedimentos) }\end{array}$ \\
\hline Video_Gol_dir & $\begin{array}{l}\text { É o stream de vídeo da imagem por trás da trave do gol da } \\
\text { direita. Assim como o vídeo anterior, esse é composto por } \\
\text { imagens de mais de uma câmera }\end{array}$ \\
\hline Video_Amplo & $\begin{array}{l}\text { Apresenta a imagem do jogo de longe e é útil para examinar a } \\
\text { tática do jogo }\end{array}$ \\
\hline Video_Zoom & $\begin{array}{l}\text { Apresenta a imagem do jogo de perto, focalizando jogadores e } \\
\text { jogadas }\end{array}$ \\
\hline Audio_Principal & Canal de áudio principal com locução e comentários \\
\hline Audio_Locucao2 & Canal de áudio do locutor alternativo
\end{tabular}




\begin{tabular}{ll}
\hline Audio_Banco_esq & $\begin{array}{l}\text { Canal de áudio com o som do banco de reservas do lado } \\
\text { esquerdo }\end{array}$ \\
\hline Audio_Banco_dir & Canal de áudio com o som do banco de reservas do lado direito \\
\hline Audio_Ambiente & Canal de áudio com o som ambiente da partida, sem locução \\
\hline estatistica_time1 & Dados e links referentes ao time 1 \\
\hline estatistica_time2 & Dados e links referentes ao time 2 \\
\hline estatistica_jogo & Estatísticas do jogo \\
\hline Campeonato & Informações online de outros jogos do campeonato \\
\hline
\end{tabular}

\section{Descrevendo o Programa}

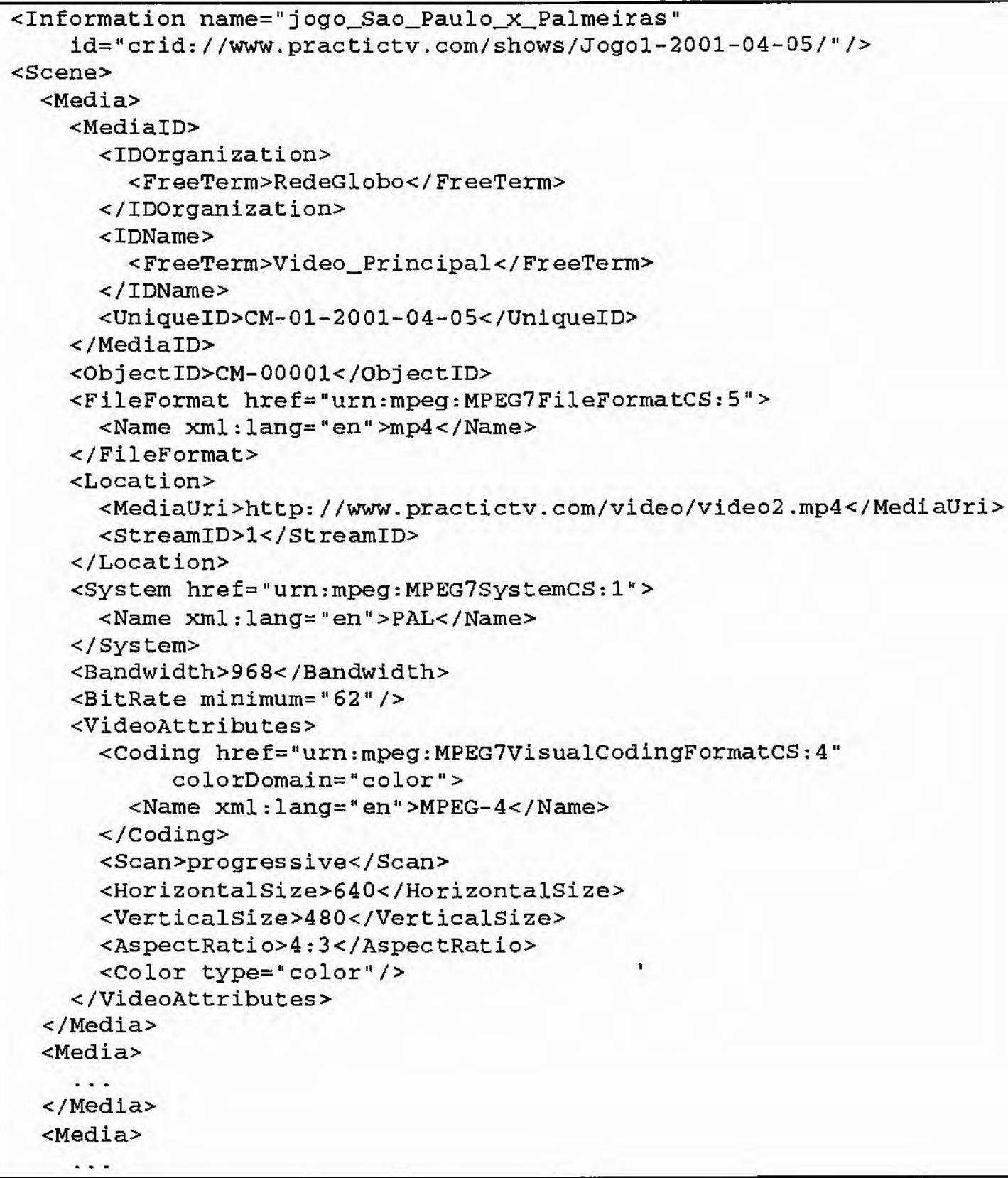


$</$ Media $>$

$<$ Media $>$

...

$</$ Media $>$

‥

$<$ Timeline>

$<$ Tobject ID $=" \mathrm{CM}-01-2001-04-05^{\prime \prime}>$

$<$ MediaTime>

<MediaTimePoint>T00:00:00:00:0F0</MediaTimePoint>

$<$ MediaDuration $>$ T3H3 OM</MediaDuration>

$</$ Mediatime $>$

<SceneTimePoint>2001-04-05T18:00:00:0F0</SceneTimePoint>

$</$ Tobject $>$

$<$ Tobject ID ="CM-02-2001-04-05"> ...

$</$ Tobject $>$

$\langle$ Tobject ID $=" \mathrm{CM}-03-2001-04-05 ">$ ...

$</$ Tobject $>$

$<$ Tobject ID $=" \mathrm{CM}-04-2001-04-05^{\prime \prime}>$ …

$</$ Tobject $>$

$<$ Tobject ID $=$ "CM-05-2001-04-05">

...

$</$ Tobject $>$

$<$ Tobject ID $="$ CM-06-2001-04-05">

...

$<$ / Tobject $>$

$<$ Tobject ID $=" \mathrm{AU}-01-2001-04-0$ " $^{\prime}>$

...

$</$ Tobject $>$

$<$ Tobject ID $=" \mathrm{AU}-02-2001-04-05 ">$

...

$</$ Tobject $>$

$<$ Tobject ID $=" \mathrm{AU}-03-2001-04-05^{\prime \prime}>$ ...

$</$ Tobject $>$

$<$ Tobject ID="AU-04-2001-04-05"> ...

$</$ Tobject $>$

$<$ Tobject ID $=$ "AU-05-2001-04-05">

...

$</$ Tobject $>$

$</ T$ imeline $>$

$<$ Ielement $>$

..

$</$ Ielement $>$

$<$ Description $>$

...

$</$ Description $>$

$</$ Scene $>$

$<$ Summary $>$

$<$ / Summary $>$

$<$ Schedule $>$

…

$<$ /Schedule

$<$ / Program $>$

Figura 47 - Exemplo da descrlção de um programa de evento esportivo 


\section{Descrevendo os Perfis}

A partir do conteúdo disponibilizado pelo programa, foram definidos três perfis para o programa de evento esportivo. O primeiro perfil seria o perfil básico, bastante semelhante à transmissão atual, com pequena possibilidade de interação. $O$ segundo perfil seria um perfil com pequena possibilidade de interação e troca de imagens e sons, porém, com grande ênfase ao acesso às informações relacionadas ao evento. O terceiro perfil seria o mais completo, com total possibilidade de interação por parte do usuário $e$ com muitas opções de imagens e de sons.

A seguir é apresentada a implementação do primeiro perfil.

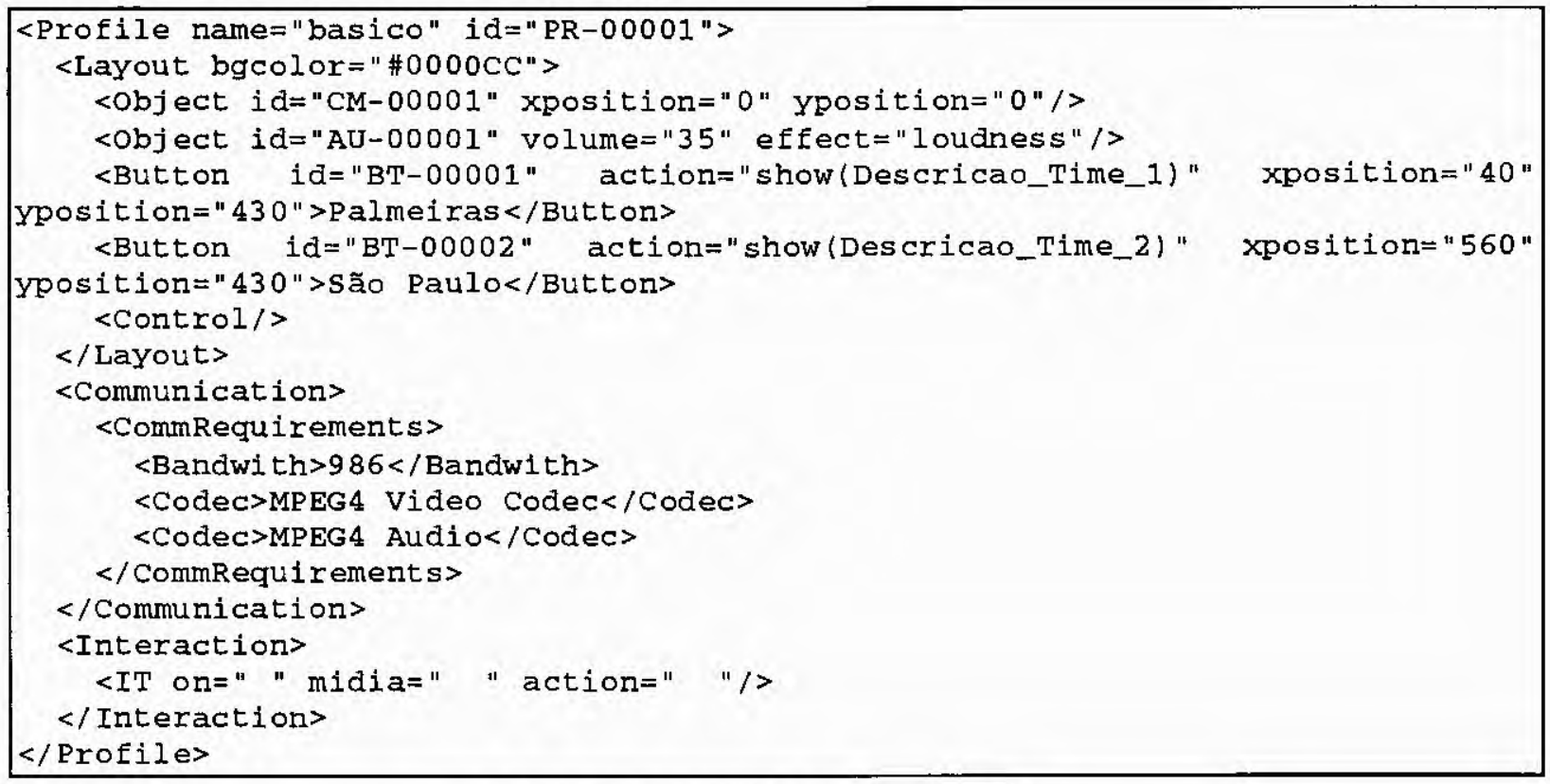

Figura 48 - Exemplo do perfil básico

A seguir será apresentado o segundo perfil, que possui diversas características de interação, principalmente com conteúdo relacionado.

$<$ Profile name="intermediario" id="PR-00002"

programid="crid://WWW - practictv.com/shows/Jogo1-2001-04-05/"

xmlns = "http: / / chapinha.intermidia.icmc.sc.usp.br/SCOTIMM/PRACTIC/PRACTICs.xsd

" xmlns: xml= "http: //www .w3 .org/2000/10/xml. xsd">

<Layout bgcolor ="\#0000CC">

<Object id="CM-00001" xposition="0" yposition="0"/>

$<$ Menu type="Popup" position="down" color $=0000 \mathrm{CC} ">$ 


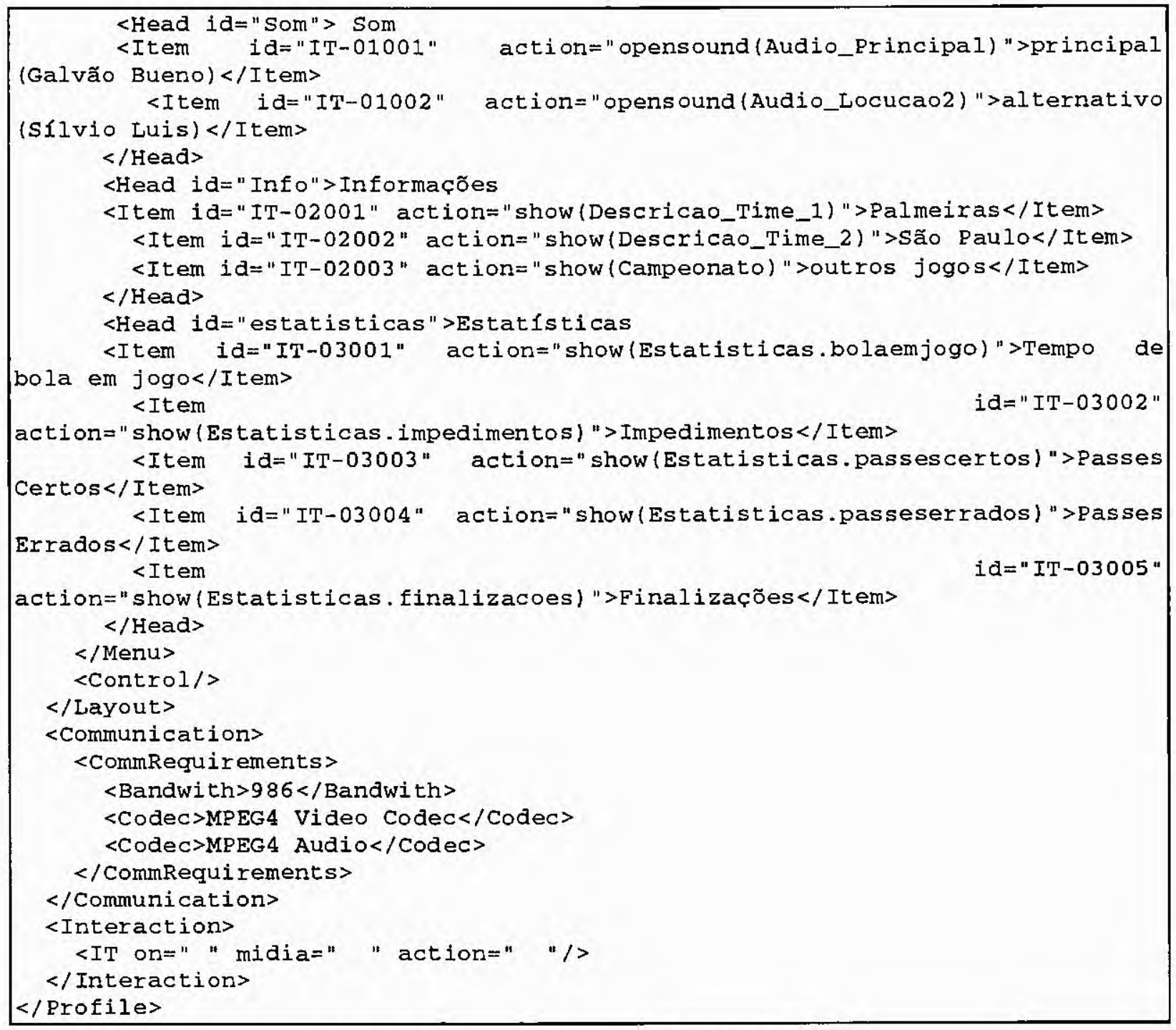

Figura 49 - Exemplo do perfil intermediário

O terceiro perfil é o avançado, que possui como característica uma grande diversidade de imagens e sons.

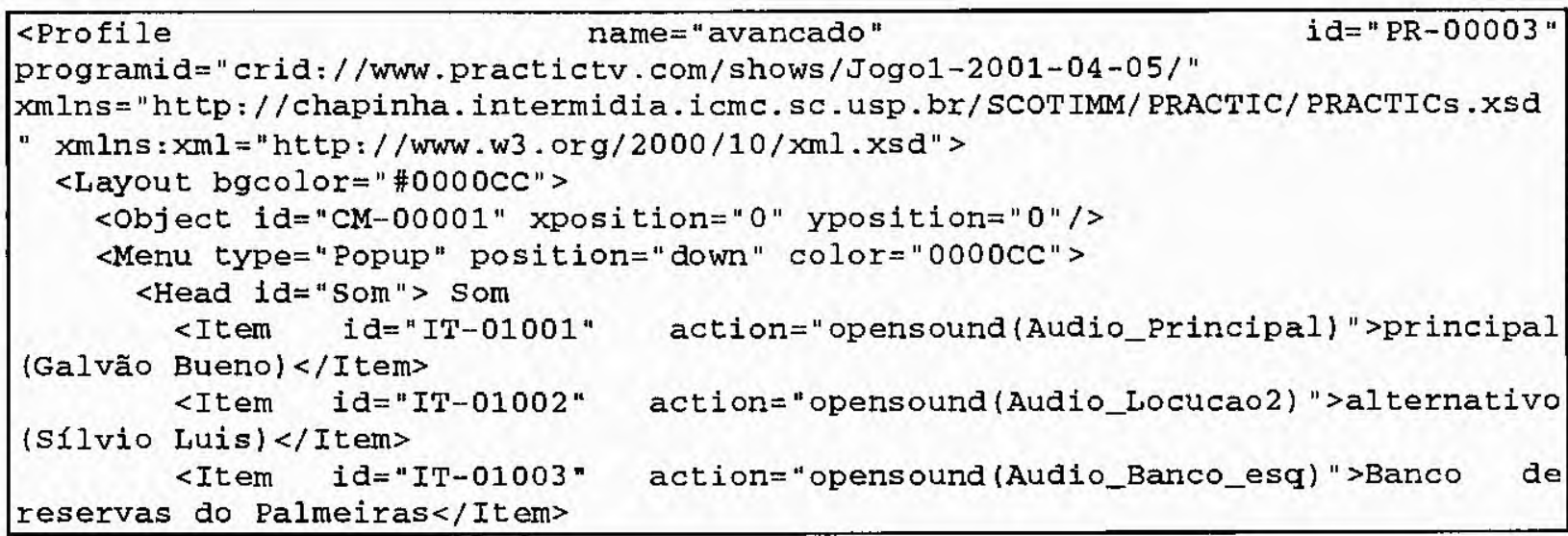




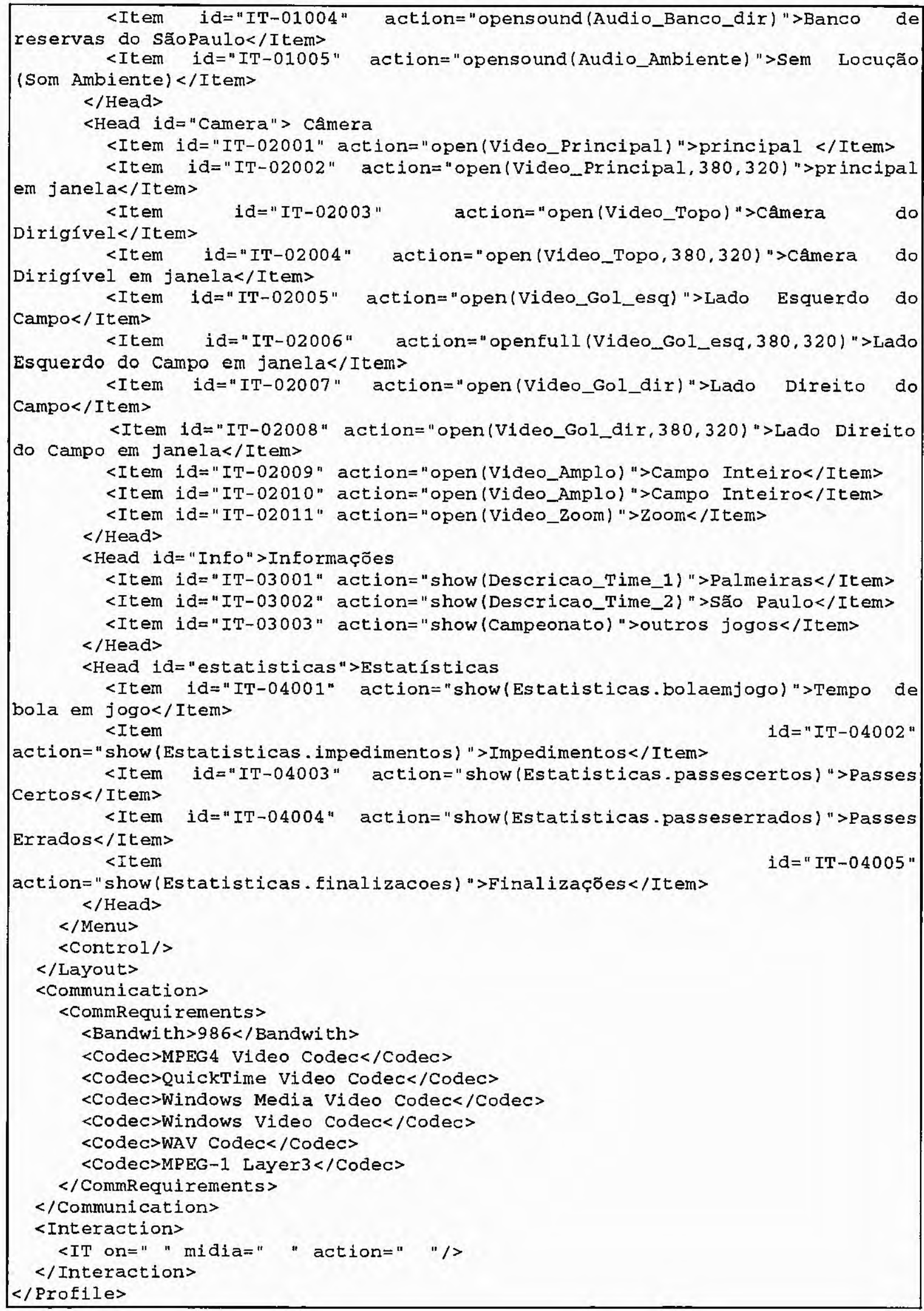


Figura 50 - Exemplo do perfil avançado

No terceiro exemplo, podemos observar a utilização dos elementos de contexto que não foram utilizados nos outros dois perfis. A utilização desses elementos não é obrigatória e, apesar de no exemplo terem sido usados para persuadir os usuários a comprarem produtos, esses elementos podem ser utilizados de modo a melhorar a interação do usuário com a televisão.

Observando os três exemplos percebemos que, utilizando os conceitos de programa e perfil, é possível o reaproveitamento de conteúdo para a apresentação de diferentes programas, de um modo relativamente fácil. Esses conceitos também são úteis na personalização da TV e permitem a utilização de consciência de contexto nesse ambiente. 


\section{Conclusões e Trabalhos Futuros}

A TV Interativa é uma aplicação atual que permite novos modos de interação com o usuário. Devido ao grande interesse das indústrias de computação e entretenimento, diversos esforços estão sendo feitos para a sua padronização. Porém, nenhum desses esforços prevê o uso de consciência de contexto como forma de melhorar a interação. Os atuais modelos de TV-I não prevêem a comunicação da TV com outros equipamentos eletrônicos, com exceção de URDs e servidores de vídeo. Este trabalho tem como base a TV inserida em um ambiente no qual é possível a comunicação com outros aparelhos eletrônicos e, com isso, a utilização de consciência de contexto.

Este trabalho introduz um novo conceito para a criação de programas para a TV Interativa que permite uma melhor adequação dos programas aos interesses e necessidades do usuário. Uma das características desse conceito é a divisão do programa em conteúdo multimidia e apresentação, permitindo diferentes apresentações para um mesmo conteúdo. Esse conceito também permite a adaptação dinâmica do programa às diferentes situações que ocorrem durante a apresentação do mesmo.

\subsection{Contribuições}

Este trabalho tem como contribuição principal um novo conceito para a modelagem de TV Interativa, permitindo uma personalizaçāo diferente que pode fazer uso de técnicas de consciência de contexto. Os conceitos de perfil e de programa, desenvolvidos neste trabalho, são compatíveis e se utilizam das tecnologias desenvolvidas para a TV Interativa, como o MPEG-4 e o MPEG-7, e as estende, de modo a possibilitar o uso integrado da TV com o ambiente.

Este trabalho também apresenta os requisitos necessários para a produção e distribuição de um programa de TV-I, de modo a permitir todas as funcionalidades projetadas. 
Como última contribuição, este trabalho auxiliou na definição de requisitos e funcionalidades de outros projetos em desenvolvimento no grupo InterMídia, como a implementação de um programa de TV-I utilizando ferramentas de edição de MPEG-4, a definição e implementação de uma infra-estrutura de redes ativas para a distribuição dos programas e a modelagem, para a TV-Interativa, do comportamento dos agentes móveis em um ambiente consciente de contexto.

\subsection{Trabalhos Futuros}

Pelo fato da TV Interativa ser bastante ampla, diversas outras áreas podem, a partir dos estudos e modelagens realizados neste trabalho, desenvolver novas pesquisas, entre elas:

Banco de Dados - estruturação de um modelo de banco de dados multimídia com suporte às tecnologias de TV-I, tais como: MPEG-4, MPEG-7, MHP e as especificações do TV-Anytime Forum.

Consciência de Contexto - implementação de um programa que integre o protótipo de TV-I, que utiliza os conceitos desenvolvidos neste trabalho, com um ambiente consciente de contexto.

Hipermídia - existem diversos trabalhos possíveis, que vão desde a implementação de EPGs à criação de programas interativos, incluindo ferramentes de busca em vídeos que utilizam MPEG-7 ou XML.

Inteligência Artificial - criação de aplicações que recomendam programas ao usuário, de acordo com suas preferências e comportamento.

Interação Usuário Computador - extensão do Schema, de modo a suportar outros elementos de layout como novos tipos de menu e comparação do comportamento do 
usuário em um programa de TV-I em relação ao seu comportamento num site na Web e assistindo a um programa da TV tradicional.

Redes de Computadores - definição e implementação de uma infra-estrutura com suporte a redes ativas ou que utilize multicasting. 


\section{Referências Bibliográficas}

[ABE2000] ABERT. Testes em Sistemas de Televisäo Digital (Fevereiro de 2000) - [On Line]http://www.anatel.gov.br/biblioteca/publicacao/relatorio_tvdigital_cp216. tm.

[ABE2001] ABERT. Comentários à consulta pública 291/2001 - Televisäo Digital (Junho de 2001) - [On Line] -

http://www.anatel.gov.br/eventos_publicos/Consulta/2001/consulta_291, oment_291.htm

[Abo1999] ABOWD, G. D.; Software Engineering Issues for Ubiquitous Computing; International Conference on Software Engineering (ICSE'99); pp. 75-84; 1999.

[ANA2001a] AGENCIA NACIONAL DE TELECOMUNICAÇŌES (ANATEL) - Relatório Integrador dos Aspectos Técnicos e Mercadológicos da TV Digital - versão 1.0 - (28/03/2001)[On Line] -

http://www.anatel.gov.br/eventos_publicos/Consulta/2001/consulta_291، Relatorio_Integrador.exe

[ANA2001b] AGÊNCIA NACIONAL DE TELECOMUNICAÇŌES (ANATEL) - Relatório Integrador dos Aspectos Técnicos e Mercadológicos da TV Digital - versão 1.0 - (28/03/2001)Apêndices- [On Line] -

http://www.anatel.gov.br/eventos_publicos/Consulta/2001/consulta_291, Apendices.exe

[ARI1998] ASSOCIATION OF RADIO INDUSTRIES AND BUSINESSES (ARIB) - Terrestrial Integrated Services Digital Broadcast - ISDB-T: Specification of Channel Coding, Framing Structure and Modulation(ISDB-T) - (1998) - [On Line] http://www.dibeg.org/Documents/Isdb-t_spec.PDF

[ARI1999] ASSOCIATION OF RADIO INDUSTRIES AND BUSINESSES (ARIB). - Overview of BXML/BML draft specification developed by ARIB - (Outubro de 1999) - [On Line] - http://lists.w3.org/Archives/Public/www-tv/1999OctDec/att-0031/02BML-BXML-Abst3.doc

[ARI2000] ASSOCIATION OF RADIO INDUSTRIES AND BUSINESSES (ARIB). - ITU Document $6 \mathrm{M} / \mathrm{J} 2-\mathrm{E}$ - Operational Guidelines of ARIB's XML-based Multimedia Coding Scheme(Ver.1.2) - (Setembro de 2000) - [On Line] http://www.itu.int/itudoc/itu-r/sg6/docs/wp6m/200003/contrib/009e.html

[ATS1995] AdVANCED TELEVISION SYSTEMS I - Digital Audio Compression Standard (AC-3)(A/52) (Dezembro de 1995) - [On Line] http://www.atsc.org/Standards/A52/A_52A.pdf

[ATS2001] ADVANCED TELEVISION SYSTEMS I - ATSC Digital Television Standard (Revision A) - (A/53) (Abril de 2001) - [On Line] http://www.atsc.org/Standards/A53/a_52.pdf 
[ATV2000] ADVANCED TELEVISION ENHANCEMENT FORUM - Enhanced Content Specification (2000) - [On Line] - http://www.atvef.com/library/spec1_1a.html

[Bac1998] BACKER, G.; BENNINGTON, J.; BOltAX,J.; GAGE, K.; GARCIA, M.; RICHMOND, M.; VICKERS, M.; WATSON, S.; ZIGMOND, D. - A Framework for Interactive Television Based on Internet Standards - Apresentado no Workshop Television and the Web - (Julho de 1998) - [On Line] http://www.atvef.com/library/9806_framework.html

[Bat1999] BATTISTA, S.; CASALINO, F.; LANDE, C. MPEG-4: A Multimedia Standard for the Third Millennium, Part1 - IEEE Multimedia, págs 74-83 (Outubro-Dezembro 1999).

[Bar2001] BARbieri, M.; CeCCARELl, M.; MeKENKAMP, G.; NesVAdBA, J. - A Personal TV Receiver with Storage and Retrieval Capabilities - Proceedings of the 1 st Workshop on Personalization in Future TV. Sonthofen, Germany, (Julho de 2001).

http://www.di.unito.it/ liliana/UM01/barbieri.pdf

[Ber1994] BERnERS-LeE, T.; CAILliAU, R.; LuOTONEN, A.; HENRIK, N.;SECRET, A. - The World-Wide Web. Communications of the ACM, págs. 76-82 (Agosto 1994).

[Bla2000] BLACKKETTER, D. J. ET ALL - The Local Identifier lide) URI Scheme - [On Line] http:/ / ietf.org/internet-drafts/draft-blackketter-lid-00.txt

[Boo1996] BOOCH, G.; RUMBAUGH, J.; JACOBSON, I. - UML: Unified Modelling Language for Object-Oriented Development Documentation set. Addendum, Santa Clara, California, Rational Software Corp, July 1996.

[Bou1992] BouDEC, J-Y LE. - The Asynchronous Transfer Mode: a Tutorial - Computer Network and ISDN Systems, n. 24, pp. 279-309 (1992).

[Bra1998] BRAY, T.; PAOLI, J.; SPERBENG-MCQUEEN, C.M. - Extensible Markup Language (XML) 1.0 Specification (Fevereiro de 1998) - [On Line]

http://www.w3.org/TR/1998/REC-xml-19980210

[Dau2000] DAUBECHIES, I. Wavelets. Philadelphia: S.I.A.M.

[Dey2000] DEY, A. K.; ABOWD, G. D. - Towards a Better Understanding of Context and Context-Awareness; CHI 2000 - Workshop on The What, Who, Where, When, and How of Context-Awareness; 2000.

[DIG2001] Digital BRoADCAST EXPERTS GROuP(DiBEG). - Comentários à Consulta Pública No. 291/01- [On Line] -

http://www.anatel.gov.br/eventos_publicos/Consulta/2001/consulta_291, oment_291.htm

[DVB1999] DIGITAL VIDEO BROADCASTING (DVB) - ETSI EN 300 744, - Framing structure, channel coding and modulation for digital terrestrial television versäo1.2.1 (07/99) [On line] http://www.etsi.org/ 
[DVB2000] DiGITAL VIDEO BROADCASTING (DVB) - ETSI TS 101 812, - Multimedia Home Platform (MHP) Speci口cation 1.1 (Draft) [On Line] http://www.mhp.org/

[DVB2001] Digital Video BROADCASTiNg (DVB) - Comentários à Consulta Pública No. 291/01 (Junho de 2001) - [On Line] http://www.anatel.gov.br/eventos_publicos/Consulta/2001/consulta_291, oment_291.htm

[Ebr1999] EBRAHINI, T. ET AL. - MPEG-4 Natural Video Coding - An Overview. Image Communication - Tutorial Issue on MPEG-4 Standard, 1999

[Eva1999] EvaIN, J. P. - The Multimedia Home Platform - an overview - [On Line] www.dvb.org/resources/pdf/evain.pdf

[Fin2000] FINSETH, C.; THOMAS, G.- Guide to TV Broadcast URLs - [On Line] http://ietf.org/internet-drafts/draft-finseth-guide-01.txt

[Gou1998] GoularTE, R. - Utilização de Metadados no Gerenciamento de Acesso a Servidores de Vídeo (Fevereiro de 1998) - Dissertação de mestrado, ICMC/USP, São Carlos 1998.

[ISO1994] ISO/IEC 13818-3, Information Technology: Generic coding of Moving pictures and associated audio: Part 3 - Audio - (1994)

[ISO1997a] ISO/IEC IS 13818-MPEG-2: Generic coding of moving pictures and audio information- (1997)

[ISO1997b] ISO/IEC 13818-7 - Information Technology: Generic coding of Moving pictures and associated audio: Part 7 - Advanced Audio Coding (AAC) - (1997)

[ISO1998a] ISO/IEC JTC1/SC29/WG11 N2460-MPEG-7: Context and Objectives(version10 Atlantic City) - (Outubro de 1998).

[ISO1998b] ISO/IEC JTC1/SC29/WG11 N1902 - Generic Coding of Audio-Visual Objects: Part2 - Visual - (Novembro de 1998).

[ISO1999a] ISO/IEC JTC1/SC29/WG11 N2725 - MPEG-4 Overview - (Seoul Version) (Março de 1999).

[ISO1999b] ISO/MPEG N2739 ISO/IEC 14496-1/PDAM1 subpart 3 - MPEG 4 version 2 MPEG-J (Março de 1999)

[ISO1999c] ISO/IEC JTC1/SC29/WG11 N2724 - MPEG4 Applications (Março de 1999)

[ISO2000] ISO/IEC JTC1/SC29/WG11 N3537- New MPEG4 Profiles Under Consideration - (Julho de 2000).

[ISO2001a] ISO/MPEG N4030, MPEG-4 Overview (v.18 - singapure version): http://www.cselt.it/mpeg/standards/mpeg-4/mpeg-4.htm, [05/13/01] 
[ISO2001b] ISO/MPEG N4002, ISO/IEC FCD 15938-2 Information Technology-Multimidia Content Description Interface - Part 2 Description Definition Language, MPEG Systems Sub-Group, [15/01/2001]. http://www.cselt.it/mpeg/public/mpeg7_ddl_fcd.zip

[ISO2001c] ISO/MPEG N4031, Overview of the MPEG-7 Standard (version 5.0), MPEG Requirements Group, ISO, Singapure. (Março de 2001). http://www.cselt.it/mpeg/standards/mpeg-7/mpeg-7.htm.[5/13/01]

[ISO2001d] ISO/MPEG N4001, ISO/IEC FCD 15938-1 Information Technology-Multimidia Content Description Interface - Part 1 Systems, MPEG Systems Sub-Group, [Março de 2001]. http://www.cselt.it/mpeg/public/mpeg-7_systems_fcd.zip

[ISO2001e] ISO/MPEG N4062, ISO/IEC FCD 15938-3 Information Technology-Multimidia Content Description Interface - Part 3 Visual, MPEG Visual Group, [Março de 2001]. http://www.cselt.it/mpeg/public/mpeg-7_visual_fcd.zip

[ISO2001f] ISO/MPEG N4004, ISO/IEC FCD 15938-4 Information Technology-Multimidia Content Description Interface - Part 4 Audio, MPEG Audio Group, [Março de 2001]. http://www.cselt.it/mpeg/public/mpeg-7_audio_fed.zip

[ISO2001g] ISO/MPEG N3996, ISO/IEC FCD 15938-5 Information Technology-Multimidia Content Description Interface - Part 5 Multimidia Description Schemes, Multimidia Description Schemes (MDS) Group [Março de 2001]. http://www.cselt.it/mpeg/public/mpeg-7_mds_fcd.zip.

[ISO2001h] ISO/MPEG N4006, ISO/IEC FCD 15938-6 Information Technology-Multimidia Content Description Interface - Part 5 Reference Software, Implementation Studies Group [Março de 2001]. http://www.cseIt.it/mpeg/public/mpeg7_reference_software_fcd.zip.

[Kat1998] KATE, W.; RADHA, H. - Bringing the Wet to the TV: Convergence Scenarios (julho de 1998) - Apresentado no Workshop Television and the Web [On Line] - http://www.w3.org/Architecture/1998/06/Workshop/paper38/

[Ket1994] KETCHPEL, S.; GENESERETH, M. - Software Agents, Communications of the ACM (1994) págs 48-53

[Kur2001] KURAPATI, K.; GUTTA, S.;SCHAFFER, D.; MARTINO, J.; ZIMMERMAN, J. - A multiagent TV recommender - Proceedings of the 1 st Workshop on Personalization in Future TV. Sonthofen, Germany, (Julho de 2001).

http://www.di.unito.it/ liliana/UM01/kurapati.pdf

[Lie1999] LIE, H. W., BOs, B. - Cascading Style Sheets, level1 - [On Line] http://www.w3.org/TR/1999/REC-CSS1-19990111

[Mar2001] Martins, L. Transmissäo de Vídeo Usando IPv6 e Multicasting em Redes de Alto Desempenho. Dissertação de Mestrado, ICMC/USP, 2001. 
[MIC2000] MICROSOFT CORPORATION - Creating Interactive Links [On Line] http://developer.webtv.net/itv/links/main.htm

[Nac1999a] NACK, F.; LINDSAY, A. T.Everything You Wanted to Know About MPEG-7: Part 1 - IEEE Multimedia, págs 65-77 (julho-setembro 1999).

[Pas1999] PASCOE, J., RYAN, N., MORSE, D.: Issues in Developing Context-Aware Computing. In Gellersen, $\mathrm{H}$. (ed.): Handheld and Ubiquitous Computing. Lecture Notes in Computer Science, Vol. 1707. Springer-Verlag, Berlin Heindelberg New York (1999) 208-221.

[Rag1999] RAGGETT, D. LE HORS, A., JACOBS, I. - HTML4.01 Specification- (29 de Dezembro de 1999) [On Line] http://www.w3.org/TR/1999/REC-html40119991224

[Rod1998] RODRIGUES, P.; GAFSI, J.; NONNENMANCHER, J. - A More Attractive and Interactive TV - (Julho de 1998) - Apresentado no Workshop Television and the Web [On Line] -

http://www.w3.org/Architecture/1998/06/Workshop/paper08

[San2001] SANTOS JR., J.B., GOULARTE, R., FARIA, G. B., MOREIRA, E. S. - Modelling of User Interaction in Context - Aware Interactive Television Application on Distributed Environments. Proceedings of the 1 st Workshop on Personalization in Future TV. Sonthofen, Germany, (Julho de 2001).

http://www.icmc.sc.usp.br/ joao/futuretv/JRGEPaperUM2001.html.(2001)

[Sun2000] SUN MICROSYSTEMS. Java TV API 1.0 specification (November 2000) [On Line] http://java.sun.com/products/javatv/

[TVA2000a] TV ANYTIME FORUM. - Requirements Series:R1: The TV-Anytime Environment (Informative) - (Agosto de 2000) -[On Line] ftp://tva:tva@ftp.bbc.co.uk/pub/Plenary/TV035r6.zip

[TVA2000b] TV ANYTIME FORUM. - Requirements Series:R2 : The System Description (Informative)- (Abril de 2000) -[On Line] -

ftp://tva:tva@ftp.bbc.co.uk/pub/Plenary/TV036r2.zip

[TVA2000c] TV ANYTTME FORUM, - Requirements Series:R3 : Metadata Requirements (Normative) - (Abril de 2000) -[On Line] ftp://tva:tva@ftp.bbc.co.uk/pub/Plenary/TV037r3.zip

[TVA2000d] TV ANYTIME FORUM. - Requirements Series:R4: Content Referencing (Normative) - (Abril de 2000) -[On Line] ftp://tva:tva@ftp.bbc.co.uk/pub/Plenary/TV038r2.zip

[TVA2000e] TV ANYTIME FORUM. - Requirements Series:R5 : Rights Management (Normative)(Dezembro de 2000) -[On Line] ftp://tva:tva@ftp.bbc.co.uk/pub/Plenary/TV039r7

[TVA2001a] TV ANYTIME FORUM. - Specification Series:S1 on Phase 1 - Benchmark 
Applications (Informative)- (Fevereiro de 2001) -[On Line] ftp://tva:tva@ftp.bbc.co.uk/pub/Specifications/SP001v10.zip

[TVA2001b] TV ANYTIME FORUM. - Specification Series:S2 on System Description (Informative)- (Junho de 2001) -[On Line] -

ftp://tva:tva@ftp.bbc.co.uk/pub/Specifications/SP002v11.zip

[TVA2001c] TV ANYTIME FORUM. - Specification Series:S3 on Metadata (Normative)-(Abril de 2001) -[On Line] -

ftp://tva:tva@ftp.bbc.co.uk/pub/Specifications/SP003v10r1.zip

[TVA2001d] TV ANYTIME FORUM. - Specification Series:S4 : Content Referencing (Normative)(Abril de 2001) -[On Line] -

ftp://tva:tva@ftp.bbc.co.uk/pub/Specifications/SP004v11.zip

[Vic2000] VICKRES, M; ZIGMOND, D- Uniform Resource Identifiers for Television Broadcasts (21 de Fevereiro de 2000) - [On Line] -

http://ietf.org/internet-drafts/draft-zigmond-tv-url-04.txt

[W3C1998] W3C WORKING DRAFT - Synchronized Multimedia Integration Language (SMIL) 1.0 Specification (15 de Junho de 1998) - [On Line] http://www.w3.org/TR/1998/REC-smil-19980615

[W3C2000a] W3C WORKING DRAFT - Document Object Model (DOM) Level 1 Specification (Second Edition) Versão 1.0 (29 de Dezembro de 2000) - [On Line] http://www.w3.org/TR/2000/WD-DOM-Level-1-20000929

[W3C2000b] W3C WORKING DRAFT - Extensible Stylesheet Language (XSL) Version 1.0 (27 de Março de 2000) - [On Line] http://www.w3.org/TR/2000/WD-xsl-20000327/

[W3C2001a] W3C RECOMMENDATION - XML Schema Part 0: Primer (2 de Maio de 2001) [On Line] http://www.w3.org/TR/2001/REC-xmlschema-0-20010502/

[W3C2001b] W3C RECOMMENDATION - XML Schema Part 1: Structure (2 de Maio de 2001) [On Line] http://www.w3.org/TR/2001/REC-xmlschema-1-20010502/

[W3C2001c] W3C RECOMMENDATION - XML Schema Part 2: Data Types (2 de Maio de 2001) - [On Line] http://www.w3.org/TR/2001/REC-xmlschema-2-20010502/ 


\section{Schema de descrição para perfis e programas de TV Interativa PRATIC - Perfil (ou Perfis) para Aplicações de Televisão Interativa Conscientes de Contexto}

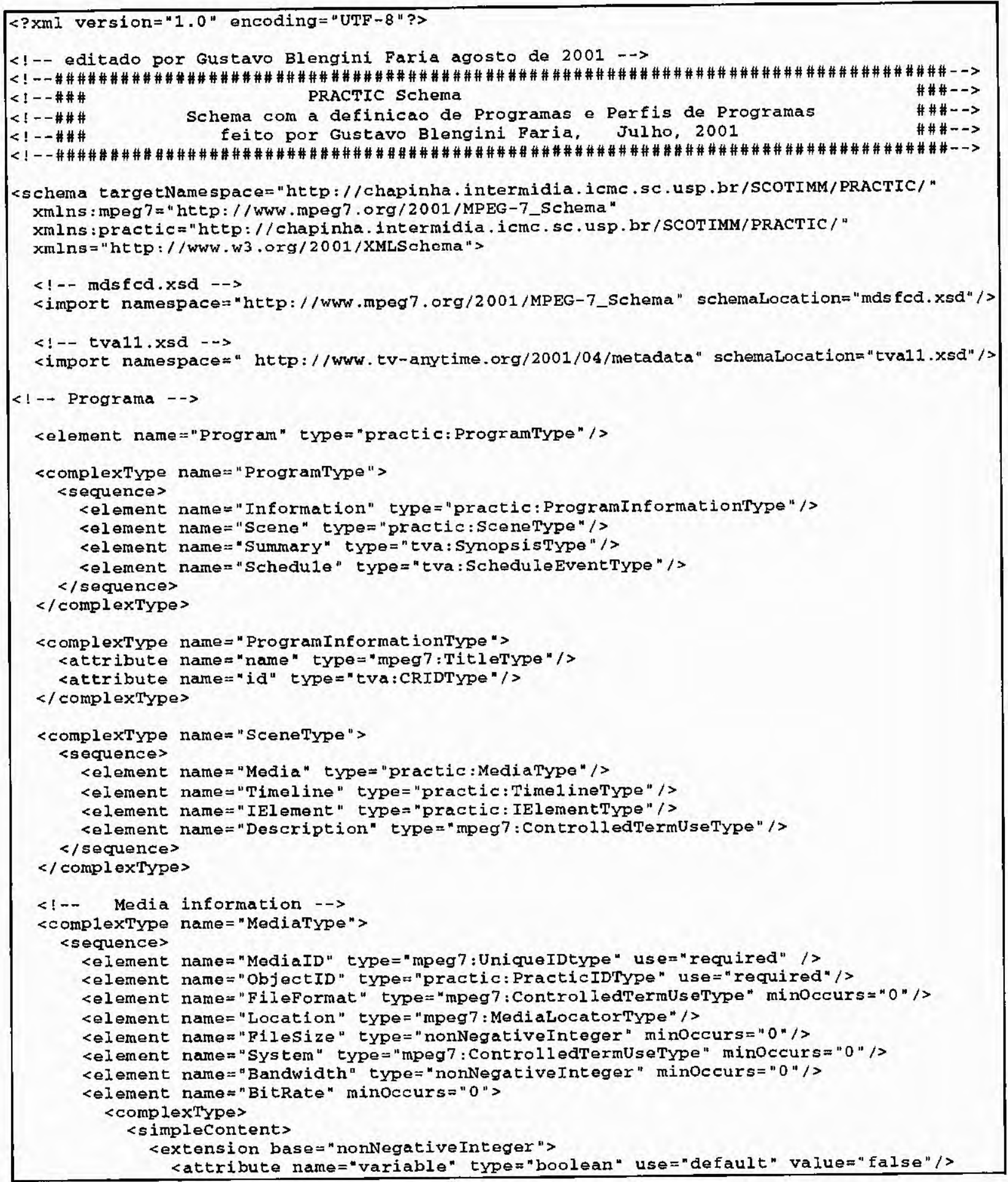




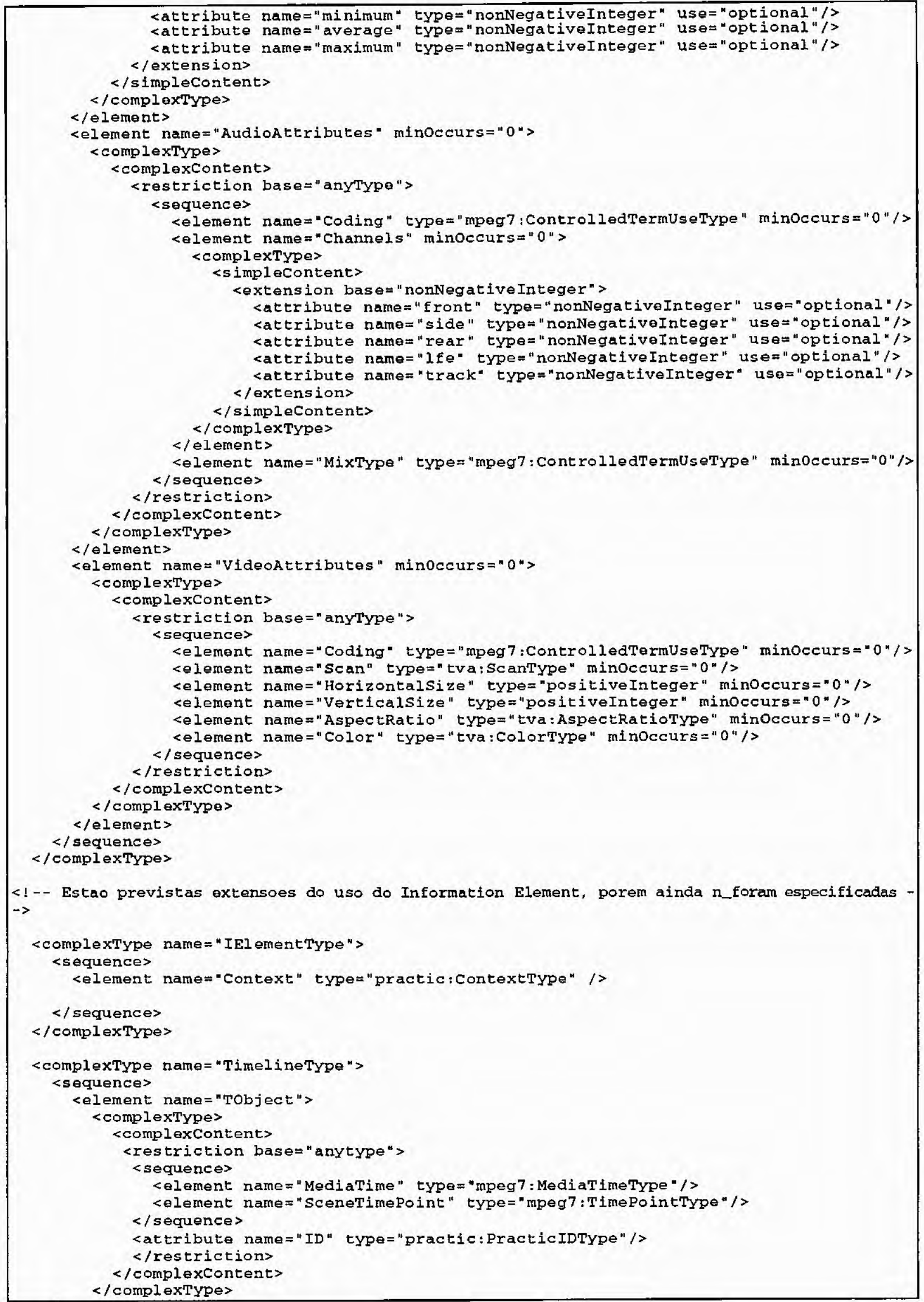




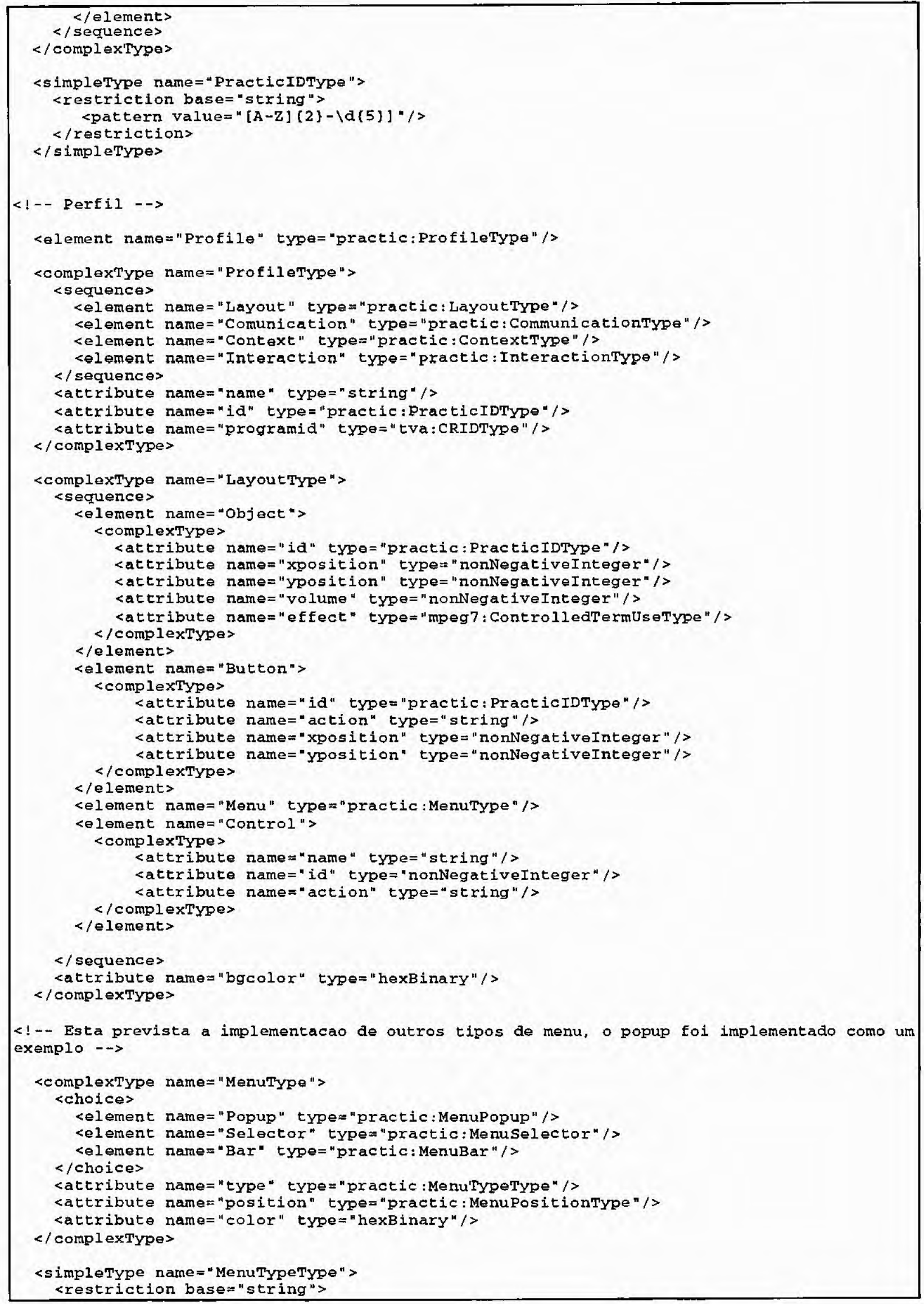




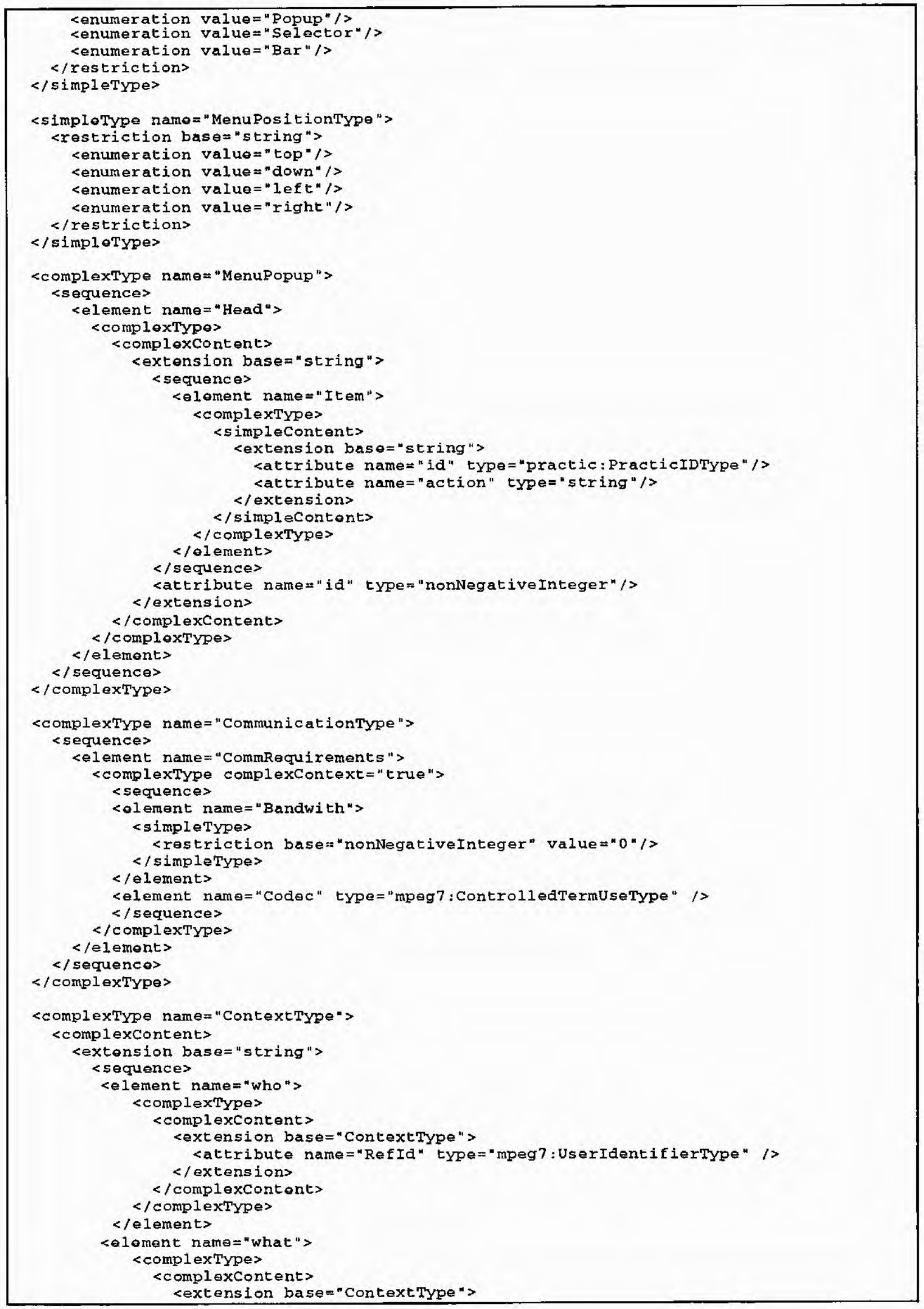




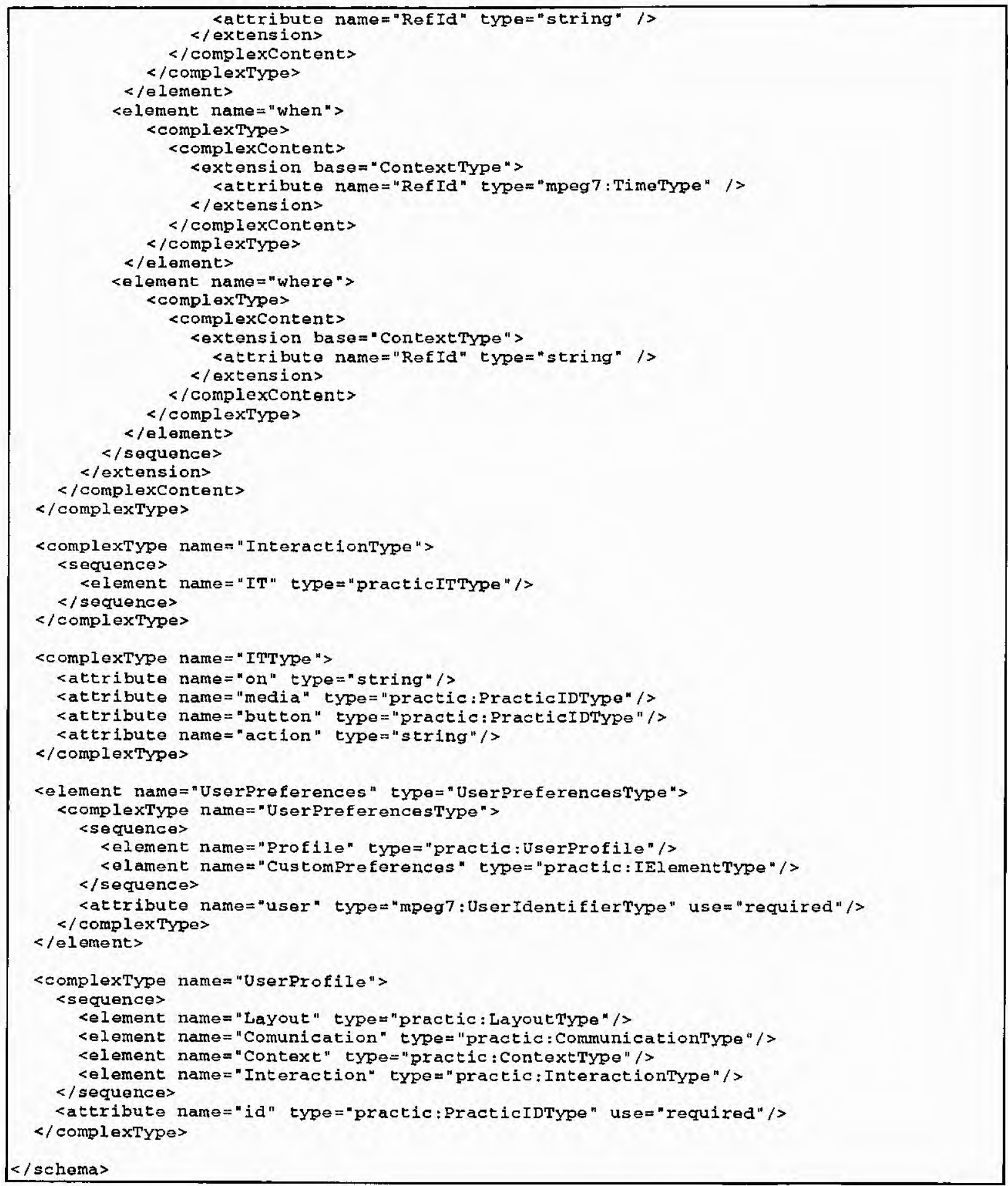




\section{Apêndice B}

\section{Exemplo do uso do PRACTIC Schema para o programa de evento esportivo}

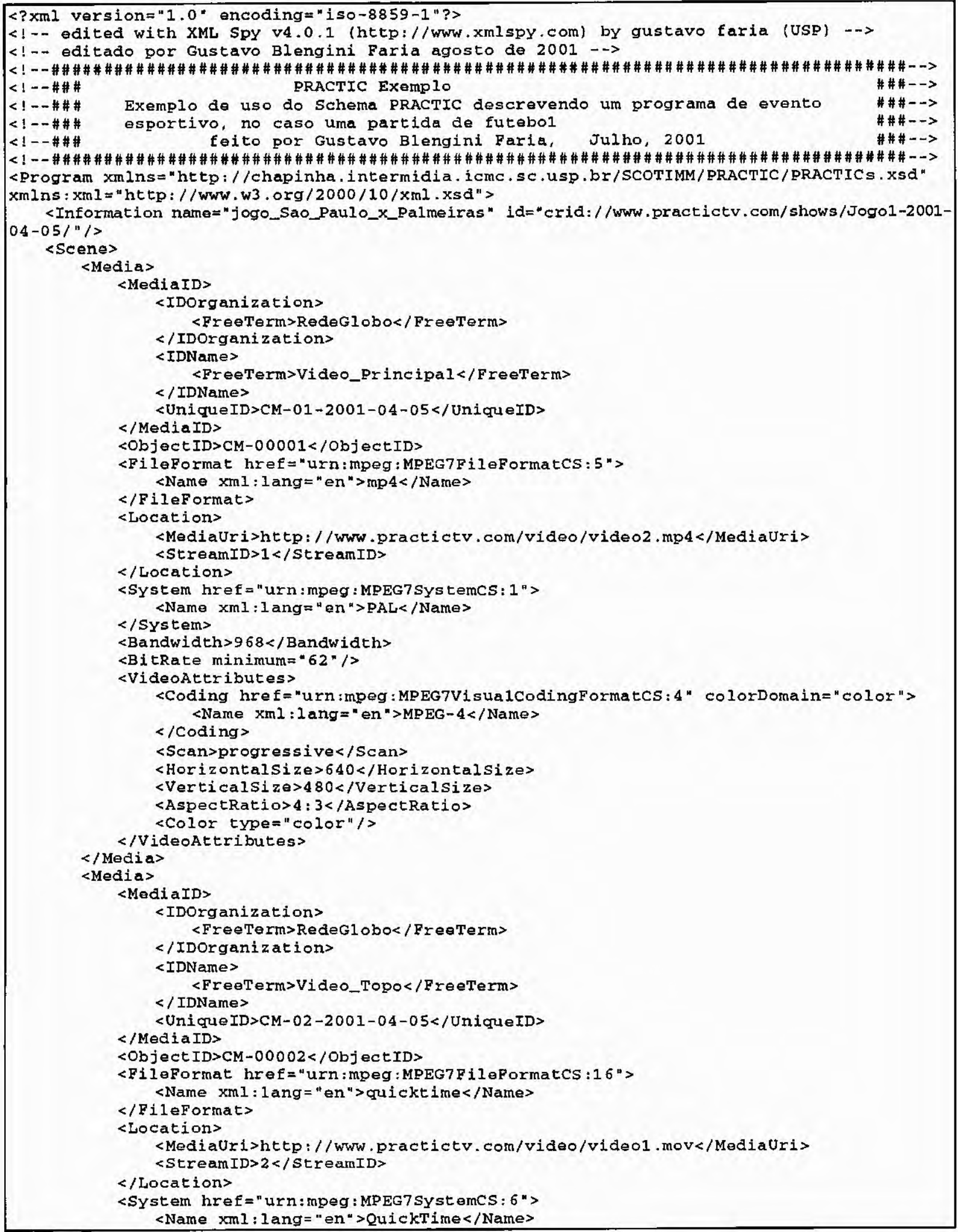




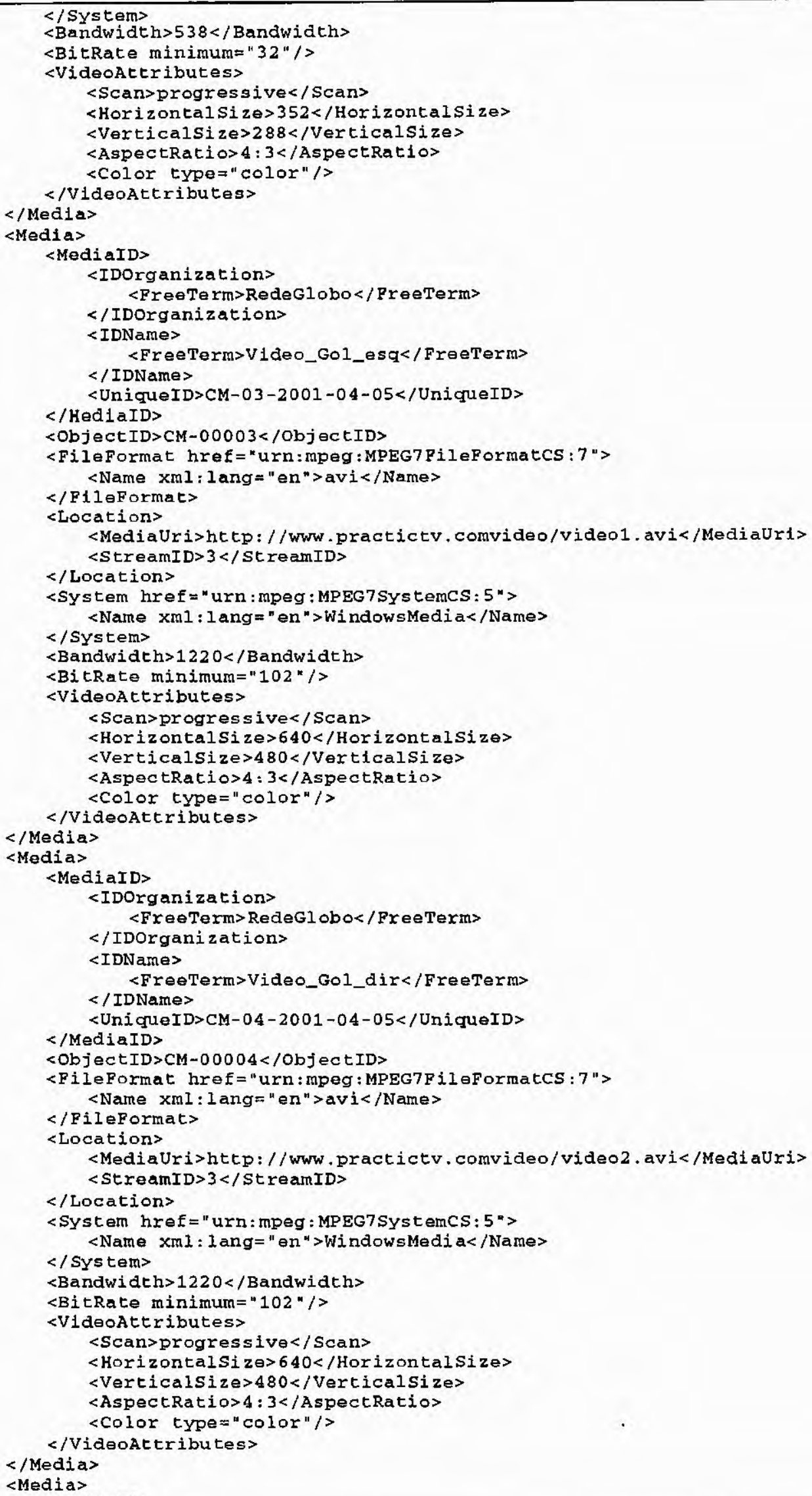




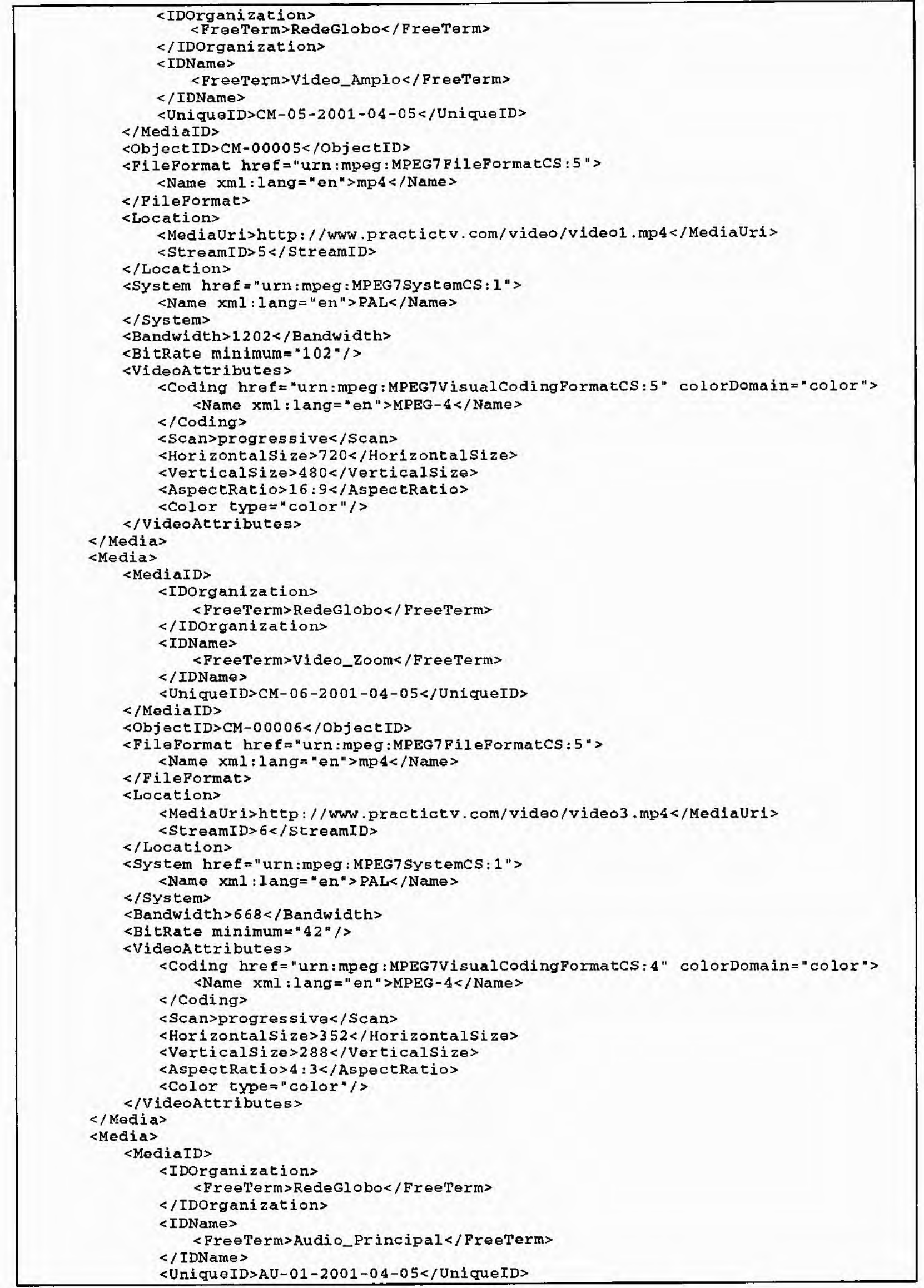


$</$ MediaID $>$

<ObjectID>AU-00001</0bjectID>

$<$ File Format href = "urn: mpeg: MPEG7FileFormatCS: 5 " $>$

$<$ Name xml:lang = "en" $>$ mp4 $</$ Name $>$

$</$ FileFormat $>$

$<$ Location $>$

<MediaUri>http://www.practictv.com/audio/audio1.mp4</MediaUri>

$<$ StreamID $>7</$ St reamID $>$

$</$ Location $>$

$<$ Bandwidth $>608</$ Bandwidth $>$

$<$ BitRate minimum $=" 12^{\circ} />$

<AudioAttributes>

<Coding href="urn: mpeg : MPEG7AudiocodingFormatcS:2 " colorDomain= "color"> <Name xml: lang =" en " $>$ DTS < / Name>

$</$ Coding $>$

<Channels front $=" 3$ " rear $=" 2$ " Ife $=" 1 ">6</$ Channels>

$<$ /Audioattributes>

$<$ Media $>$

$<$ Media $>$

<MediaID>

<IDOrganization>

$<$ FreeTerm>RedeGlobo</FreeTerm>

</IDorganization>

<IDName>

<FreeTerm>Audio_Locucao 2</FreeTerm>

</IDName >

<UniqueID>AU-02-2001-04-05</UniqueID>

$</$ MediaID $>$

$<$ ObjectID>AU-00002<1ObjectID>

$<$ FileFormat href="urn:mpeg:MPEG7FileFormatCS :5" $>$

$<$ Name xml:lang="en" $>$ mp $4</$ Name $>$

$<$ FileFormat $>$

$<$ Location>

<Mediauri>http: //WWw.practictv.com/audio/audio2 .mp4</MediaUri>

$<$ StreamID $>8</$ StreanID>

$</$ Location $>$

$<$ Bandwi dth $>608</$ Bandwidth>

$<$ BitRate minimum="12" />

<Audioattributes>

<Coding href="urn:mpeg:MPEG7AudioCodingFormatcs:2" colorDomain= "color"> $<$ Name $x m 1$ : lang $=$ "en " $>$ DTS $</$ Name $>$

$</$ Coding $>$

<Channels front=" 3" rear=" 2" 1 fe="1" >6</Channels>

$</$ Audioattributes>

$<$ Media

$<$ Media>

$<$ MediaID>

<IDOrganization>

$<$ FreeTerm $>$ RedeGlobo</FreeTerm $>$

$</$ IDOrganizations

$<$ IDName $>$

$<$ FreeTerm>Audio_Banco_esq</FreeTerm>

$</$ IDName>

<UniqueID>AU-03-2001-04-05</UniqueID>

$</$ MediaID $>$

<ObjectID>AU-00003</ObjectID>

$<$ FileFormat href = "urn: mpeg: MPEG7FileFormatCS $: 4$ ">

$<$ Name xml: lang=" en " $>$ mp $3</$ Name $>$

$</$ FileFormat $>$

$<$ Location>

$<$ MediaUri>http://www.practictv.com/audio/audiol, mp 3 /MediaUri>

$<$ StreamID $>9</$ StreamID $>$

$</$ Location $>$

$<$ Bandwidth $>108</$ Bandwidth $>$

$<$ BitRate minimum $=$ " 2 " $1>$

<AudioAttributes>

<Coding href = "urn:mpeg:MPEG7AudiocodingFormatCS : 3 " colorDomain="color"> $<$ Name xml : lang = "en " $>$ mp $3</$ Name $>$

$</$ coding $>$

$<$ Channels side= "2" $>2</$ Channels>

</Audioattributes>

$<$ Media $>$

$<$ Media>

<MediaID>

<IDOrganization> 


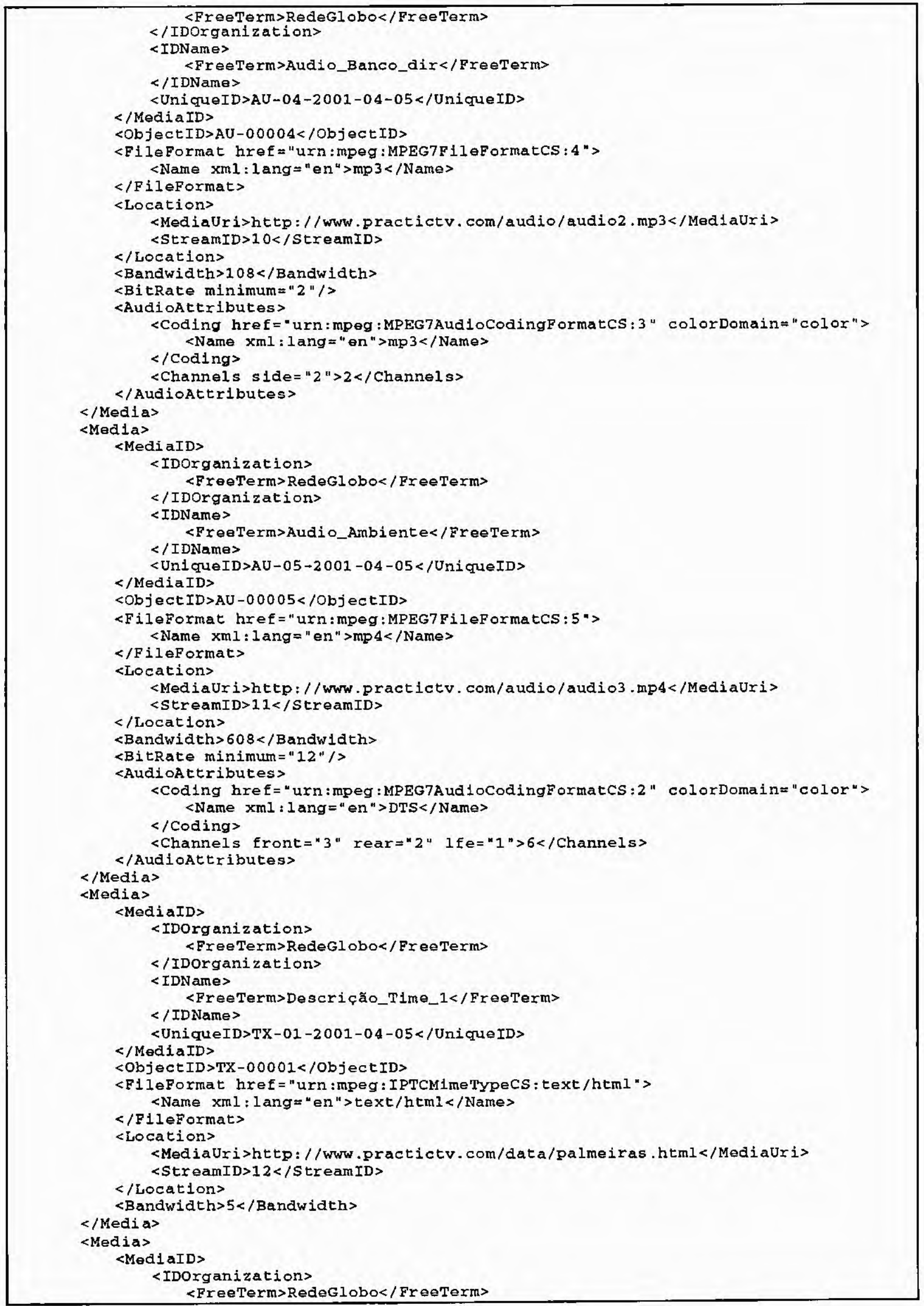




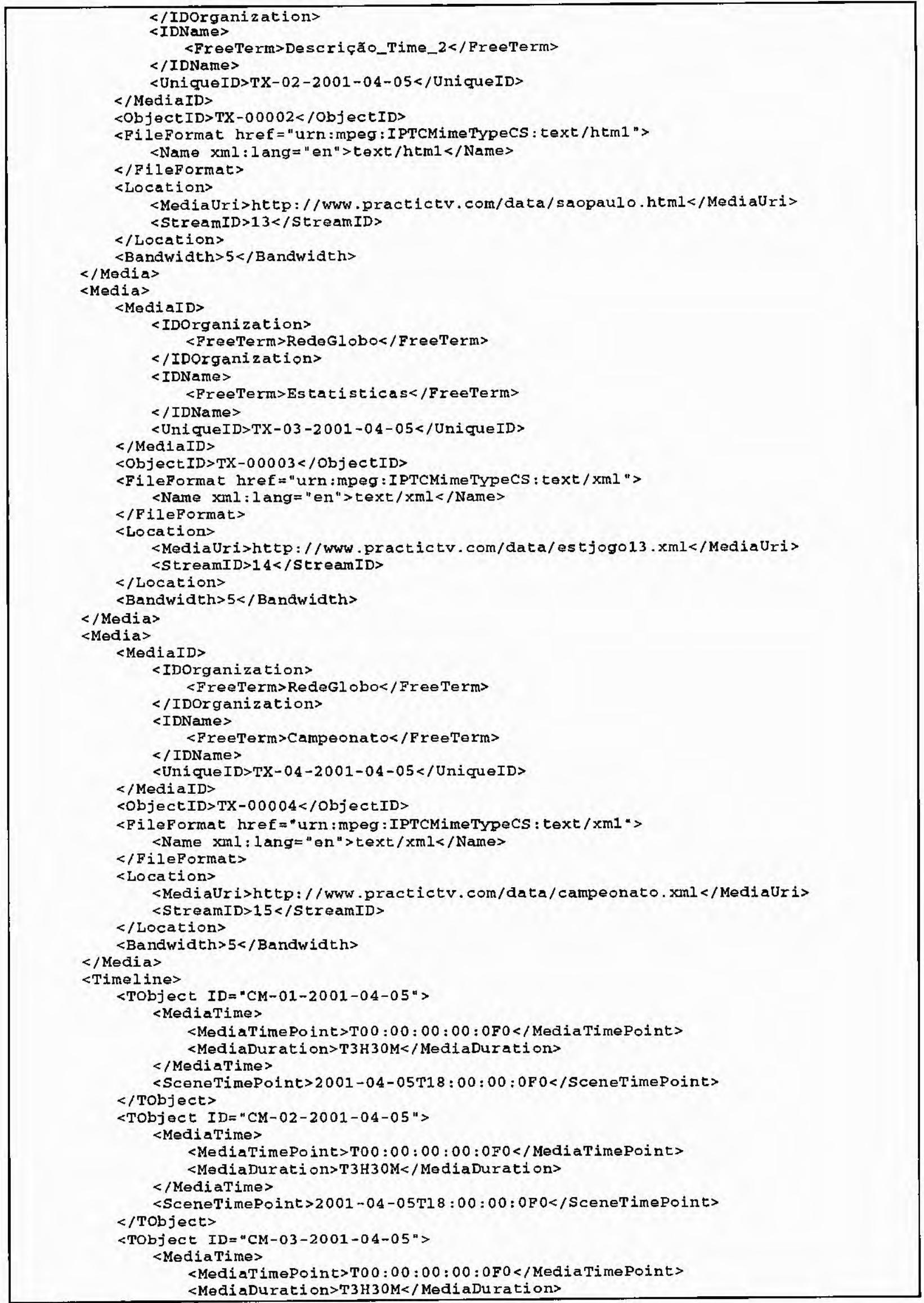




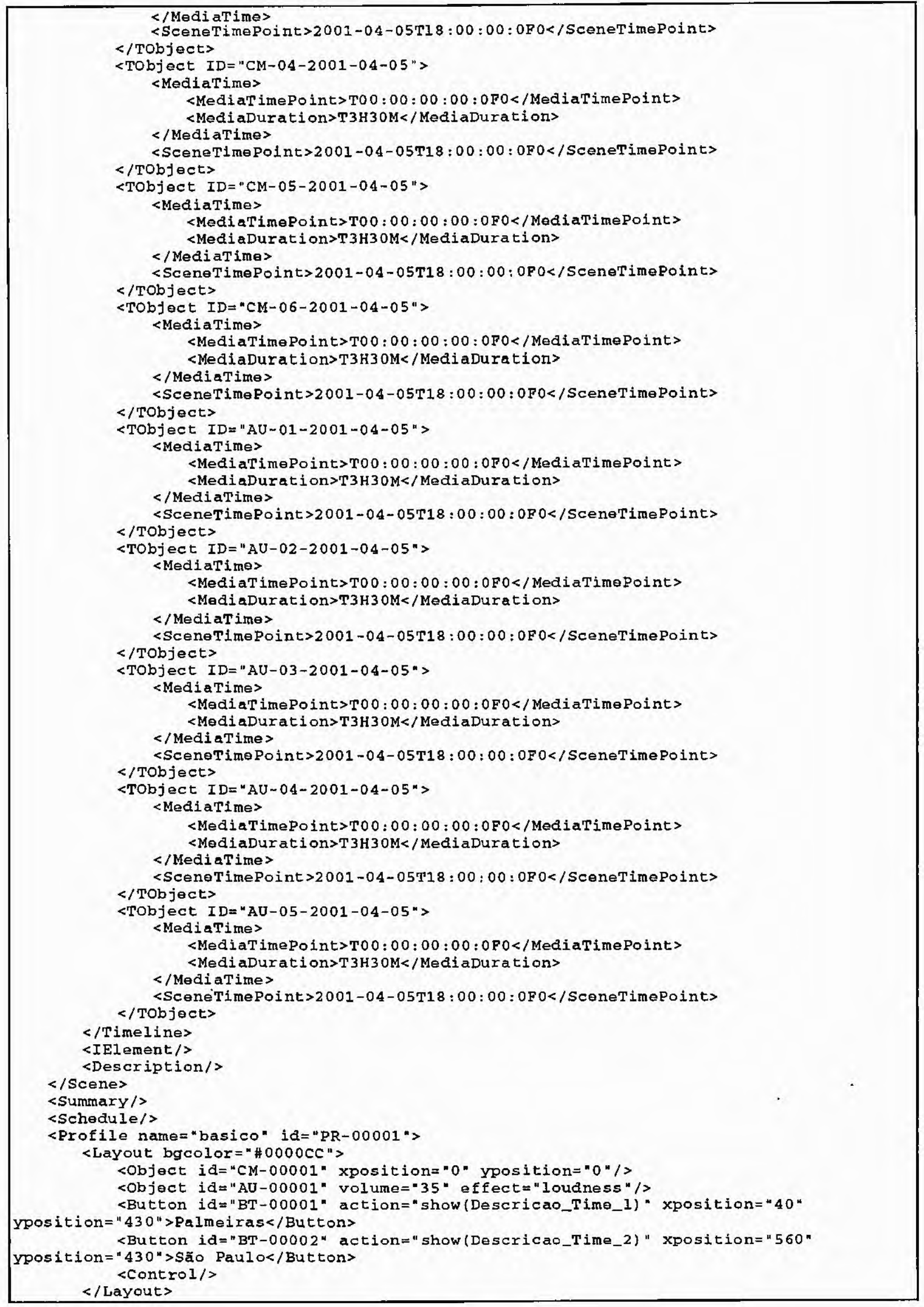




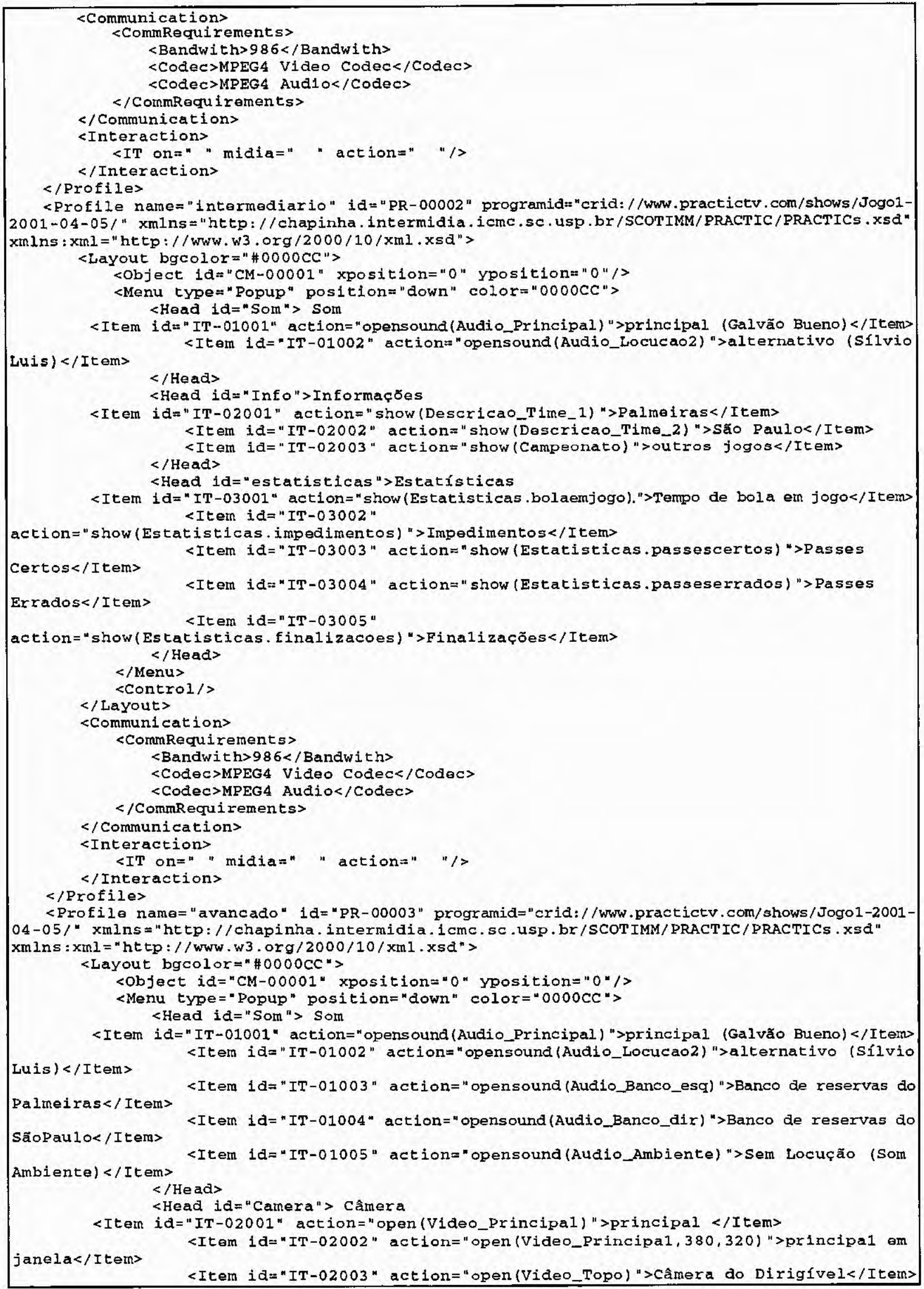




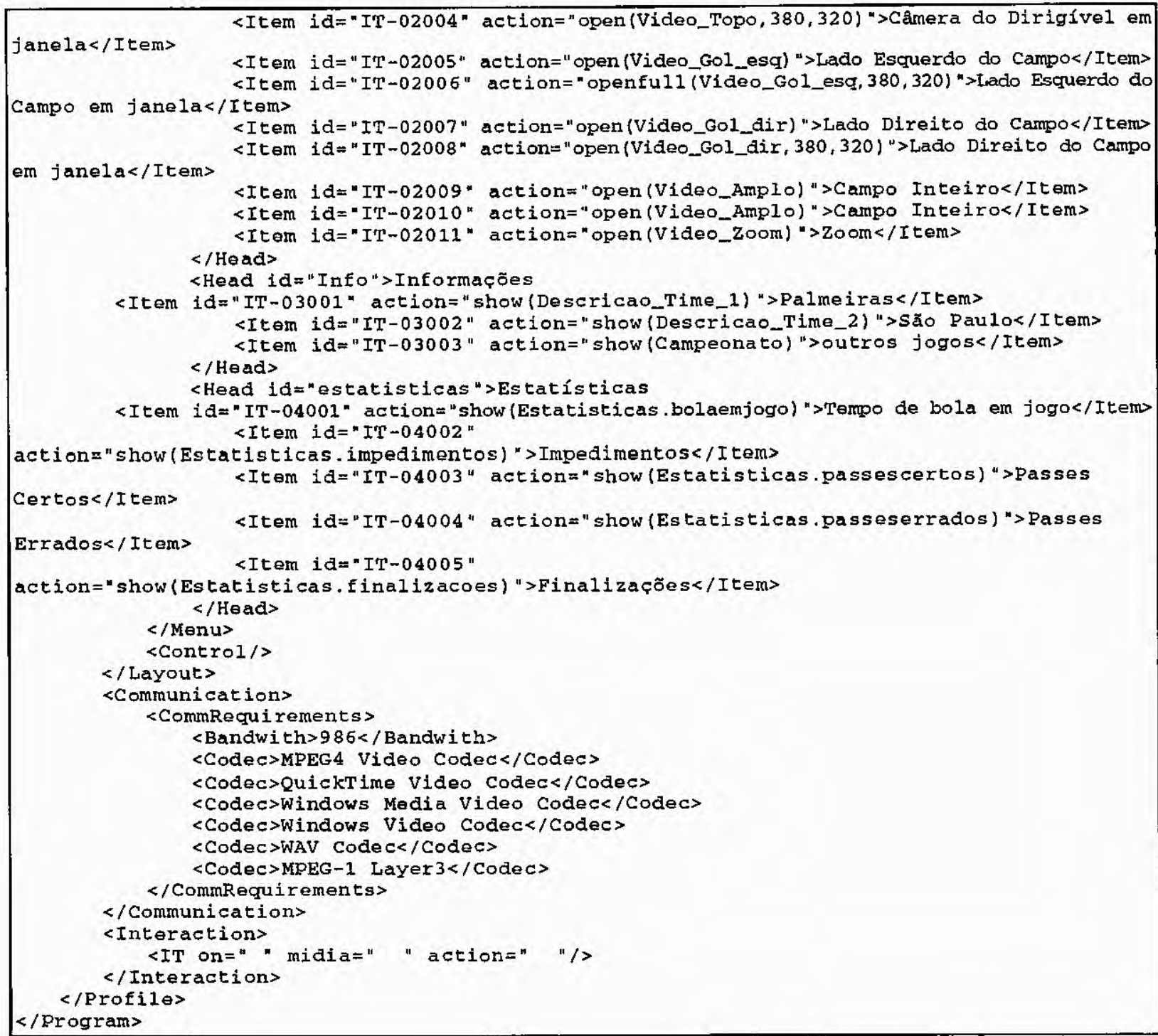




\section{Glossário}

AC-3

Aliasing

Canal alpha

Chroma keying

Closed caption

$\mathrm{DCT}$

$\mathrm{GoP}$

JPEG

Metadado

M-JPEG

MP3

Realidade aumentada

VHS

Wavelet
Padrão de áudio com 6 canais discretos. Também chamado de Dolby Digital 5.1.

É a diferença brusca entre as cores em uma imagem, uma técnica para suavizar é chamada de anti-aliasing.

Representa a quantidade de transparência existente em uma imagem.

O processo de sobrepor um sinal de vídeo sobre áreas de outro. Estas áreas são definidas pelo uso de uma cor específica (normalmente azul ou verde).

Legenda transmitida em alguns programas de TV.

Discrete Cosine Transform. Um método de compressão de imagens digital utilizado em larga escala. Normalmente transformanto blocos de $8 \times 8$ pixels em frequêencias, amplitudes e cores.

Group of Pictures. Conjunto de frames em um stream MPEG, todo GoP deve iniciar com um frame do tipo I.

Joint Photographic Experts Group. É um padrão para a compressão de imagens que utiliza DCT.

Normalmente chamado de dados sobre os dados.

Motion JPEG. Vídeo composto por uma seqüencia de frames JPEG.

MPEG -1 Audio layer 3 - padrão de compressão de áudio

Uma vertente da realidade virtual, porém não totalmente imersiva e que provê informaçōes adicionais do ambiente real.

Video Home System. Sistema de gravação não profissional com a resolução de 240 linhas.

Uma técnica de compressão de imagem assimétrica que é escalável e permite alta qualidade de imagens. O JPEG-2000 utilizará wavelets ao invés do DCT. 